\title{
Caspase-8 is the molecular switch for apoptosis, necroptosis and pyroptosis
}

\author{
Inaugural-Dissertation \\ zur \\ Erlangung des Doktorgrades \\ der Mathematisch-Naturwissenschaftlichen Fakultät \\ der Universität zu Köln \\ Vorgelegt von \\ Melanie Fritsch \\ aus Köln
}

Köln, 2020 
Berichterstatter:

Prof. Dr. Hamid Kashkar

Prof. Dr. Kay Hofmann 


\section{Table of Contents}

I Abstract

II Zusammenfassung

1 Introduction 3

1.1 Caspases

1.1 1 Classification of caspases

1.1.2 Proteolytic activation of caspases 5

1.2 Caspases in cell death

1.2.1 Cell death - an overview

1.2.1.1 Apoptosis

1.2.1.2 Necroptosis

1.2.1.3 Pyroptosis

1.3 Casp8 - central regulator of cell death $\quad 12$

1.3.1 Casp8 inhibits necroptosis 13

1.3.2 Casp8 mediates inflammation $\quad 14$

$\begin{array}{ll}\text { 1.3.3 Relevance of Casp8 enzymatic activity } & 15\end{array}$

$\begin{array}{ll}\text { 1.3.4 Casp8 in infection } & 17\end{array}$

1.4 Aim of the study 18

2 Material and Methods $\quad 19$

2.1 Mice $\quad 19$

2.2 Genotyping of mouse lines $\quad 19$

2.3 Embryological studies $\quad 20$

2.4 Antibodies and reagents $\quad 21$

2.5 Immunohistochemistry (IHC) 22

2.6 Cell culture $\quad 23$

2.6.1 Endothelial cell culture $\quad 23$

2.6.2 Macrophage differentiation 23

2.6.3 Infection of BMDMs with Shigella flexneri 24

2.6.4 Cultivation and transfection of human cells 24

2.7 Generation of CRIPSR/Cas9 Casp8 knockout cells 25

2.8 Purification of HTNCre 25

2.9 Immunoprecipitation (IP) 26

2.10 Western blot (WB) analysis 26

2.11 Immunofluorescence microscopy 27

2.12 Viability assay $\quad 28$

2.13 Cell death assay $\quad 28$

2.14 Casp8 activity measurement $\quad 28$

$\begin{array}{ll}2.15 \text { Tissue homogenates } & 28\end{array}$

$\begin{array}{ll}2.16 \text { Cytokine ELISA } & 28\end{array}$ 
2.17 Cytokine Array $\quad 28$

2.18 Blood parameter analysis $\quad 28$

2.19 Intravenous infection of mice with Shigella flexneri 29

2.20 Bacterial burden in livers and spleens 29

2.21 Statistics 29

3 Results $\quad 30$

3.1 Casp8 is activated during bacterial infection 30

3.2 Generation of Casp8 ${ }^{\mathrm{C} 362 \mathrm{~S}}$ mice 31

3.3 Casp8 enzymatic activity is required for the embryonic development of mice $\quad 32$

3.4 Expression of Casp8 ${ }^{\mathrm{C} 362 \mathrm{~S}}$ results in inflammatory tissue destruction 33

3.5 Casp8 ${ }^{\mathrm{C} 362 \mathrm{~S}}$ induces TNF $\alpha$-mediated necroptosis 36

3.6 RIPK3 deficiency partially rescues the Casp8 ${ }^{\mathrm{C362S}}$ phenotype 37

3.7 MLKL deficiency results in perinatal death of Casp8 ${ }^{\mathrm{C} 362 \mathrm{~S}}$ mice 39

3.8 Inhibition of necroptosis prevents the inflammatory phenotype of Casp8 ${ }^{\mathrm{C} 362 \mathrm{~S}} \quad \mathbf{4 0}$ mice in the endothelium and the skin

3.9 Casp8 ${ }^{\mathrm{C} 362 \mathrm{~S}}$ induces necroptosis-independent tissue destruction in the gut 41

3.10 Casp8 ${ }^{\mathrm{C} 362 \mathrm{~S}}$ activates the inflammasome $\quad 43$

3.11 Catalytically inactive Casp8 induces the formation of the inflammasome $\quad 46$

3.12 ASC or Casp1 deficiency rescues embryonal lethality and restores 51 inflammatory tissue destruction of adult mice expressing Casp8 ${ }^{\mathrm{C} 362 \mathrm{~S}}$

3.13 Casp8 inhibition prolongs the survival of mice infected with Shigella flexneri $\quad 54$

4 Discussion $\quad 56$

4.1 Casp8 enzymatic activity in embryonic development and tissue homeostasis 56

4.2 Casp8 enzymatic activity is required to inhibit necroptosis 59

4.3 Catalytically inactive Casp8 has a scaffold function activating the inflammasome 60

4.4 Casp8 enzymatic activity influence anti-microbial immunity 62

4.5 Conclusion $\quad 63$

5 References $\quad 64$

6 Appendix $\quad 73$

$\begin{array}{ll}6.1 \text { Abbreviations } & 73\end{array}$

6.2 Danksagung 75

6.3 Erklärung $\quad 76$

$\begin{array}{ll}6.4 \text { Lebenslauf } & 78\end{array}$ 


\section{Abstract}

The regulation of cell death is a critical step in embryonic development, tissue homeostasis and in the defence against invading pathogens. Caspase-8 (Casp8) represents the key initiator caspase inducing extrinsic apoptosis. Casp8 also inhibits necroptosis and thereby safeguard embryonic development. Here we show that Casp8 enzymatic activity is required for the inhibition of pyroptosis.

In order to elucidate the specific role of Casp8 enzymatic activity we established a mouse line harbouring a point mutation in the substrate binding pocket of Casp8 (mutation of catalytic cysteine 362 to serine) which results in the lack of enzymatic activity of Casp8 $8^{\mathrm{C} 362 \mathrm{~S}}$. Expression of catalytically inactive Casp8 ${ }^{\mathrm{C} 362 \mathrm{~S}}$ resulted in embryonic lethality at E10.5 due to cardiovascular defects similar to $\operatorname{Casp} 8^{-/}$mice. Inhibition of necroptosis via additional deletion of MLKL rescued the cardiovascular phenotype but unexpectedly caused perinatal lethality of Casp8 $8^{\mathrm{C362S/C362S}}$ mice, indicating that loss of Casp8 enzymatic activity compromises perinatal development by additional, necroptosis-independent functions.

Specific loss of Casp8 catalytic activity in intestinal epithelial cells (IECS) drives intestinal inflammation similar to Casp $8^{I E C-K O}$. MLKL deficiency exacerbated the ileitis and caused prematured lethality of $\mathrm{Casp} 8^{\mathrm{C} 362 \mathrm{~S} / \mathrm{IEC}-} / \mathrm{MIKI}^{-/}$mice due to induction of pyroptotic cell death associated with ASC speck formation, Casp1 activation and the maturation of pro-IL-1ß. Our cell culture analyses showed that catalytically inactive Casp8 co-localises with ASC, induces ASC nucleation and Casp1 activation. Accordingly, deletion of either ASC or Casp1 prevented intestinal inflammation and premature death of $\mathrm{Casp} 8^{\mathrm{C} 362 \mathrm{~S} / \mathrm{C} 362 \mathrm{~S}} / \mathrm{MIkI}^{--}$mice. These results reveal a yet unknown and unexpected role for Casp8 enzymatic activity and scaffold function involving the inflammasome and pyroptosis under circumstances where apoptosis and necroptosis are blocked. 


\section{Zusammenfassung}

Die Regulation des Zelltods ist ein kritischer Schritt in der Embryonalentwicklung, der Gewebehomöostase und bei der Abwehr eindringender Krankheitserreger. Hierbei spielt Caspase-8 (Casp8) eine entscheidende Rolle, indem das Enzym extrinsische Apoptose induziert. Außerdem hemmt Casp8 Nekroptose und sichert so die embryonale Entwicklung. Wir zeigen hier, dass eine weitere wichtige Funktion der enzymatische Aktivität von Casp8 die Hemmung der Pyroptose ist.

Um die spezifische Rolle der enzymatischen Aktivität von Casp8 zu untersuchen, haben wir eine Mauslinie etabliert, welche eine Punktmutation in der Substratbindetasche von Casp8 (Mutation des katalytischen Cysteins 362 zu Serin) aufweist. Diese Mutation führt zum Verlust der enzymatischer Aktivität von Casp8 ${ }^{\mathrm{C362S}}$. Die Expression von katalytisch inaktiver Casp $8^{\text {C362S }}$ resultiert in eine embryonale Letalität bei E10,5 aufgrund von kardiovaskulären Defekten, ähnlich zu Casp8 ${ }^{\text {/- }}$ Mäusen. Die Blockade von Nekroptose durch zusätzliche Deletion von MLKL verhinderte den kardiovaskulären Phänotyp, verursachte jedoch

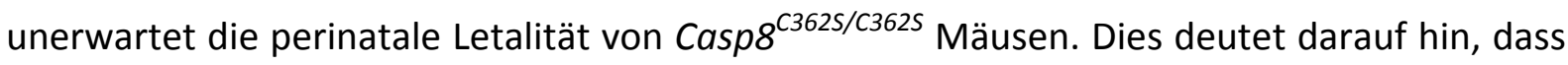
der Verlust der enzymatischen Aktivität von Casp8 die perinatale Entwicklung durch zusätzliche, Nekroptose-unabhängigen Funktionen beeinträchtigt.

Der spezifische Verlust der katalytischen Aktivität von Casp8 in Darmepithelzellen (IECs) führte zu einer Darmentzündung ähnlich zu $\operatorname{Casp} 8^{I E C-K O}$ Mäusen. Eine zusätzliche Deletion von MLKL verschlimmerte die Entzündung des Darms und verursachte ein vorzeitiges Versterben von Casp8 $8^{\text {C362S/IEC- } / M I k I-/-~ M a ̈ u s e n ~ d u r c h ~ d i e ~ I n d u k t i o n ~ d e s ~ p y r o p t i s c h e n ~ Z e l l t o d s . ~}$ In diesem Zusammenhang konnten Prozesse, welche charakteristisch für Pyroptose sind, wie die Bildung von ASC-Specks, die Aktivierung von Casp1 sowie die Produktion von IL-1ß beobachtet werden. Unsere Zellkulturanalysen zeigen, dass katalytisch inaktive Casp8 mit ASC kolokalisiert, sowie ASC-Nukleation und Casp1-Aktivierung induziert. Dementsprechend verhinderte die Deletion von ASC oder Casp1 die Entzündung des Darms und den vorzeitigen

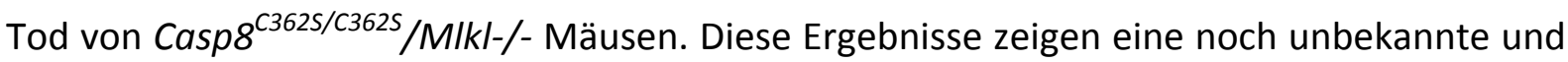
unerwartete Rolle für Casp8 als Proteingerüst eines Signalkomplexes, welcher unter Gegebenheiten bei denen Apoptose und Nekroptose blockiert sind, gebildet wird. 


\section{Introduction}

\subsection{Caspases}

Already in 1986 the function of caspases in cell death was discovered by the identification of the cell death abnormal protein 3 (ced-3) gene of $C$. elegans encoding a cysteine protease mediating cell death during development (Ellis and Horvitz 1986). Independently, the human Interleukin-1 $\beta$-Converting Enzyme (ICE, later renamed caspase-1, here referred to Casp1) was described as the first mammalian cysteine protease mediating inflammation in monocytes (Cerretti et al., 1992; Thornberry et al., 1992). Functional and structural similarities of ced-3 to the mammalian Ice gene postulate an involvement of cysteine proteases in the regulation of programmed cell death (J. Yuan et al. 1993). Cysteinedependent aspartate-specific proteases, short caspases are named due to their specific protease activity - a cysteine protease (giving the " $c$ " in caspase) preferentially cleaving their substrates C-terminal of an aspartic acid residue (referring the "aspase" in caspase) (Alnemri et al. 1996; Stennicke et al. 2000; Thornberry et al. 1997).

\subsubsection{Classification of caspases}

To date, 14 members of the caspases family have been identified in all metazoans including C. elegans, Drosophila, humans and mice (Julien and Wells 2017). Mainly, human and mouse caspases represent functional orthologs. In the human genome, additionally Casp4 and -5 , functional orthologs of murine Casp11, are present, while Casp10 is absent in mice. All caspases share a common conserved protein domain at the C-terminus, the catalytic domain that is composed of a large subunit (17-20 kDa, p20), carrying the catalytic cysteine and a small subunit (10-12 kDa, p10) (Figure 1.1) (Julien and Wells 2017). N-terminally the composition of caspases varies between a long and a short prodomain. Whereas the short prodomain possess unknown functions, the long prodomain either contains the specialised death effector domain (DED) or a caspase activation and recruitment domain (CARD) motif, both enabling protein-protein interactions. 
Based on their function and sequence similarities, theses caspases have been subdivided into those involved in mediating apoptosis and inflammation, clustering into three independent groups (Salvesen and Ashkenazi 2011). The first group, the apoptotic initiator caspases, is mainly involved in regulating apoptosis and share a long prodomain facilitating the interaction with upstream adaptor molecules. Casp2 and -9 possess a CARD domain, whereas the prodomain of Casp8 and -10 consists of two DEDs. The second group is formed by apoptotic executioner caspases with a short prodomain typically lacking a DED or CARD. Executioner Casp3, -6 and -7 are activated by upstream initiator caspases to execute the final steps in apoptosis by cleaving multiple cellular substrates, culminating in the apoptotic phenotype. Among these caspase substrates are proteins relevant for cell adhesion, cell and nuclear structure, cytoskeleton assembly, cell cycle as wells as DNA synthesis (Fischer, Jänicke, and Schulze-Osthoff 2003).

The third group is comprised of Casp1, $-4,-5,-11,-12,-13$ and 14 and form the group of inflammatory caspases, which mainly regulate cytokine maturation during inflammation. Additionally, inflammatory Casp1 and -11 are involved in the regulation of a distinct form of cell death called pyroptosis (Bergsbaken, Fink, and Cookson 2009). However, most inflammatory caspases, except Casp14 contain the characteristic CARD domain responsible for the formation of larger protein-complexes via direct interaction of individual CARDs between CARD-containing proteins (Shalini et al. 2015).

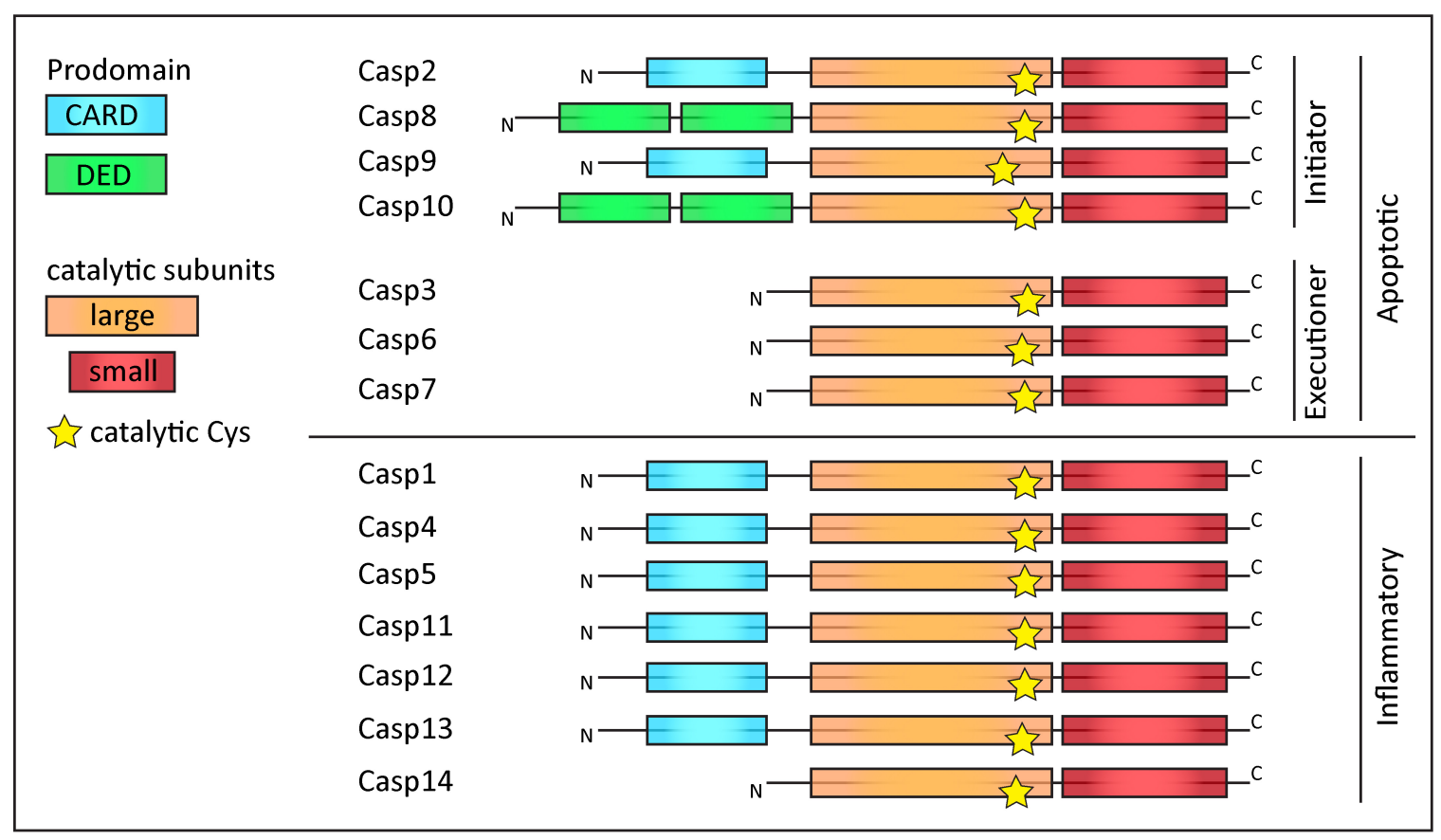


Figure 1.1 Domain structure and classification of human and murine caspases. Caspases are a class of cysteine proteases all sharing a prodomain and a catalytic subunit comprised of a large and a small subunit. Casp2, $-8,-9$ and -10 are apoptotic initiator caspases, whereas Casp3, -6 and -7 are key apoptotic executioner caspases. The group of inflammatory caspases consist of Casp1, $-4,-5,-11,-12,-13$, and -14. CARD, caspase activation and recruitment domain; DED, death effector domain; star, catalytic cysteine (adapted from Shalini, Dorstyn, Dawar, \& Kumar, 2015).

\subsubsection{Proteolytic activation of caspases}

All Caspases are expressed as a cytosolic inactive zymogen (procaspase) that needs to be proteolytically cleaved to achieve full activity. Recruitment of initiator and inflammatory caspases is facilitated through their protein-interaction domains CARD or DED into large multiprotein activation platforms such as the inflammasome or the death inducing signalling complex (DISC). Within this multimeric platforms procaspases are forced into close proximity to form homodimers leading to conformational changes and the generation of active sites by autocleavage (Boatright et al. 2003; Salvesen and Dixit 1999). However, a recent study uncovered that inflammatory Casp1 gains full activity only upon cleavage between the large and the small subunit when recruited to the activation platform (Boucher et al. 2018). In contrast, executioner caspases are expressed as inactive dimers and need to be processed through the cleavage between the large and the small subunit by initiator caspases leading to active caspases.

The catalytic activity of caspases is guaranteed by a dyad in the p20 region consisting of a cysteine, which is part of a conserved 'QACXG' peptide sequence, and a histidine (FuentesPrior and Salvesen 2004). All caspases recognise substrates with a unique peptide sequence of at least 4 residues, named P4-P3-P2-P1. Upon recognition, caspases cleave the C-terminal residue (P1) of the peptide sequence, which is most commonly an aspartic acid (Shi 2002). However, several studies indicate that some caspases are also able to cleave after a glutamic acid (Hay 2000; Srinivasula et al. 2001). Additionally, the preferred P3-residue of caspases is glutamic acid, describing the favoured peptide sequence of caspases as X-Glu-X-Asp (Thornberry et al. 1997).

\subsection{Caspases in cell death}

Over the last decades it has become increasingly evident that caspases play an essential role in the regulation of programmed cell death. Starting with the first observation of caspases mediating cell death in 1993 (Miura et al. 1993; J. Yuan et al. 1993) our knowledge about the 
crosstalk between different modes of cell death and the contribution of caspases in controlling these diverse processes has greatly expanded. The potential of uncontrolled cell death as an important factor driving tissue homeostasis, inflammation and disease pathogenesis illustrates the need of a tight regulation (Wallach, Kang, and Kovalenko 2014). On the other hand, programmed cell death is crucial for numerous different physiological mechanisms such as shaping of developing organs, epithelial cell renewal and lymphocyte selection (Pasparakis and Vandenabeele 2015). Therefore, the balance between life and death is essential for the survival of multicellular organisms.

\subsubsection{Cell death - an overview}

To date, a number of different modes of regulated cell death have been discovered. Although the list of cell death modes is constantly increasing, the most prominent types are apoptosis, necroptosis and pyroptosis. Characteristic morphological changes and molecular signalling pathways classify the different modes of cell death. Apoptosis is morphologically defined by plasma membrane blebbing, cell shrinkage, nuclear condensation associated with DNA condensation (pyknosis), and the formation of apoptotic bodies (Figure 1.2) (Kerr, Wyllie, and Currie 1972; Wyllie, Kerr, and Currie 1980). The formation of apoptotic bodies prevent the release of cytoplasmic content into the extracellular environment and therefore ensures a non-inflammatory response as these bodies, including the apoptotic cell itself, are engulfed by different professional and non-professional phagocytes (Juncadella et al. 2013; Monks et al. 2008; Parnaik, Raff, and Scholes 2000; Wood et al. 2000).

In comparison, necroptosis is characterised by organelle and cell swelling and loss of membrane integrity (Figure 1.2) (Berghe et al. 2010). Rupture of the plasma membrane results in the liberation of cytosolic content into the extracellular milieu defining necroptosis as an exclusively pro inflammatory mode of cell death culminating in considerable tissue damage (Lamkanfi and Dixit 2010). Pyroptosis shares similar morphological features to necroptosis, such as membrane rupture and the release of the intracellular content but is characterised by a caspase-dependent signalling pathway that involves the canonical and non-canonical inflammasomes (Kayagaki et al. 2011; Lamkanfi and Dixit 2014).

However, a recent study described clear morphological differences to necroptosis (Figure 1.2). Cell swelling is minimal during pyroptosis and the formation of pyroptotic bodies has been identified (Chen et al. 2016). 

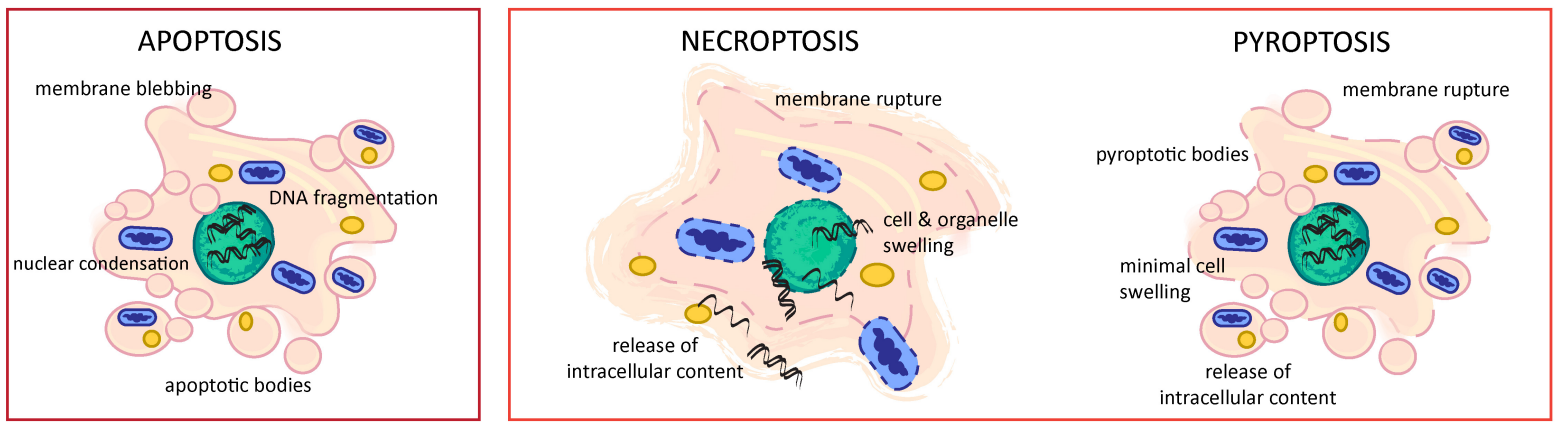

proinflammatory

Figure 1.2 Characteristic morphological changes of programmed cell death modes. Apoptosis is characterised by the maintenance of the plasma membrane integrity and the formation of apoptotic bodies demonstrating apoptosis as an immunologically silent mode of death. In contrast, necroptosis and pyroptosis represents proinflammatory forms of cell death, as the release of the intracellular content is distinctive for these cell death modes (modified from Lamkanfi \& Dixit, 2010).

\subsubsection{Apoptosis}

First described in 1972 by Kerr, Wyllie and Currie, apoptosis is nowadays subdivided into two distinct, but interconnected signalling pathways known as the intrinsic and the extrinsic apoptotic pathways (Figure 1.3) (Creagh 2014; Kerr, Wyllie, and Currie 1972). The intrinsic pathway (also referred to as the mitochondrial pathway) can be initiated by different intracellular stress cues such as DNA damage, growth arrest or viral infection and operates via the release of mitochondrial cytochrome $c$ (Green and Llambi 2015). In response to such stimuli, mitochondrial outer membrane permeabilisation (MOMP) occurs, which is strictly regulated process, controlled by members of the $\mathrm{Bcl} 2$ protein family. The $\mathrm{Bcl} 2$ family consists of 3 broad classes: the proapoptotic BH3-only members (e.g. Bim, Bid, Puma) activating proapoptotic effectors; the antiapoptotic $\mathrm{Bcl} 2$ proteins (e.g. $\mathrm{Bcl} 2, \mathrm{Bcl}-\mathrm{xL}$ and $\mathrm{Mcl} 1$ ) blocking MOMP; and the proapoptotic effector proteins (Bax and Bak), necessary for MOMP (Green and Llambi 2015). Upon apoptotic stimulation BH3-only proteins (transcriptionally upregulated or post-translational modification) induce conformational activation of proapoptotic Bax and Bak or block anti-apoptotic members and subsequently induce MOMP (Youle and Strasser 2008). MOMP in turn triggers the release of pro-apoptotic factors such as cytochrome $c$ and Smac/Diablo from the mitochondrial intermembrane space into the cytosol (Green and Llambi 2015; Saelens et al. 2004). Cytolsolic cytochrome $c$ initiates the oligomerisation of apoptotic protease-activating factor-1 (Apaf-1) to form the multimeric apoptosome complex, that recruits and activates proCasp9 (Creagh 2014). 
Within the apoptosome, Apaf-1 interacts with the initiator proCasp9 via the homotypic CARD-CARD interactions, bringing inactive initiator proCasp9 monomers into close proximity for auto-cleavage and activation (Yu et al. 2005; Yuan et al. 2010). Active Casp9 subsequently cleaves and activates its downstream effector caspases, Casp3/-7, resulting in apoptosis.

The extrinsic apoptotic pathway is triggered by extracellular death ligands of the TNF family (TNF $\alpha$, tumour necrosis factor $\alpha$; FasL, Fas Ligand; and TRAIL, TNF-related apoptosisinducing ligand) (Peter and Krammer 2003; Strasser, O'Connor, and Dixit 2000). Each ligand is recognised through its respective death receptor, which harbour a specialised proteinprotein interaction motif (DD, the death domain) in the cytoplasmic part of the molecule. Upon extracellular detection of death ligands, the death receptor most likely trimerises to form the minimal intracellular death-inducing signalling complex (DISC). For the Fas and TRAIL receptors, trimerisation initiates the recruitment of FADD (Fas-associated death domain) to the DISC representing a caspase-activation platform. FADD is composed of a DD domain, necessary for interaction with the death receptor, and a DED, enabling the binding to DEDs in the prodomain of caspases (Chinnaiyan et al. 1995; Muzio et al. 1996; Zhang and Winoto 1996). Caspase binding is mediated by a homotypic death effector domain (DED) interaction present in both FADD and proCasp8. Whereas FADD possesses a single $\mathrm{N}$ terminal DED, the precursor of Casp8 (proCasp8) is expressed as a zymogen that comprises a $\mathrm{N}$-terminal pro-domain that includes two DEDs (tandem DED) (Figure 1.1). ProCasp8 binds to the exposed DED of FADD through a pocket in its first DED. Additional proCasp8 molecules are then recruited and bind through a first DED pocket to a motif in second DED of the prior proCasp8 by dominant hydrophobic interactions. This results in DED-mediated proCasp8 oligomerisation, thereby facilitating proximity-induced homodimerisation of proCasp8 thereby triggering its subsequent conformatial activation of Casp8 associated with autoprocession between the small and the large subunit yielding the full proteolytic activity (Dickens et al. 2012). Further auto-cleavage of Casp8 between the prodomain and the large subunit releases active initiator Casp8 from the DISC. Active Casp8 then processes and activates the downstream effectors Casp3 and -7 causing the typical changes accompanied with apoptosis. In some cases, the proteolytic activity of executioner Casp3/7, and consequently apoptosis, is blocked by the X-linked inhibitor of apoptosis (XIAP) (Jost et al. 2009). Inhibition of executioner caspases is circumvented by Casp8 mediated cleavage of the BH3-only protein Bid upon death receptor signalling (Li et al. 1998; Luo et al. 1998). 
Truncated Bid (tBid) in turn activates Bax/Bak triggering MOMP and the subsequent release of the XIAP antagonists Smac, thereby representing the central the crosstalk between intrinsic and extrinsic apoptosis.

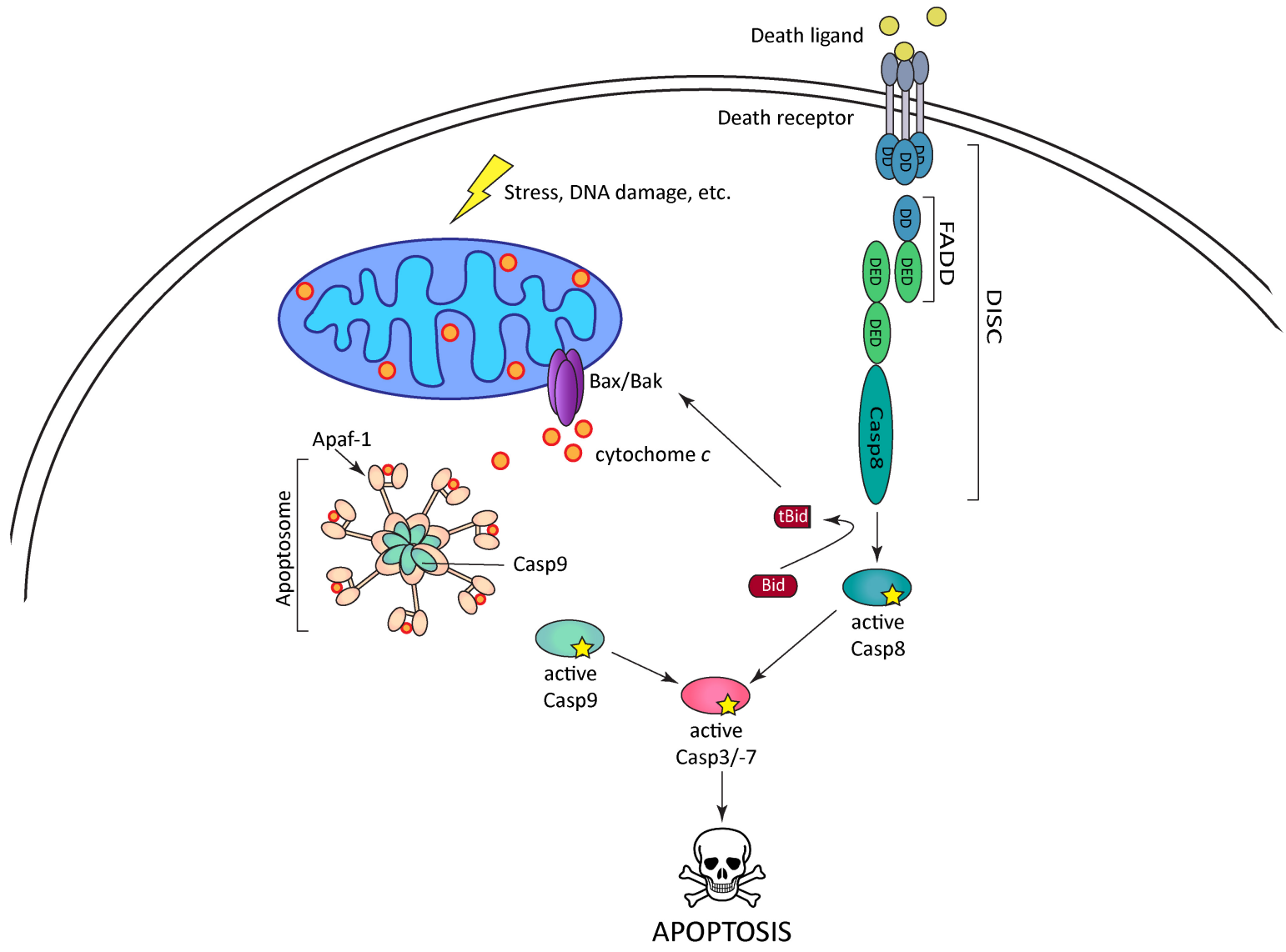

Figure 1.3 Intrinsic and extrinsic apoptosis. Intrinsic apoptosis is activated upon different stimuli, such as stress or DNA damage, mediating the release of cytochrome $c$ from the mitochondria activating the apoptosome. Within the apoptosome Casp9 becomes activated subsequently cleaving and activating Casp3/-7, which as a result execute apoptosis. The intrinsic pathway is initiated upon ligation of a ligand to the death receptor. Recruiting FADD and Casp8 to the death receptor through DD-DD and DED-DED protein interaction forms the DISC. Casp8 gets activated and cleaves its substrates Casp3 and -7 culminating in apoptosis. Apaf-1, apoptotic protease-activating factor-1; FADD, Fas-associated death domain; DISC, death-inducing signalling complex; DD, death domain; DED, death effector domain (adapted from Creagh, 2014). 


\subsubsection{Necroptosis}

To date, also several forms of controlled necrosis, such as necroptosis and pyroptosis have been discovered. Necroptosis is a certain form of programmed cell death that depends strictly on the function of a class of serine kinases, the receptor-Interacting serine/threonine-protein kinases (RIPKs) (Degterev et al. 2005). Loss of Casp8 enzymatic activity, for example by chemical inhibition or genetic deletion, leads to the formation of the necrosome (composed of RIPK1, RIPK3, and MLKL), predominantly upon activation of the TNF-receptor (Holler et al. 2000; Matsumura et al. 2000; Pasparakis and Vandenabeele 2015; Scheller et al. 2002; Vercammen et al. 1998). As part of the necrosome RIPK1 and RIPK3 interact via their RHIM-domains, mediating the phosphorylation of the RIPK3 substrate, the pseudokinase mixed-lineage kinase domain-like protein (MLKL). Active MLKL undergoes a conformational change facilitating its oligomerisation and the migration to the plasma membrane (Hildebrand et al. 2014; Murphy et al. 2013; Sun et al. 2012). At the plasma membrane, MLKL forms cation channels, inducing the influx of selected ions (Chen et al. 2016; Xia et al. 2016). The increase of intracellular osmolality causes membrane rupture ultimately culminating in necroptosis and the consequent pro-inflammatory release of intracellular content. Recent studies revealed that MLKL cation channel formation can result in the activation of the NLRP3 inflammasome due to $\mathrm{K}^{+}$efflux indicating an interplay between necroptotic and pyroptotic cell death pathways (Conos et al. 2017; Gutierrez et al. 2017).

\subsubsection{Pyroptosis}

Similar to necroptosis, pyroptosis is an exclusively pro-inflammatory form of programmed cell death. However, in contrast to necroptosis, pyroptosis is strictly dependent on the proteolytic function of caspases. The involvement of large cytosolic multimeric protein complexes, called the inflammasomes, acting as caspase activation platforms is characteristic for pyroptotic cell death. Inflammasomes are typically composed of a NLR protein or AIM2, the adaptor ASC (Apoptosis-associated Speck-like protein containing a CARD, encoded by the Pycard gene) and Casp1 (Figure 1.4) (Latz, Xiao, and Stutz 2013). To date, several inflammasome complexes have been identified, all named after their specific sensor protein. Most common NLR proteins (e.g. NLRP1, NLRP3) involved in inflammasome formation (except of NLRC4) and AIM2 share the presence of a PYD-domain essential for 
protein-protein interactions. In response to pathogens such as viruses, bacteria and fungi pathogen-associated molecular pattern (PAMPs) or in response to cellular or environmental stress factors (such as changes in intracellular potassium levels or ATP) damage-associated molecular pattern (DAMPs) are recognised by NLRs which upon conformational change promote the binding of ASC via homotypic PYD-PYD interaction (Franchi, Muñoz-Planillo, and Núñez 2012). Besides a PYD-domain, ASC additionally contains a CARD domain necessary for the recruitment of Casp1 resulting in the assembly of the canonical inflammasome (Faustin et al. 2007; Franchi et al. 2009; Martinon, Burns, and Tschopp 2002). Recruitment of additional proCasp1 molecules causes proximity-induced activation of Casp1, which is followed by auto-proteolytic cleavage yielding mature Casp1. Active Casp1 subsequently cleaves pro-IL-1 $\beta$ and pro-IL18 into their mature form which can be released from cells and induce immunity. Recent studies revealed gasdermin D (GSDMD) as important substrate for Casp1, which is cleaved by active Casp1 and is essential for pyroptotic cell death (Kayagaki et al. 2015; Shi et al. 2015). Active/cleaved gasdermin D causes plasma membrane rupture via the formation of large oligomeric ring-shaped pores enabling the release of processed cytokines (Ding et al. 2016; Liu et al. 2016). Unlike, MLKL, gasdermin D forms non-selective pores that did not result in cell swelling and ion influx (Chen et al. 2016).

Besides the formation of the canonical inflammasome, which involves the activation of Casp1, the non-canonical inflammasome is induced by Casp11 activation (in human Casp4 and -5) upon direct recognition of cytosolic Lipopolysaccharide (LPS) derived from most Gram-negative bacteria (Figure 1.4) (Kayagaki et al. 2011; Shi et al. 2014, 2015). Intracellular LPS induces Casp4, -5 and -11 activation, most likely, via direct binding. Active Casp4, -5 and -11 cleave and activate gasdermin D, mediating pore formation ultimately leading to pyroptosis (Kayagaki et al. 2015; Shi et al. 2015). The N-terminal domain of gasdermin D can additionally induce the formation of canonical NLRP3 inflammasome and Casp1 activation associated with proteolytic cleavage of pro-IL-1 $\beta$ and pro-IL18 (Kayagaki et al. 2015). 

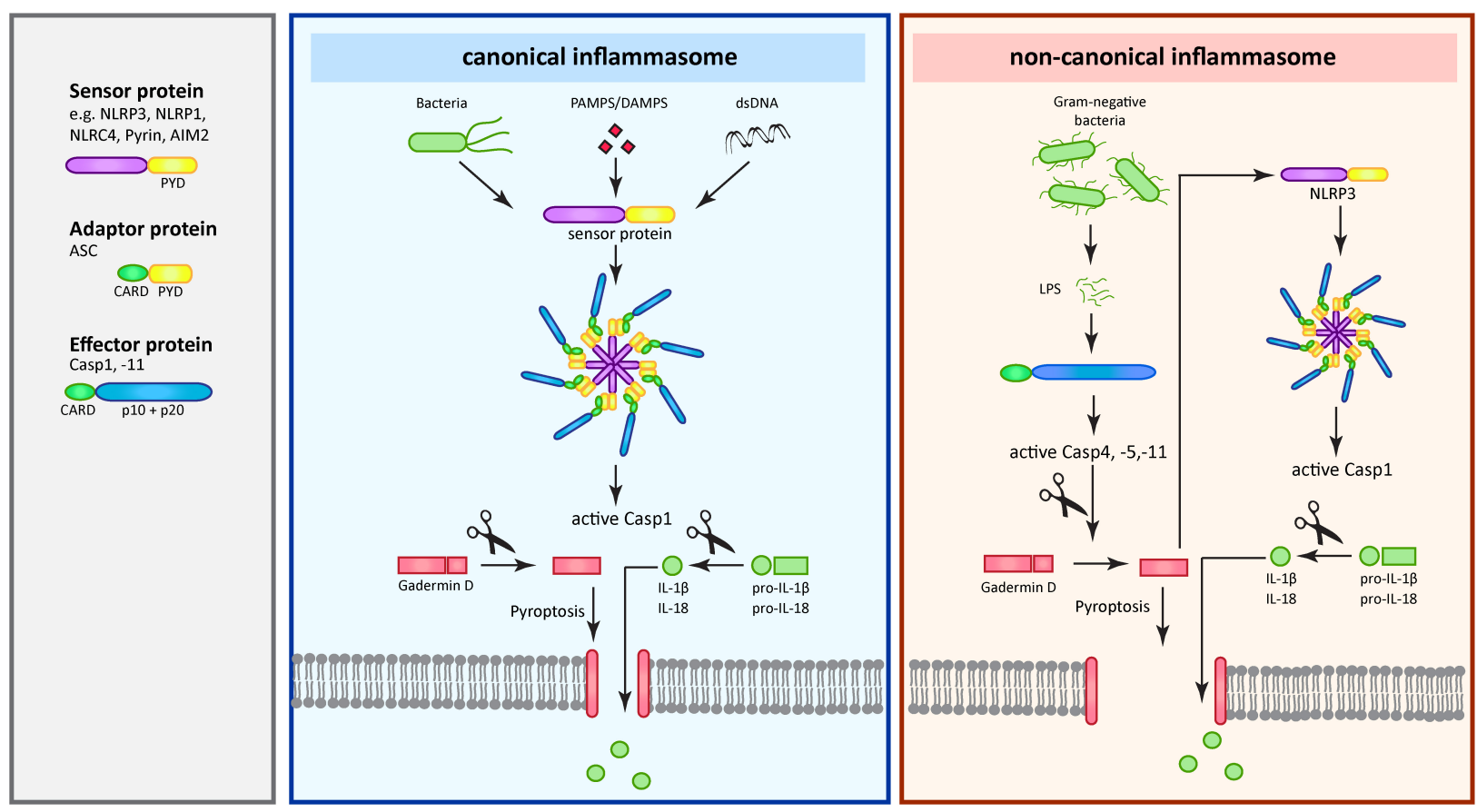

Figure 1.4 Canonical and non-canonical inflammasomes. The canonical inflammasome is typically composed of a sensor protein (e.g. NLRP3, NLRP1, NLRC4, Pyrin or AIM2), the adaptor protein ASC and the effector protein Casp1. Upon recognition of bacterial particals, PAMPs/ DAMPs or dsDNA formation of the inflammasome is induced leading to the activation of Casp1. Active Casp1 cleaves gasdermin $D$, inducing pore formation, and pro-IL-1 $\beta$ and pro-IL-18 ultimately culminating in pyroptosis and the release of IL-1 3 and IL-18. For the non-canonical inflammasome, LPS from Gram-negative bacteria is directly detected by Casp11 mediating the cleavage of gasdermin D resulting in pyroptosis. ASC, Apoptosis-associated Speck-like protein containing a CARD; PYD, Pyrin domain; CARD, caspase activation and recruitment domain; PAMPs, pathogenassociated molecular pattern; DAMPs, damage-associated molecular pattern DAMPS; dsDNA, double-stranded DNA; IL-1 $\beta$ and IL-18, Interleukine-1 $\beta$ and -18; LPS, Lipopolysaccharide (adapted from Man \& Kanneganti, 2015).

\subsection{Casp8 - central regulator of cell death}

Ongoing research progress mainly achieved by innovative methods to genetically manipulate whole organisms discovered novel insights into the molecular mechanisms governing cellular death process and demonstrated the importance of regulated cell death in organismal health. Dysregulation of cell death processes results in developmental disorders and cause an imbalance in tissue homeostasis. In fact, multiple studies suggested a role of regulated necrosis and enhanced release of cellular cytokines in human autoimmune diseases such as Crohn's disease, atherosclerosis and psoriasis (Feltham, Vince, and Lawlor 2016; Meng, Jin, and Wang 2015). Moreover, cell death has been implicated in the control of cancer and infections (Green and Llambi 2015). In this wide-ranging field, Casp8 plays a central role, as it participates in a number of different cell death modes guiding their crosstalk. Besides its well-known function in mediating extrinsic apoptosis (Boldin et al. 1996; Muzio et al. 1996), 
loss of Casp8 in mice demonstrates an inhibitory role of Casp8 in necroptosis (Varfolomeev et al. 1998). Moreover, recent studies provided further evidence that Casp8 is involved in inflammasome-dependent cytokine secretion by directly cleaving pro-IL-1 $\beta$ (Man et al. 2013; Sagulenko et al. 2013). Additionally Casp8 can act as a scaffold protein promoting cytokine production independent of its proteolytic activity in TRAIL-mediated signalling (Hartwig et al. 2017; Henry et al. 2017).

\subsubsection{Casp8 inhibits necroptosis}

Contradicting to knockout mutations of death receptors such as TNFR1 (Pfeffer et al. 1993), which do not develop an obvious phenotypes, lack of Casp8 results in embryonic lethality around E10.5, revealing a pro-survival function of Casp8 during embryonic development (Varfolomeev et al. 1998). In addition, identification of a human CASP8 mutation leading to Casp8 deficiency in patients accentuates the hypothesis of a pro-survival role of Casp8 (Chun et al. 2002). Individuals with this mutation were shown to develop symptoms similar to the autoimmune lymphoproliferative syndrome (ALPS), including defective T, B and neutral killer (NK) cell activation and exhibit defects in lymphocyte apoptosis. Several groups uncovered the regulatory property of Casp8 in the inhibition of necroptosis directly in the mouse by codeleting factors essential for necroptosis, RIPK3 and MLKL (Alvarez-Diaz et al. 2016; Kaiser et al. 2011; Oberst et al. 2011).

$\operatorname{Casp}^{-/} / \mathrm{RIPK}^{-/}$and $\mathrm{Casp}^{-\%} \mathrm{MLKL}^{-/}$mice were born viable and the expected mendelian ratio, but developed a severe lymphadenopathy and splenomegaly. Together with in vitro data, using specific inhibitors of Casp8 (z-VAD-fmk) and RIPK1 kinase activity (Necrostatin-1) (Dillon et al. 2014b) this indicates that Casp8 directly acts on necroptosis upon death receptor signalling.

Already in 1999, Lin and colleagues proposed RIPK1, besides Casp3/7 and Casp8 itself, as a substrate of Casp8, suggesting cleavage of RIPK1 as potential mechanism regulating death receptor-mediated signalling (Lin et al. 1999). Recently, several in vivo studies, by generating knock-in mice mutating the potential Casp8 cleavage site in RIPK1 (D325) illustrated the role of Casp8 in preventing inappropriate TNF-induced cell death (Newton et al. 2019b; Zhang, Dowling, and Zhang 2019). Similar to deletion of Casp8 in mice, RIPK1 $1^{D 325 A / D 325 A}$ mutation results in embryonic lethality around E10.5, which can be rescued upon additional deletion of RIPK3. 
Another substrate of Casp8 is RIPK3 and cleavage of RIPK3 results in inhibition of necroptosis similar to RIPK1 (Feng et al. 2007). The hypothesis of Casp8 as an inhibitor for necroptosis could be further confirmed, as increased phosphorylation of MLKL and insoluble RIPK1 and RIPK3 aggregates were detected in cortical lesions found in brains from multiple sclerosis (MS) patients when Casp8 levels were reduced (Ofengeim et al. 2015).

The importance of Casp8 in regulating programmed cell death by suppressing necroptosis has additionally been shown by conditional deletion of Casp8 in certain tissues. Conditional deletion of Casp8 in intestinal epithelial cells (IECS), achieved by intercrossing of Villin-Cre, demonstrated a pivotal function of Casp8 in maintaining intestinal homeostasis and the protection of IECS in response to mucosal pathogens and TNF $\alpha$-induced necroptotic cell death (Günther et al. 2011, 2015). Moreover, conditional deletion of Casp8 in the skin drives the development of inflammatory skin lesions, whereas mice with a deletion of Casp8 in endothelial cells die embryonally due to vascular defects both results of necroptotic cell death (Kang et al. 2004; Kovalenko et al. 2009b; Lee et al. 2009; Weinlich et al. 2013).

\subsubsection{Casp8 mediates inflammation}

Surprisingly, although Casp8 is traditionally associated with anti-inflammatory functions in extrinsic apoptosis and the inhibition of necroptosis, recent findings propose a unexpected role of Casp8 in mediating inflammatory cell death (Chen et al. 2015; Moriwaki et al. 2015a; Sarhan et al. 2018; Schneider et al. 2017). One characteristic feature of pro-inflammatory cell death, in particular pyroptosis, is the release of cytokines such as IL-1ß. In Line with this, Casp8 was shown to have the ability to cleave pro-IL-1 $\beta$ either directly or indirectly by processing and therefore activating Casp1 contributing to IL-1ß-mediated inflammation (Gurung et al. 2014; Moriwaki et al. 2015).

Over the last years, a variety of different stimuli, including TLR4 ligation, FasL or ER stress, were discovered triggering cleavage of pro-IL-1 $\beta$ directly by Casp8 (Bossaller et al. 2012; Moriwaki et al. 2015; Shenderov et al. 2014). Furthermore, mitochondrial intrinsic apoptosis was shown to trigger Casp8-dependent pro-IL-1 $\beta$ maturation (Chauhan et al. 2018; Vince et al. 2018). Another concrete example is the bacterial and fungal c-type lectin receptor dectin1. In primary human dendritic cells, activation of dectin-1 leads to the formation of a noncanonical Casp8 inflammasome complex composed of mucosa-associated lymphoid tissue lymphoma translocation protein 1 (MALT1), ASC and Casp8. 
Within this complex Casp8 is able to directly process and activate IL-1ß (Gringhuis et al. 2012). The observation of increased IL-1 $\beta$ maturation upon TLR4 ligation in an Casp8 dependent manner by formation of a non-canonical ripoptosome was further enhanced by inhibition of RIPK3 (Moriwaki et al. 2015b). This indicates that apart from inhibiting necroptosis Casp8 induces the secretion of pro-inflammatory cytokines.

Another mechanism, of the involvement of Casp8 in processing pro-IL-1 $\beta$, is the activation of the canonical inflammasome. Gurung et al. proposed a model, where the FADD-RIPK3-Casp8 complex associates with the inflammasome as an upstream regulator of the canonical as well as the non-canonical NLRP3 inflammasome (Gurung et al. 2014). Lately, the assembly of a cell death complex, composed RIPK1, FADD and Casp8 was discovered independently by three groups, mediating Casp8-directed cleavage of gasdermin D (Chen et al. 2019; Orning et al. 2018; Sarhan et al. 2018).

Casp8 was also shown to bind ASC via DED-PYD interaction fundamentally allowing the formation of an inflammasome where Casp8 takes part (Vajjhala et al. 2015). Indeed, plenty of studies identified Casp8-dependent inflammasomes and the co-localisation of Casp8 with Casp1 and/or ASC in the last years. For example, in response to bacterial infection, Casp8 is recruited to the NLRP3 and NLRC4 inflammasome but is only catalytically active upon genetic deletion of Casp1/-11 (Man et al. 2014; Mascarenhas et al. 2017). In line with this, mice with a site-directed mutation of the catalytic cysteine, which generates a proteolytic inactive Casp1 (Casp1 $\left.{ }^{\text {C284A }}\right)$, results in ASC-dependent activation of Casp8 at the inflammasome driving cell death and the release of IL-1 $\beta$ of infected macrophages (Van Opdenbosch et al. 2017; Schneider et al. 2017). On the other hand, Casp8 was shown to induce the formation of an alternative inflammasome independent of ASC, where NLRP3 is the main factor (Gaidt et al. 2016). These observations together indicate that Casp8 plays a key role in the regulation of inflammasome activity and thereby in pyroptosis. More importantly, due to cytokine maturation Casp8 possess an apoptotic and necroptotic independent role.

\subsubsection{Relevance of Casp8 enzymatic activity}

Casp8 enzymatic activity dictates the cell fate and determines how a cell dies. The importance of Casp8 enzymatic activity in switching between different cell death modes is underlined by the evolution of mammalian and viral Casp8 inhibitors, such as CrmA, vICA 
and CFLIP (Mocarski, Guo, and Kaiser 2015). The mammalian cellular FLICE inhibitory protein (cFLIP) is a proCasp8-like protein lacking the catalytic cysteine in the large subunit and exists in two isoforms. The presence of two DED domains enables cFLIP to interact with the DISC and the levels of the different isoforms define the outcome of ripoptosome formation. cFLIP short (cFLIPS) forms a complex with Casp8, inhibiting its enzymatic activity by disrupting proCasp8 homodimerisation at the DISC consequently blocking apoptosis and inducing necroptosis (Hughes et al. 2016). Additionally, high levels of the long form of cFLIP (cFLIPL) heterodimerise with proCasp8 suppressing apoptosis, whilst low levels of CFLIP trigger proCasp8 oligomerisation and induce apoptosis associated with the inhibition of necroptosis (Oberst et al. 2011; Pop et al. 2011).

The ability of caspase auto-cleavage puts viruses under evolutionary pressure to acquire specific Casp8 inhibitors. Thus, many viruses block Casp8 enzymatic activity thereby supressing apoptosis. The cytokine response modifier $\mathrm{A}(\mathrm{CrmA})$ is a cowpox-virus protein that inhibits Casp8 enzymatic activity (Oberst et al. 2011; Zhou et al. 1997). Another example is the viral inhibitor of Casp8-induced apoptosis (VICA) of the murine cytomegalovirus which binds to the prodomain of Casp8, preventing its activation and as a result inhibits Fasmediated apoptosis (McCormick et al. 2010; Skaletskaya et al. 2001). The adaption of necroptosis, which is triggered upon Casp8 inhibition, is a backdoor for the host to cope with viruses that supress Casp8 enzymatic activity.

The existence of viral and mammalian Casp8 inhibitors raises the question whether catalytic inactive Casp8 loses its raison d'êter or if, apart from its enzymatic activity, Casp8 has any influence on other signalling pathways. Here, the recently discovered scaffold function of Casp8 must be mentioned. Kang and colleagues proposed a model, where Casp8 is recruited to a complex formed by FADD, RIPK1 and RIPK3 upon TLR3 stimulation subsequently activating the NLRP3 inflammasome in an MLKL dependent manner but independent of Casp8 enzymatic activity (Kang et al. 2015). Furthermore, Casp8 has been shown to serve as a scaffold protein for the assembly of a Casp8-FADD-RIPK1 complex, that is necessary for Trail-induced pro-inflammatory cytokine production (Hartwig et al. 2017; Henry et al. 2017). Conclusively, these observations make Casp8 an all-round talent as a scaffold protein and proteolytic active enzyme, which plays an indispensable role in various mechanisms dictating the fate of the cell. 


\subsubsection{Casp8 in infection}

Viral and bacterial infections often interfere with cell death as part of the host defence mechanism or as smart survival strategy of the pathogen. In the evolutionary armed race between the host and the pathogen, the host uses different cell death modes, with a complex crosstalk to ensure the elimination of infected cells and as a consequence the replicative niche of the pathogen. Here, the best-described pathogen-induced cell death modes are apoptosis, necroptosis and pyroptosis. In contrast, pathogens have evolved an array of effector proteins and toxins to bypass cell death by modulating host signalling pathways (Jorgensen, Rayamajhi, and Miao 2017).

Since Casp8 plays a central role in the regulation of programmed cell death, viruses take the advantage of Casp8 inhibition as warfare to prevent apoptosis. Conversely, host cells benefit from the Casp8-dependent crosstalk of various signalling pathways to fight against invading bacteria. For instance, the Gram-negative bacterium Yersinia express the effector protein YopJ that inhibit MAPK and NF-KB signalling silencing cytokine production while inducing Casp8-dependent cell death (Philip et al. 2014; Weng et al. 2014). Moreover, it has been shown, that Yersinia spp. infection and YopJ activity results in the direct cleavage of gasdermin D by Casp8 leading pyroptosis (Orning et al. 2018; Sarhan et al. 2018). As another example, Casp8 is recruited to the inflammasome together with ASC and Casp1 mediating IL$1 \beta$ maturation in response to Salmonella enterica serovar Typhimurium, but is redundant for Salmonella-induced cell death (Man et al. 2013). Activation of the NLRP3 inflammasome in a Casp8-dependent manner has been described in response to Francisella tularensis, Citrobacter rodentium and the fungal pathogen Cryptococcus neoformans (Chen et al. 2015; Gurung et al. 2015; Pierini et al. 2012). Flagellin from the Gram-negative bacterium Legionella pneumophilia, triggers the activation of the NLRC4 inflammasome and the recruitment of Casp8 to ASC forming a complex where active Casp8 mediates pore formation and cell death independently of gasdermin D (Mascarenhas et al. 2017). A recent study showed, that $\mathrm{Casp}^{-\%} / \mathrm{RIPK}^{-/-}$mice are more resistant against LPS-mediated endotoxic shock and E. coli sepsis (Mandal et al. 2018). All these are examples of Casp8 as a defensive line in the host-pathogen and life-death battle. 


\section{Aim of the study}

Appropriate cell death has a major impact in embryonic development, tissue homeostasis and in the defence against invading pathogens. Thus, the regulation of programmed cell death represents an essential requirement in the decision between life and death. Casp8 stands out with its unique properties in regulating three different cell death modes as proteolytically active enzyme as well as scaffolding platform. However, the role of Casp8 and its enzymatic activity in development and in the course of bacterial infection is still fragmentary. The present work aims to unravel the exact mechanism of Casp8 enzymatic activity in the mouse and during bacterial infection, especially for cytosolic pathogens such as Shigella flexneri. 


\section{Material and Methods}

\subsection{Mice}

Casp $8^{C 362 S}$ mice were generated by pronuclear injection of C57BL/6N zygotes with $20 \mathrm{ng} / \mu \mathrm{l}$ Cas9 mRNA (Trilink Biotechnologies), $10 \mathrm{ng} / \mu \mathrm{l}$ sgRNA and $20 \mathrm{ng} / \mu \mathrm{l}$ template DNA (Eurofins). Sequence of single-guide RNA (5'-CACC GTTTCATTCAGGCTTGCCA-3') and template DNA (5'CACTGGTTCAAAGTGCCCTTCCCTGTCTGGGAAACCCAAGATCTTTTTTCATTCAGGCTAGCCAAGGAA GTAACTTCCAGAAAGGAGTGCCTGATGAGGCAGGCTTCGAGCAACAGAAC-3). Founder carrying the intended C362S mutation were backcrossed to a C57BL/6N genetic background for five generations. All mouse studies were performed after approval by local government authorities (LANUV, NRW, Germany) in accordance with the German animal protection law. Animals were housed in the animal care facility of the University of Cologne under standard pathogen-free conditions with a $12 \mathrm{~h}$ light/dark schedule and provided with food and water ad libitum. Calculations to determine sample size, randomization and blinding was not performed. Mice were grouped according to their genotype in mixed sexes.

\subsection{Genotyping of mouse lines}

Ear cuts were taken from mice at weaning and lysed using the KAPA Express Extract Kit (KAPA). Amplification of DNA fragments was performed with GoTaq ${ }^{\circledR}$ Hot Start Green Master Mix (Promega) and the designated primers. PCR products were then loaded onto a $1.5 \%$ agarose gel stained with PeqGreen for fragment separation and were visualised using the ChemiDoc Imaging System (BioRad). Casp8 C362S was genotyped by Sanger sequencing (Microsynth SEQLAB).

Table 2.1 PCR Primer used for genotyping

PCR Primer

Casp8 C362S

5'-TGCAAATGAAATCCACGAGA-3'

5'-CCAGGTTCCATTCACAGGAT-3'

Casp8 ko/flox 5'-ATAATTCCCCCAAATCCTCGCATC-3'

5'-TCCTGTACCATATCTGCCTGAACGCT-3' ko

5'-GGCTCACTCCCAGGGCTTCCT-3' flox 


\begin{tabular}{|c|c|}
\hline MLKL & 5'-CATCAAGTTAGGCCAGCTCA-3' \\
\hline & 5'-TCTGCTGGTTAGCCTCCTTC-3' \\
\hline RIPK3 & 5'-CGCTTTAGAAGCCTTCAGGTTGAC-3' \\
\hline & 5'- GCCTGCCCATCAGCAACTC-3' \\
\hline & 5'-CCAGAGGCCACTTGTGTAGCG-3' \\
\hline VilCre & 5'-ACAGGCACTAAGGGAGCCAATG-3' \\
\hline & 5'-ATTGCAGGTCAGAAAGAGGTCACAG-3' \\
\hline & 5'-GTTCTTGCGAACCTCATCACTC-3' \\
\hline K14 / Tie2 & 5'-CTAGGCCACAGAATTGAAAGATCT-3' \\
\hline & 5'-GTAGGTGGAAATTCTAGCATCATCC-3' \\
\hline & 5'-GCGGTCTGGCAGTAAAAACTATC-3' \\
\hline & 5'-GTGAAACAGCATTGCTGTCACTT-3' \\
\hline ASC & 5'-GGCTTAGTGTTCTAGCTGTT-3' \\
\hline & 5'-ACCAGGAAGTCAGCTGCTTA-3' \\
\hline & 5'-TTCACACAATACGATCTTCA-3' \\
\hline Casp1 & 5'-ATGGGGAGTGATACTGGGTCA-3' \\
\hline & 5'-GATGGAGGATCTGCCTTGGG-3' \\
\hline & 5'-TGTCTTTCAAGCTTGGGCAC-3' \\
\hline
\end{tabular}

\subsection{Embryological studies}

For time mating experiments a male mouse was paired with a single female mouse. Embryonic day count started at E0.5 with the day of positive plug check. For staining of vascularisation of yolk sac, yolk sac was fixed in $4 \%$ PFA in PBS for $1 \mathrm{~h}$ at $4{ }^{\circ} \mathrm{C}$, washed in PBS with $0.5 \%$ Tween-20 (PBS-T) followed by blocking with blocking buffer (PBS-T, $0.2 \%$ BSA and $2 \%$ normal goat serum) for 2 h. Yolk sacs were then incubated with Alexa Fluor 647 antimouse CD31 antibody (BioLegend) overnight at $4{ }^{\circ} \mathrm{C}$, washed with PBS and mounted with Mowiol. Imaging was conducted on a motorised inverted Olympus IX81 microscope (Cell ${ }^{R}$ Imaging Software). 


\subsection{Antibodies and reagents}

All chemicals were purchased from the companies Roth (Karlsruhe), Sigma-Aldrich (Taufkirchen) or Merck (Darmstadt) or otherwise mentioned within the text. mTNF $\alpha$ was obtained from R\&D (Wiesbaden, Germany), Cycloheximide from Sigma (Taufkirchen, Germany), Necrostatin-1 from Enzo (Farmingdale, U.S.) and IDN-6556/Emricasan MedChemExpress (Sollentuna, Sweden). HTNCre was purchased from Excellgene (Monthey, Switzerland). All chemicals and solutions were prepared with deionised water or, if necessary, dilutions were autoclaved or filter sterilised ( $0.2 \mu \mathrm{m}$ filter, $B$, Braun, Meinsungen).

Table 2.2 Primary antibodies.

\begin{tabular}{|c|c|c|}
\hline Antibody & Isotype & Supplier \\
\hline Caspase-3 (8G10) & rabbit, monoclonal & Cell Signaling (Frankfurt a.M., Germany) \\
\hline cleaved Caspase-3 & rabbit, polyclonal & Cell Signaling (Frankfurt a.M., Germany) \\
\hline Caspase-8 (mouse specific) & rabbit, polyclonal & Cell Signaling (Frankfurt a.M., Germany) \\
\hline cleaved Caspase-8 (Asp387) & rabbit, polyclonal & Cell Signaling (Frankfurt a.M., Germany) \\
\hline $\begin{array}{l}\text { Caspase-8 (1C12) } \\
\text { (human specific) }\end{array}$ & mouse, monoclonal & Cell Signaling (Frankfurt a.M., Germany) \\
\hline Caspase-7 & mouse, monoclonal & Cell Signaling (Frankfurt a.M., Germany) \\
\hline Caspase-9 & rabbit, polyclonal & Cell Signaling (Frankfurt a.M., Germany) \\
\hline Caspase-1 p10 (M-20) & rabbit, polyclonal & Santa Cruz (Heidelberg, Germany) \\
\hline Caspase-1 p20 (clone Casper-1) & mouse, monoclonal & Adipogen (San Diego, U.S.) \\
\hline Caspase-1 (clone 5B10) & rat, monoclonal & Biolegend (San Diego, U.S.) \\
\hline RIPK1 (clone G322-2) & mouse, monoclonal & BD Biosciences (Heidelberg, Germany) \\
\hline RIPK3 & rabbit, polyclonal & Enzo (Farmingdale, U.S) \\
\hline cFLIP alpha & rabbit, polyclonal & Sigma-Aldrich (Taufkirchen, Germany) \\
\hline FADD & mouse, monoclonal & BD Biosciences (Heidelberg, Germany) \\
\hline ASC (N15) & rabbit, polyclonal & Santa Cruz (Heidelberg, Germany) \\
\hline$\beta$-Actin HRP (C4) conjugated & mouse, monoclonal & Santa Cruz (Heidelberg, Germany) \\
\hline dsRed & rabbit, polyclonal & BD Biosciences (Heidelberg, Germany) \\
\hline Lysozyme (EC.3.2.1.17) & rabbit, polyclonal & DAKO (Santa Clara, U.S.) \\
\hline $\begin{array}{l}\text { Caspase-8 (clone 1G12) } \\
\text { (mouse-specific) }\end{array}$ & rat, monoclonal & Enzo (Farmingdale, U.S) \\
\hline MLKL (phospho S345) & rabbit, monoclonal & Abcam (Cambridge, U.K.) \\
\hline
\end{tabular}


Table 2.3 Secondary antibodies for Western Blotting (WB) and Immunohistochemistry (IHC).

\begin{tabular}{lll}
\hline Antibody & Isotype & Supplier \\
\hline anti-mouse conjugated to HRP & goat & Sigma-Aldrich (Taufkirchen, Germany) \\
\hline anti-rabbit IgG biotin-labeled & goat & Perkin Elmer (Waltham, U.S.) \\
\hline Rat IgG (H+L) secondary Antibody HRP & goat & Invitrogen (Carlsbad, U.S.) \\
\hline anti-mouse IgG light chain HRP & goat & Jackson ImmunoResearch (Ely, U.K.) \\
\hline Biotin-SP conj. AffiniPure Anti-Rat IgG & goat & Jackson ImmunoResearch (Ely, U.K.)
\end{tabular}

Table 2.4 Direct-labelled and secondary antibodies for Immunofluorescence (IF).

\begin{tabular}{lll}
\hline Antibody & Isotype & Supplier \\
\hline $\begin{array}{l}\text { anti-mouse CD31-Alexa Fluor 647 } \\
\text { (MEC13.3) }\end{array}$ & rat, monoclonal & Biolegend (San Diego, U.S.) \\
\hline anti-rabbit Alexa Fluor 568 & goat & ThermoFisher Scientific (Waltham, U.S.) \\
\hline anti-rabbit Alexa Fluor 594 & goat & ThermoFisher Scientific (Waltham, U.S.)
\end{tabular}

\subsection{Immunohistochemistry (IHC)}

Intestinal tissue and skin were fixed in Roti-HistoFix $4 \%$ (Carl Roth), embedded in paraffin and cut in $5 \mu \mathrm{m}$ sections. After rehydration and heat-induced antigen retrieval in $10 \mathrm{mM}$ citrate buffer or by proteinase $\mathrm{K}$ treatment and sections were stained with the appropriate primary and secondary antibodies. Staining was visualised using the ABC Kit Vectastain Elite (Vector Laboratories) and DAB staining Kit (Dako) and counterstained with Hematoxylin (Carl Roth). Incubation time of substrate for DAB staining was equal for all tissue sections. Tissue sections were stained with Haematoxylin \& Eosin (H\&E). Goblet cells were stained using Periodic Acid-Schiff (PAS) staining (Sigma Aldrich) according to the manufacturer's instructions. Stained sections were scanned with an SCN4000 Slide Scanner (Leica) and analysed with the imaging software Aperio ImageScope v 12.2.2.5015 (Leica). For Paneth cell count 30 crypts and for dead cell count 15 villi were analysed per mouse. 


\subsection{Cell culture}

\subsubsection{Endothelial cell culture}

Murine ECs were isolated from lungs of $\operatorname{Casp} 8^{\text {wt/fl }}$ and $C a s p 8^{C 362 S / f l}$ mice. Organs were resected and briefly washed in PBS, before being minced and enzymatically digested with $0.5 \%$ collagenase. Cell solution was then processed through a cell strainer $(70 \mu \mathrm{m})$ and subjected to magnetic bead enabled enrichment of CD31 positive endothelial cells (murine CD31, Miltenyi Biotec) according to manufacturer's protocol. CD31 positive ECs were seeded on gelatine-coated wells and cultured in a 1:1 mixture of EGM2 (PromoCell) and full supplemented Dulbecco's Modified Eagle Medium (DMEM containing $20 \%$ FCS, 4 g/l glucose, $2 \mathrm{mM}$ glutamine, $1 \%$ penicillin/streptomycin $(100 \mathrm{U} / \mathrm{ml}$ penicillin, $100 \mathrm{\mu g} / \mathrm{ml}$ streptomycin), sodium pyruvate $1 \%(1 \mathrm{mM})$, HEPES (20 mM) and $1 \%$ non-essential amino acids). After first passage, cells were resorted using the same magnetic beads. Isolated primary endothelial cells were analysed using CD31 antibody, sprouting response and mRNA levels to distinguish endothelial cells from other cell types and were tested routinely negative for Mycoplasma contamination by PCR DNA fragments of $\operatorname{Casp}^{\mathrm{wt} / f \mathrm{fl}}$ and $\operatorname{Casp} 8^{\mathrm{C} 362 \mathrm{~S} / \mathrm{fl}}$ alleles were excised by treatment with recombinant HTNCre $(5 \mu \mathrm{M})$ purified from E. coli for $24 \mathrm{~h}$ in a mixture of DMEM/PBS 1:1 twice. Complete knockout was confirmed by PCR and Western blot analysis. Casp $8^{-/}$cells were used as controls. ECs were treated with murine TNFa (R\&D), Cycloheximide (Sigma) and Necrostatin-1 (Enzo) as indicated.

\subsubsection{Macrophage differentiation}

Murine bone marrow-derived macrophages (BMDMs) were differentiated from bone marrow of mice with respective genotypes. BMDMs were generated by culturing mouse bone marrow in RPMI supplemented with $15 \%$ L929-conditioned medium, 10 \% FCS (Sigma), 10 mM HEPES (Biochrom), 1 mM Sodium-Pyruvat (Biochrom), 2 mM L-Glutamine (Biochrom), $100 \mathrm{U} / \mathrm{ml}$ penicillin, $100 \mu \mathrm{g} / \mathrm{ml}$ streptomycin for 7 days. DNA fragments of Casp $8^{w t / f l}, \operatorname{Casp}^{\mathrm{C} 362 S / f l}$ and $\operatorname{Casp} 8^{f / f l}$ alleles were excised by treatment with recombinant HTNCre $(2.5 \mu \mathrm{M})$ (Excellgene, Purity: > 98\%, Endotoxin Levels: < 0,1 EU/ $\mu \mathrm{g}$ ) for $24 \mathrm{~h}$ in a mixture of RPMI/PBS 1:1 (v/v) or LPS (200 ng/ml) (Invivogen) and IDN-6556 (20 $\mu \mathrm{M})$. 


\subsubsection{Infection of BMDMs with Shigella flexneri}

Shigella flexneri M90T afaE is a wild-type (WT) invasive strain of Shigella flexneri serotype 5a harbouring the plasmid pIL22, which encodes the afimbrial adhesion from uropathogenic $E$. coli to allow better synchronisation of infection. Shigella flexneri M90T was a kind gift from Philippe Sansonetti (Institute Pasteur, Paris, France) (P. L. Clerc et al. 1987; P. Clerc and Sansonetti 1987). Bacterial infection was performed using the Shigella flexneri strain M90T afaE as described elsewhere (Andree et al. 2014; Philpott et al. 2000). In brief, cells were incubated with the indicated MOI (multiplicity of infection) in RPMI containing $10 \%$ FCS for $15 \mathrm{~min}$ at RT to allow synchronised infection. Subsequently, cells were transferred to $37^{\circ} \mathrm{C}$ for $2 \mathrm{~h}$ (time point zero). Fresh RPMI containing $10 \% \mathrm{FCS}$ and $50 \mu \mathrm{g} / \mathrm{ml}$ gentamycin to kill extracellular bacteria was added.

\subsubsection{Cultivation and transfection of human cells}

HCT-116 and HEK293T cells were purchased from ATCC. All cell lines were tested routinely negative for Mycoplasma contamination by PCR. HCT-116 cells were cultured in McCoy's 5A modified medium (Merck) supplemented with $10 \%$ heat-inactivated fetal bovine serum (Biowest) and transfected with Lipofectamine ${ }^{\mathrm{TM}} 2000$ (Invitrogen). HEK293T cells were cultured in DMEM (Merck) supplemented with $10 \%$ heat-inactivated fetal bovine serum (Biowest) and were transfected with polyethylenimine (PEI) (Polysciences Europe GmbH). HEK293T and HCT-116 cells were transfected for $14 \mathrm{~h}$ with respective constructs and subsequently treated with IDN-6556 (MedChemExpress) and Necrostatin-1 (Enzo) as indicated. Casp8 coding sequence and site-directed C360S (forward: 5'ATTCAGGCTTCTCAGGGGGAT-3'; reverse: 5'-ATCCCCCTGAGAAGCCTGAAT-3') (Eurofins) mutation was cloned into the plasmid pcDNA3.1+. ASC coding sequence was cloned into pDsRed2. 


\subsection{Generation of CRIPSR/Cas9 Casp8 knockout cells}

Oligonucleotide sgRNAs (\#1: GCTCTTCCGAATTAATAGAC; \#2: CTACCTAAACACTAGAAAGG) (Eurofins) targeting the Casp8 locus were cloned into the pSpCas9(BB)-2A-GFP (PX458) vector, which was a gift from Feng Zhang (Addgene plasmid \# 48138), and transfected into HCT-116 and HEK293T cells. $24 \mathrm{~h}$ post transfection, cells were plated onto 96-well plates (1 cell / well) and Casp8 deficiency was checked after 3-4 weeks in single cell clones by Western blot analysis.

\subsection{Purification of HTNCre}

For site-specific recombination of floxed Casp8 alleles HTNCre (His-tagged, TAT-fusion Cre with nuclear localisation signal) from transformed E. coli was purified. Transformed E. coli expressing HTNCre was a kindly gift from Dr. Thomas Wunderlich (Max Planxk Institute for Metabolism Research, Cologne, Germany). Briefly, bacteria were grown from a diluted overnight culture until an OD at $600 \mathrm{~nm}$ of $0.6-1.1$ was reached. Transcription of the HTNCre construct was initiated by the addition of IPTG (1 mM). The culture was incubated for additional $4 \mathrm{~h}$ at $37{ }^{\circ} \mathrm{C}$ and then centrifuged for $25 \mathrm{~min}$ at $8500 \mathrm{rpm}$ at $4{ }^{\circ} \mathrm{C}$. One gram of pellet was resuspended in $10 \mathrm{ml}$ PBS, $1 \mathrm{mg}$ lysozyme per $\mathrm{ml}$ suspension, 1:1000 benzonase (Novagen) and protease inhibitor (Roche). Lysate was homogenated through a high-pressure homogeniser and HTNCre was purified by affinity chromatography using HisTrap ${ }^{\mathrm{TM}}{ }^{\mathrm{FF}}$ crude column (GE Healthcare).

\section{Buffers}

Binding buffer

PBS

$0.5 \mathrm{M} \mathrm{NaCl}$

$40 \mathrm{mM}$ Imidazol

$\mathrm{pH} 7.4$

Elution buffer $\quad$ PBS

$0.5 \mathrm{M} \mathrm{NaCl}$

250 mM Imidazol

$\mathrm{pH} 7.4$

\begin{tabular}{ll}
\hline Glycerol stock solution & $50 \%$ Glycerol \\
$600 \mathrm{mM} \mathrm{NaCl}$ \\
$20 \mathrm{mM} \mathrm{HEPES}$
\end{tabular}




\subsection{Immunoprecipitation (IP)}

HEK293T cells were transfected for $14 \mathrm{~h}$ with respective constructs and subsequently treated with IDN-6556 as indicated. Cells were trypsinised, washed twice with chilled PBS and centrifuged at $700 \times \mathrm{g}$ for $3 \mathrm{~min}$ at $4{ }^{\circ} \mathrm{C}$. The cell pellet was resuspended in RIPA buffer $(1 \%$ Triton, $150 \mathrm{mM} \mathrm{NaCl}, 50 \mathrm{mM}$ Tris, 0.1 \% SDS, 0.5 \% Deoxycholate, 10 \% Glycerole, 1mM EGTA) and incubated for $30 \mathrm{~min}$ on ice and centrifuged for $20 \mathrm{~min}$ at $20,800 \times \mathrm{g}$ at $4{ }^{\circ} \mathrm{C}$. Prior to antibody incubation, IP incubation buffer (20 mM Tris, pH 8.0, $137 \mathrm{mM} \mathrm{NaCl}, 1$ \% NP-40, 2 mM EDTA) was added in ratio 1:2. Lysate was incubated with Casp8 human-specific antibody (Cell Signaling) for $1 \mathrm{~h}$ at $4{ }^{\circ} \mathrm{C}$ prior to addition of $\mu$ MACS Protein G MicroBeads (Miltenyi Biotech). Normal mouse IgG (Santa Cruz) served as control. IP was performed according to manufacturer's instructions.

\subsection{Western blot (WB) analysis}

Cells were lysed in $20 \mathrm{mM}$ Tris- $\mathrm{HCl} \mathrm{pH}$ 7.5, $135 \mathrm{mM} \mathrm{NaCl}, 1.5 \mathrm{mM} \mathrm{MgCl}, 1 \mathrm{mM}$ EGTA, 1 \% Triton X-100, 10 \% glycerol, protease inhibitor (Roche) and phosphatase inhibitor (Roche). After $20 \mathrm{~min}$ on ice, cells were centrifuged at $20,000 \times \mathrm{g}$ for $20 \mathrm{~min}$ at $4{ }^{\circ} \mathrm{C}$, the soluble fraction was collected and the insoluble fraction was mechanically disrupted in $6 \mathrm{M}$ urea, 3 \% SDS, $10 \%$ glycerine $50 \mathrm{mM}$ and Tris pH 6.8. Cell lysates of ECs, HCT-116, HEK293T were prepared in CHAPS lysis buffer (10 mM HEPES pH 7.4, $150 \mathrm{mM} \mathrm{NaCl}, 1 \%$ CHAPS, protease inhibitor (Roche) and phosphatase inhibitor (Roche)) $)^{30}$. Protein concentrations of cell lysates and tissue lysates were determined using Pierce BCA Protein Assay Kit (ThermoFisher Scientific) or DC protein assay (Bio Rad) according to the manufacturer's instructions. Proteins were separated by SDS-PAGE and transferred to a nitrocellulose or PVDF membrane. Proteins were stained with the appropriate primary and secondary antibodies and then developed using a ChemiDoc MP Imaging System (BioRad).

\section{Buffers}

Bovine Serum Albumin

(BSA)

\author{
$5 \%$ BSA (w/v) \\ $20 \mathrm{mM}$ Tris Base \\ $150 \mathrm{mM} \mathrm{NaCl}$ \\ 0.1 \% Tween \\ pH 7.6
}




Blocking Milk $\quad \begin{aligned} & 5 \% \text { non-fat dried milk (w/v) } \\ & 10 \mathrm{mM} \mathrm{Tris} \mathrm{Base} \\ & 150 \mathrm{mM} \mathrm{NaCl} \\ & 0.1 \% \text { Tween } \\ & \text { pH } 7.4-7.6\end{aligned}$

Laemmli sample buffer (5x) $\quad 0,6 \mathrm{M}$ Tris- $\mathrm{HCl}$ pH 6,8

144 mM SDS

$25 \%$ Glycerol

$0,1 \%(w / v)$ Bromphenole blue

$5 \% \beta$-Mercaptoethanol

\begin{tabular}{ll}
\hline SDS Running buffer & $14.4 \%(\mathrm{w} / \mathrm{v})$ Glycin \\
& $3 \%(\mathrm{w} / \mathrm{v})$ Tris Base \\
& $0.1 \%(\mathrm{w} / \mathrm{v}) \mathrm{SDS}$ \\
\hline Transfer buffer (Blot) & $25 \mathrm{mM}$ Tris Base $\mathrm{pH} 8.3$ \\
& $192 \mathrm{mM}$ Glycin \\
& $20 \%(\mathrm{v} / \mathrm{v})$ Methanol
\end{tabular}

\subsection{Immunofluorescence Microscopy}

Microscopic immunofluorescence analysis is described elsewhere. In brief, cells were seeded on glass coverslips, treated as indicated and fixed with $3 \%$ PFA in PBS for 20 min at room temperature. Afterwards, cells were washed twice with PBS and incubated with blocking buffer (0.1 \% saponin (Roth), 3 \% BSA (Roth) in PBS) for 30 min at room temperature. Coverslips were incubated with diluted primary antiodie in blocking buffer in a humid chamber overnight at $4{ }^{\circ} \mathrm{C}$. After incubation, coverslips were washed with washing buffer (0.1\% saponin in PBS) 3 times and incubated with secondary for $1 \mathrm{~h}$ at room temperature. Afterwards, cells were stained with 300 nM DAPI (Molecular Probes) for $10 \mathrm{~min}$ and washed 3 times, before embedded with Mowiol overnight. Imaging was performed on an UltraView Vox Spinning Disk confocal microscope (Perkin Elmer and Nikon) and analysed using Volocity Version 5.4.2 (PerkinEImer). 


\subsection{Viability assay}

Viability was analysed using the neutral red assay (Repetto, del Peso, and Zurita 2008). In brief, 20,000 endothelial cells per well were seeded on gelatine-coated 96-well plates and cultured in the appropriate medium overnight. Cells were then exposed to the specific conditions and neutral red assay was performed $6 \mathrm{~h}$ post treatment.

\subsection{Cell death assay}

LDH release was measured to analyse cell death using the cytotoxicity detection kit (Roche) according to the manufacture's instructions.

\subsection{Casp8 activity measurement}

Casp8 activity was determined using Caspase-Glo ${ }^{\circledR 8}$ (Promega) according to the manufacture's instructions.

\subsection{Tissue homogenates}

Tissue sections of the small intestine from mice with the indicated genotypes were homogenised in RIPA buffer containing protease and phosphatase inhibitors (Roche) $(20 \mathrm{ml}$ buffer / $1 \mathrm{~g}$ tissue) using gentleMACS $\mathrm{C}$ tubes (Miltenyi Biotec). Supernatants of tissue homogenates were used for determination of cytokine levels.

\subsection{Cytokine ELISA}

Cytokine levels were determined using IL-1 $\beta$ ELISA (R\&D Systems) according to the manufacturer's instructions.

\subsection{Cytokine Array}

LUNARIS $^{\text {TM }}$ Mouse Cytokine Kit (AYOXXA Biosystems) was performed to determine cytokine levels in tissue homogenates according to the manufacturer's instructions.

\subsection{Blood parameter analysis}

After cervical dislocation of mice blood was collected from the heart with EDTA-coated syringe and immediately diluted with Cellpack (Sysmex) in a ratio of 1:5. Blood was analysed by the Institute for Clinical Chemistry at the University Hospital Cologne. 


\subsection{Intravenous infection of mice with Shigella flexneri and treatment with IDN-6556}

C57BL/6N mice were infected with Shigella flexneri M90T as previously described (Andree et al. 2014). Briefly, a colony forming units (CFU) of $1 \times 10^{8}$ Shigella flexneri M90T were resuspended in $200 \mu \mathrm{l}$ steril PBS and injected into the tail vein of the mice.

IDN-6556 (Emricasan, MedChemExpress) was dissolved with sterile PBS/3 \% Captisol (CyDex Pharmaceuticals) and $5 \mathrm{mg} / \mathrm{kg}$ was injected intraperitoneally in C57BL/6N mice. PBS with $3 \%$ Captisol was used as negative control.

\subsection{Bacterial burden in livers and spleens}

For determination of viable bacteria, livers and spleens were homogenised in sterile PBS with the gentleMACS dissociator (Miltenyi Biotech) and lysates were plated in serial dilutions on LB agar plates.

\subsection{Statistics}

Data are presented as mean \pm SEM. Sample sizes (replicates, animals) are traceable as individual data points in each Figure. In vitro experiments were repeated at least two times. Data involving animals depict pooled data of at least two independent experiments. All statistical tests used to examine statistical significance were two-sided. Exact $p$-values and the respective test/analysis are listed in the figure legends. ${ }^{*}$ indicates $p<0.05 * * p<0.01$ *** $p<0.001$ n.s. not significant. LUNARIS ${ }^{\mathrm{TM}}$ Analysis Suite 1.3, Graphpad Prism 7.0 and Excel were used to analyse data in this study. 


\section{Results}

Caspases play an essential role in regulated cell death during the pathogenesis of bacterial infection. Our recent investigations showed that cytosolic appearance and growth of Shigella flexneri, an invasive Gram-negative enteropathogenic bacterium, causes MOMP without inducing cell death in epithelial cells and thereby safeguards the intracellular replicative niche for bacterial propagation (Andree et al, 2014). Shigella was also able to inhibit apoptosis in response to TRAIL and our data additionally showed that cytosolic Shigella can efficiently inhibit executioner caspase activity (Günther et al, 2020). Mechanistically, LPS derived from intracellular Gram-negative bacteria bound and inhibit executioner caspase activity in cells thereby safeguarding intracellular bacterial replication (Andree et al. 2014, Günther et al. 2020). In contrast to epithelial cells, myeloid cells die upon Shigella flexneri infection, a process which mainly involved Casp1 (Hilbi 1998). However, the contribution of other caspases apart from Casp1 and Casp3 in Shigella-mediated signalling pathways, in particularly in the regulation of macrophages cell death remains unknown.

\subsection{Casp8 is activated during bacterial infection}

In order to elucidate the involvement of other caspases than Casp1 and Casp3 in response to Shigella flexneri, bone marrow-derived macrophages (BMDMs) were infected with Shigella flexneri with increasing multiplicities of infection (MOI) (Figure 3.1 a). Western blot analysis revealed an activation of Casp8 in a concentration dependent manner as cleavage of Casp8 increased with the MOI. Moreover, Casp8 cleavage was not detectable upon additional treatment of infected cells with the pan-caspase inhibitor IDN-6556 (Emricasan). This result was confirmed by an independent measurement of Casp8 activity (Figure $3.1 \mathrm{~b}$ ). Together, these observations indicate that Casp8 is activated in BMDMs upon infection with Shigella flexneri. 
a

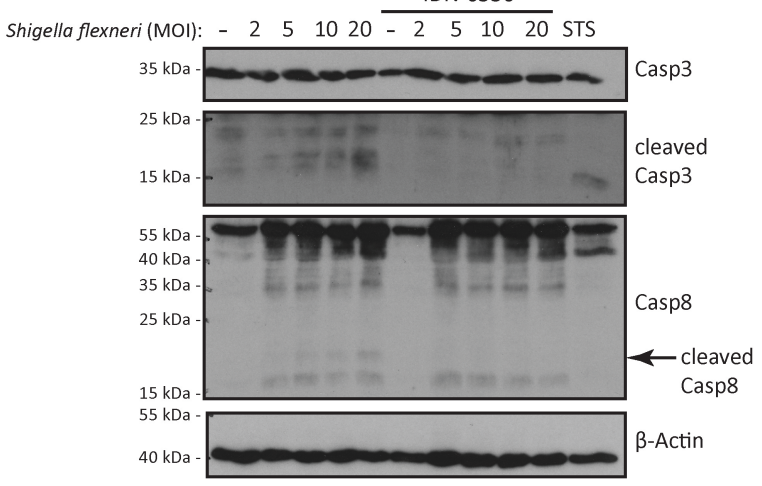

b

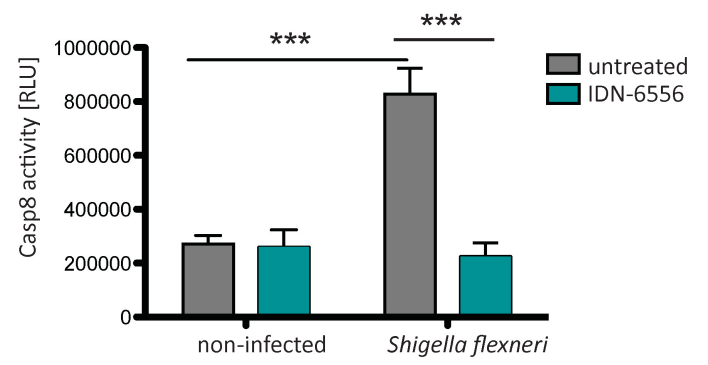

Figure 3.1 Casp8 is activated during bacterial infection. a Western blot analysis of BMDMs $6 \mathrm{~h}$ post infection with Shigella flexneri and co-treatment with $2.5 \mu \mathrm{M}$ IDN-6556. Lanes, different MOI. Staurosprine (STS) serves as control for Casp3 cleavage. Results representative for two individual experiments. $\beta$-Actin serves as loading control. b Casp8 activity measurement of BMDMs $6 \mathrm{~h}$ post infection with Shigella flexneri and cotreatment with $2.5 \mu \mathrm{M}$ IDN-6556. $\mathrm{n}=3$ biologically independent replicates. Bars, mean \pm s.e.m. Statistical significance to the corresponding untreated value was determined by One-way ANOVA followed by Bonferroni post-analysis. Results representative for two individual experiments.

\subsection{Generation of Casp8 ${ }^{\mathrm{C} 362 \mathrm{~S}}$ mice}

The exact role of Casp8 enzymatic activity in macrophages during bacterial infection, especially with Shigella flexneri remains unknown. In order to investigate the function of Casp8 enzymatic activity during bacterial infection in vivo and in vitro, a mouse line expressing an enzymatic inactive version of Casp8 was generated. The catalytic cysteine at the substrate-binding pocket in the large subunit of Casp8 at position 362 was specifically mutated to a serine via a single base-pair exchange ( $T$ to $A$, thymine to adenine) using the CRISPR/Cas9 system (Figure 3.2). Mice carrying Casp8 ${ }^{\mathrm{C} 362 \mathrm{~S}}$ mutation were backcrossed five times with wildtype mice in order to minimise possible off-target effects. 
a

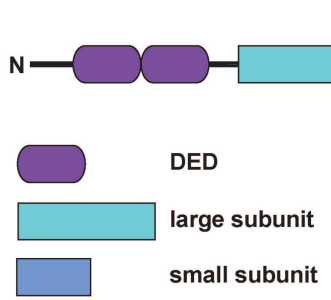

b

Casp $8^{w t / w t}$ Casp8 $8^{\mathrm{C} 362 \mathrm{~S} / \mathrm{C} 362 \mathrm{~S}}$

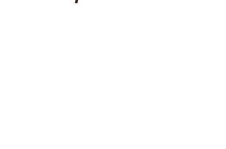

Casp $8^{w t / w t}$
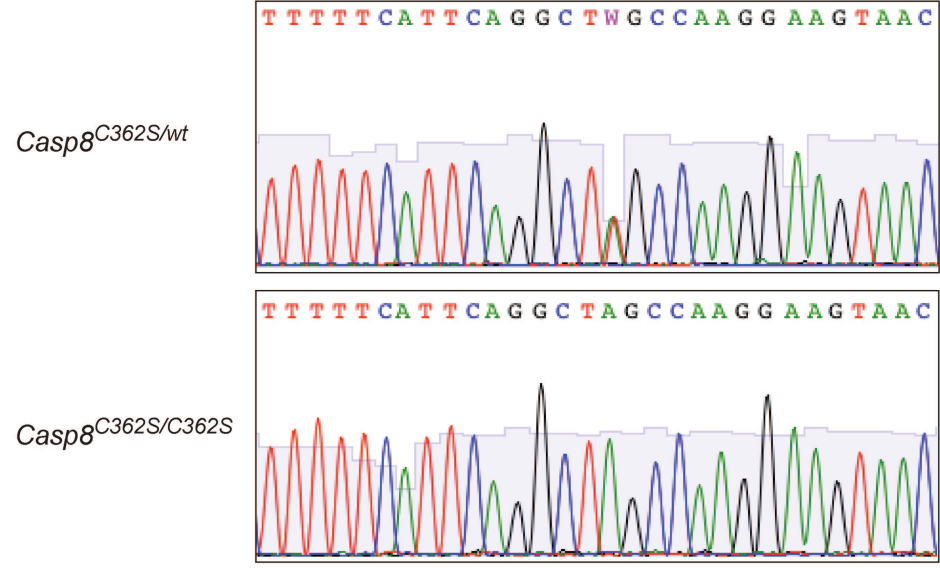

Figure 3.2 Generation of Casp8 ${ }^{\mathrm{C} 362 \mathrm{~S}}$ mice. a Schematic illustration of the Casp8 protein with domain structure and the position of catalytic cysteine (star) in the large subunit. b Targeted genomic sequence of Casp 8 and representative sequence analysis in embryos at E11.5 with respective genotypes.

\subsection{Casp8 enzymatic activity is required for the embryonic development of mice}

Previous studies showed, that Casp8 deficiency leads to embryonic lethality between E10.5 and E11.5 (Varfolomeev et al. 1998). Heterozygous Casp8 $8^{\text {C362s/wt }}$ mice were viable and showed no phenotypic alterations compared to their control littermates (Figure $3.3 \mathrm{a}$ and b). In contrast, heterozygous intercross of Casp $8^{\mathrm{C} 3625 / w t}$ mice did not produce any progeny carrying homozygous Casp $8^{\mathrm{C} 362 S}$ mutation similar to mice with a deletion of Casp8. Analysis of the embryonic development of these mice revealed that homozygous Casp $8^{\mathrm{C} 362 S}$ mutation results in embryonic lethality around E11.5. Hyperaemia in the abdominal areas was detected in Casp8 $8^{\mathrm{C} 3625 / C 362 S}$ embryos, presumably due to defects in vascular development resembling the phenotype of $\mathrm{Casp}^{-/}$embryos (Figure $3.3 \mathrm{~b}$ ). 
a

\begin{tabular}{|c|c|c|}
\hline \\
\hline \multicolumn{3}{|c|}{$\begin{array}{l}\text { Casp } 8^{\mathrm{C} 362 \mathrm{~S} / \mathrm{wt}} \times \mathrm{Casp}^{\mathrm{C} 362 \mathrm{~S} / \mathrm{wt}} \\
\text { Animals weaned }\end{array}$} \\
\hline & Expected & Observed \\
\hline Casp $8^{w t / w t}$ & 11.75 & 17 \\
\hline Casp8 ${ }^{C}$ C362S/wt & 23.5 & 30 \\
\hline Casp $8^{C 362 S / C 362 S}$ & 11.75 & 0 \\
\hline Total & 47 & 47 \\
\hline
\end{tabular}

b

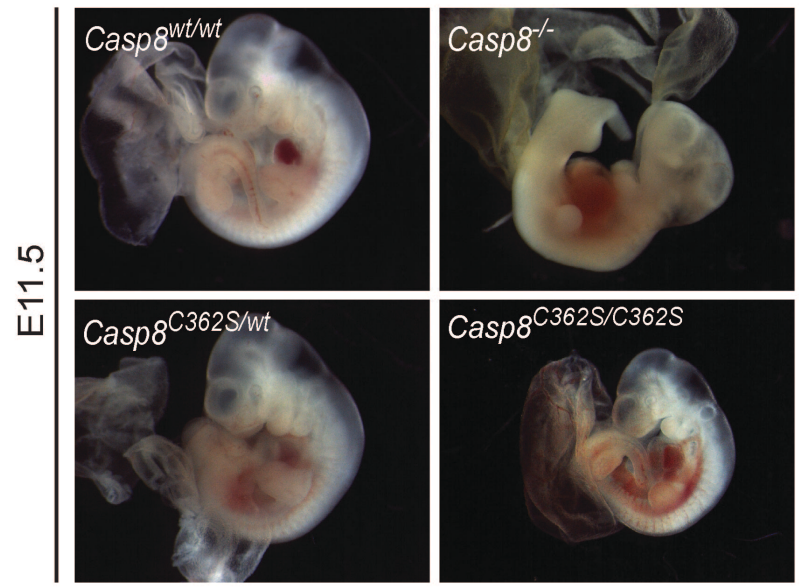

Figure 3.3 Casp8 enzymatic activity is required for the embryonic development of mice. a Expected and observed numbers of mice per genotype obtained from the indicated crossing. $\mathbf{b}$ Representative images of

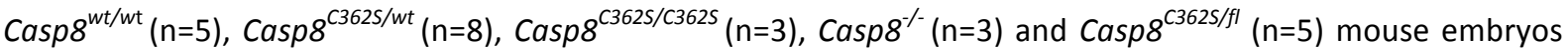
at E11.5.

\subsection{Expression of Casp8 ${ }^{\mathrm{C} 362 \mathrm{~S}}$ results in inflammatory tissue destruction}

Tissue-specific deletion of Casp8 uncovered a key role of Casp8 in tissue damage and inflammation (Günther et al. 2011; Kang et al. 2004; Kovalenko et al. 2009a). In order to investigate the physiological role of Casp8 enzymatic activity in tissue homeostasis, a mouse line with a heterozygous whole body $\operatorname{Casp} 8^{\mathrm{C} 362 S}$ mutation was generated, where the other allele of Casp8 is floxed. Tissue-specific deletion of the floxed allele was introduced by the intercross of mice expressing Cre recombinase under the Tie2 promotor (endothelial and majority of haematopoetic cells) (Constien et al. 2001), the K14 promoter (keratinocytes) (Hafner et al. 2004) and the Villin promotor (intestinal epithelial cells) (Madison et al. 2002). Casp $8^{C 362 S / f 1}$ Tie2-Cre mice (hereafter referred to as Casp8 ${ }^{C 362 S / E C-}$ ) or endothelial cell (EC)specific knockout of Casp8 in Casp $8^{f l / f l}$ Tie2-Cre mice $\left(\operatorname{Casp} 8^{E C-K O}\right)$ were not observed at weaning (Figure 3.4 a). Analysis of the embryonic development indicate that loss of Casp8 catalytic activity or deletion of Casp8 caused embryonic lethality at the same developmental stage as Casp8 $8^{\mathrm{C362S/C362S}}$ embryos with the same gross pathology (Figure $3.4 \mathrm{~b}$, upper panel). CD31 staining, as marker for endothelial cells of the yolk sac, from Casp $8^{\text {C362S/EC- }}$ and Casp $8^{E C-}$ ${ }^{K O}$ embryos showed a decreased yolk sac vascularisation (Figure $3.4 \mathrm{~b}$, lower panel). 
a

\begin{tabular}{|lcc|}
\hline${\text { Casp } 8^{\text {fl/fl }} \times \text { Tie2 }}^{\text {tg/wt }}$ Casp $^{\text {C362S/wt }}$ \\
Animals weaned & & \\
& & \\
Casp $8^{\text {wt/fl }}$ & 8.75 & 11 \\
Casp $8^{\text {C362S/fl }}$ & 8.75 & 13 \\
Casp $8^{\text {wt/EC- }}$ & 8.75 & 11 \\
Casp $8^{\text {C362S/EC- }}$ & 8.75 & 0 \\
Total & 35 & 35 \\
\hline
\end{tabular}

\begin{tabular}{|c|c|c|}
\hline \multicolumn{3}{|c|}{ Casp $8^{f / f l} \times$ Tie $2^{t g / w t}$ Casp $^{f l / w t}$} \\
\hline \multicolumn{3}{|l|}{ Animals weaned } \\
\hline & Expecte & Observed \\
\hline Casp $8^{w t / f l}$ & 8.25 & 13 \\
\hline Casp $8^{f l / f l}$ & 8.25 & 9 \\
\hline Casp $8^{\text {wt/EC- }}$ & 8.25 & 11 \\
\hline Casp ${ }^{E C-K O}$ & 8.25 & 0 \\
\hline Total & 33 & 33 \\
\hline
\end{tabular}

b
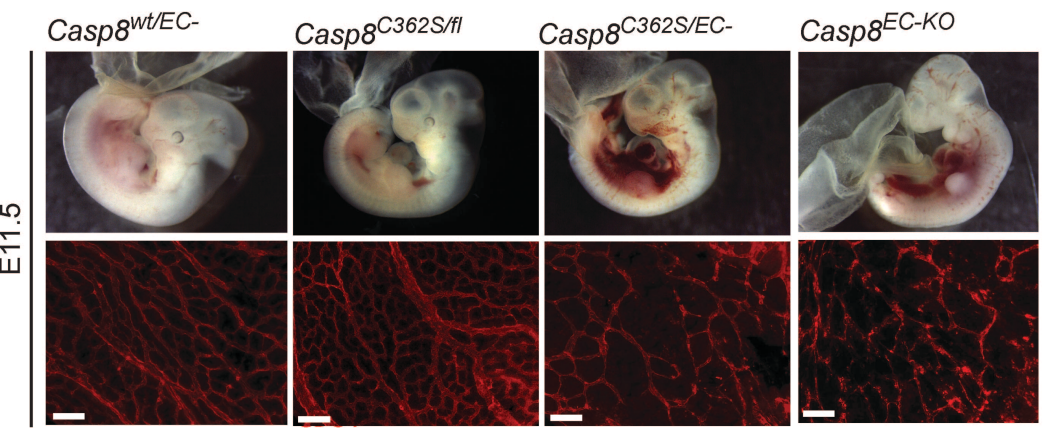

CD31

Figure 3.4 Endothelial-specific expression of Casp8 ${ }^{\mathrm{C} 362 \mathrm{~S}}$ results in embryonic lethality. a Expected and observed numbers of mice per genotype obtained from the indicated crossings. $\mathbf{b}$ Representative images of $\operatorname{Casp}^{\text {wt/EC- }}(\mathrm{n}=2), \operatorname{Casp}^{\mathrm{C} 362 S / f I}(\mathrm{n}=5)$ and $\operatorname{Casp}^{\mathrm{C} 362 S / E C-}(\mathrm{n}=5)$ and $\operatorname{Casp}^{E C-K O}(\mathrm{n}=5)$ mouse embryos at E11.5 (upper panel). CD31 staining as marker for endothelial cells of whole mount yolk sacs (lower panel). Scale bar, $100 \mu \mathrm{m}$.

Specific loss of Casp8 catalytic activity in epidermal keratinocytes (Casp $8^{\text {C362S/E- }}$ ) achieved by crossing Casp ${ }^{C 362 S / f l}$ with K14-Cre mice, respectively, caused similar pathologies to Casp8 deficiency in the skin (Figure 3.5 a). $C a s p 8^{C 362 S / E-}$ and $\operatorname{Casp} 8^{E-K O}$ mice developed inflammatory skin lesions with focal epidermal thickening and scaling that appeared 5-7 days after birth and gradually increased in size as well as in distribution covering large cutaneous areas. Histological skin analyses revealed epidermal hyperplasia and immune cell infiltration into the dermis of $\operatorname{Casp} 8^{\mathrm{C} 362 \mathrm{~S} / \mathrm{E}-}$ and $\operatorname{Casp} 8^{\mathrm{E}-\mathrm{KO}}$ mice (Figure 3.5 a lower panel).

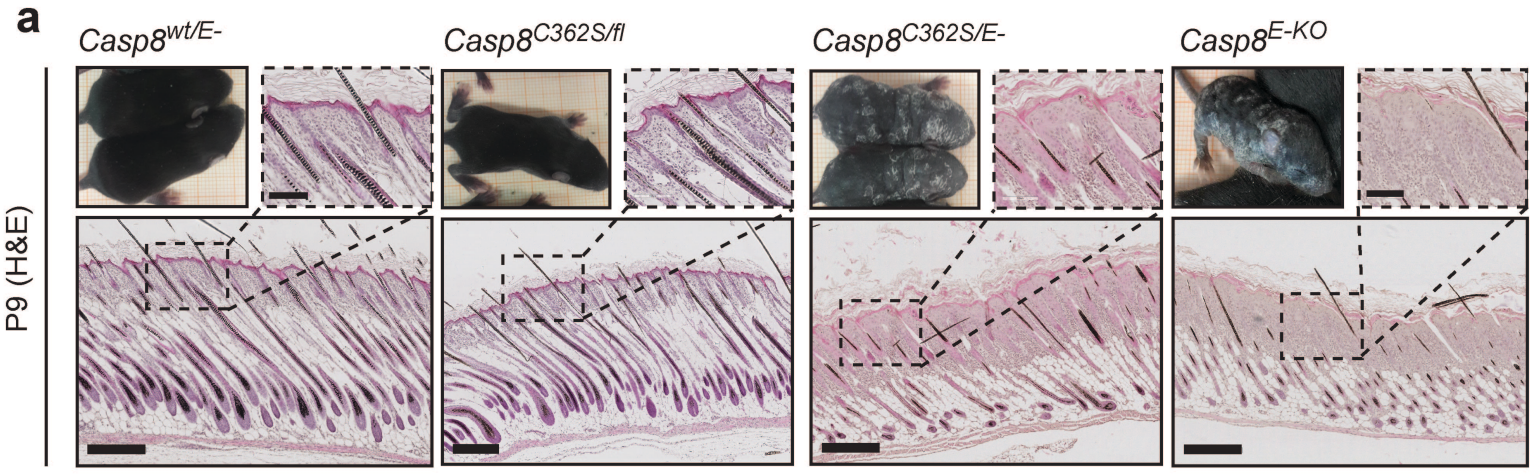


Figure 3.5 Tissue-specific expression of Casp8 ${ }^{\mathrm{C} 362 \mathrm{~S}}$ results inflammatory destruction of the skin. a Mice from

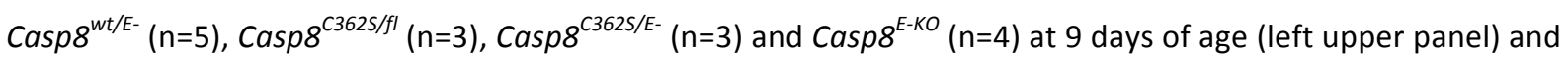
skin sections stained with H\&E. Scale bars, $100 \mu \mathrm{m}$ (upper panel) and $300 \mu \mathrm{m}$ (lower panel).

Mice with IEC-specific loss of Casp8 catalytic activity (Casp8 ${ }^{\text {C362S/IEC- }}$ ) generated by intercross of $C a s p 8^{C 362 S / f I}$ with Villin-Cre mice survived weaning at the expected mendelian ratio and showed no macroscopic alterations compared to their control littermates (Figure 3.6 a). Immunohistochemistry of sections from the small intestine was performed to analyse the intestinal pathology. Lysozyme was stained to visualise Paneth cells, whereas PAS was carried out for goblet cells staining, both marker for ilietis. Casp8 ${ }^{\text {C362S/IEC- }}$ mice developed ileitis at 8-10 weeks of age, associated with increased numbers of dying intestinal epithelial cells (IECS), altered goblet cell distribution and loss of Paneth cells, similar to Casp ${ }^{I E C-K O}$ mice (Figure 3.6 b, c \& d). Furthermore, epithelial hyperplasia associated with villus atrophy and altered mucosal architecture was observed in Casp $8^{\text {C362S/IEC- }}$ as well as Casp $8^{\text {IEC-KO mice }}$ together indicating a severe inflammation of the small intestine in these mice due to the loss of Casp8 or its catalytic activity.

a

\begin{tabular}{|c|c|c|c|c|c|c|c|}
\hline \multicolumn{4}{|c|}{$\operatorname{Casp}^{f / / f l} \times$ VilCre ${ }^{\text {tg/wt }}$ Casp $8^{C 362 S / w t}$} & \multicolumn{4}{|c|}{ Casp $^{f l / f l} \times$ VilCre ${ }^{t g / w t}$ Casp $8^{w t f l}$} \\
\hline Animals weaned & Expected & Observed & Weaned & Animals weaned & Expected & Observed & Weaned \\
\hline Casp $8^{w t / f l}$ & 21.25 & 25 & 25 & Casp8 $8^{\text {wtfl }}$ & 10.75 & 15 & 15 \\
\hline Casp8 $8^{\mathrm{C} 362 \mathrm{~S} / \mathrm{fl}}$ & 21.25 & 25 & 25 & Casp $8^{f / f f l}$ & 10.75 & 8 & 8 \\
\hline Casp8 $8^{w t / E C-}$ & 21.25 & 20 & 20 & Casp8 $8^{w t / E C-}$ & 10.75 & 8 & 8 \\
\hline Casp8 $8^{C 362 S / I E C-}$ & 21.25 & 15 & 15 & Casp8 $8^{I E C-K O}$ & 10.75 & 12 & 12 \\
\hline Total & 85 & 85 & 85 & Total & 43 & 43 & 43 \\
\hline
\end{tabular}

b

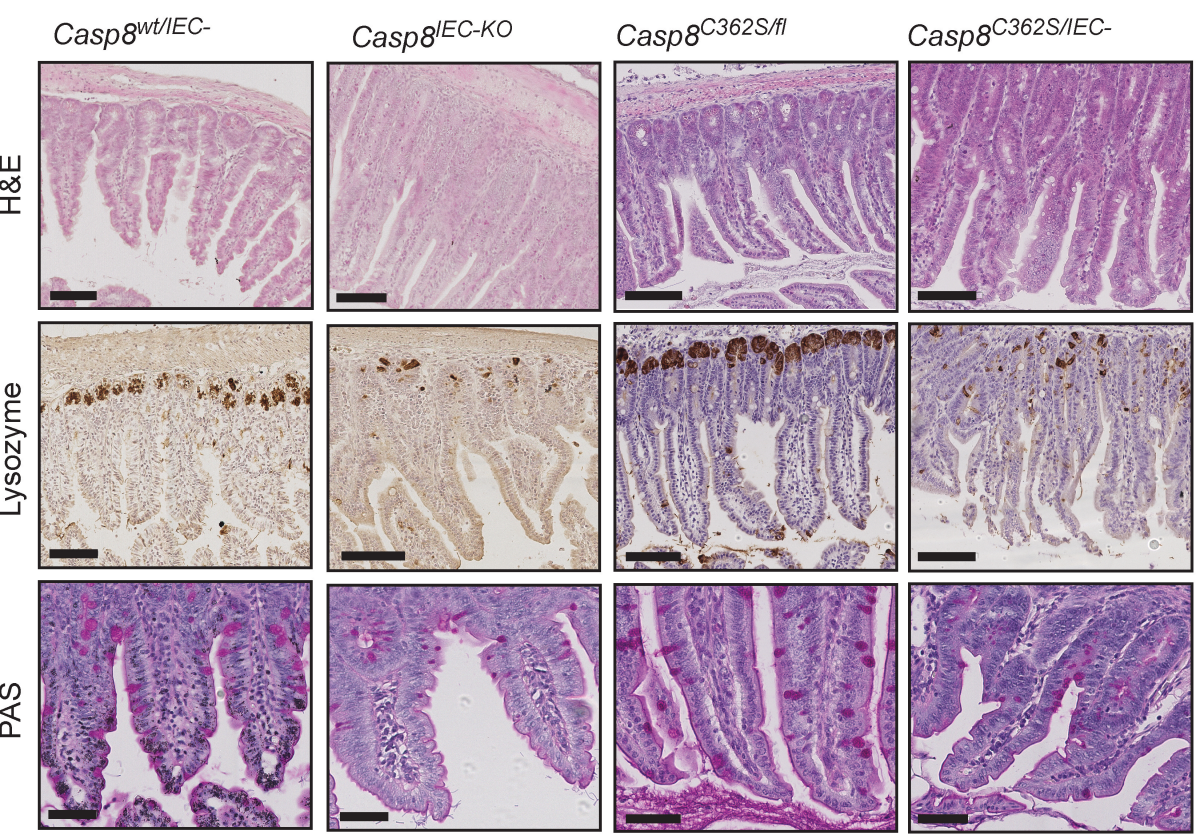


C

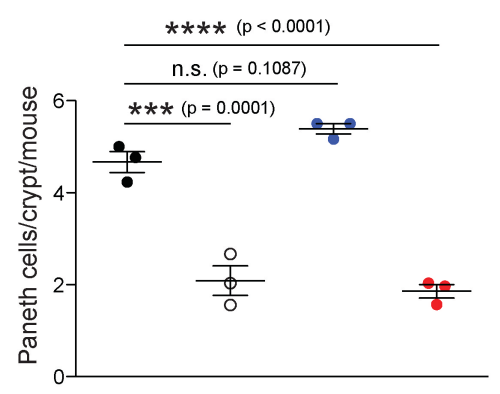

d

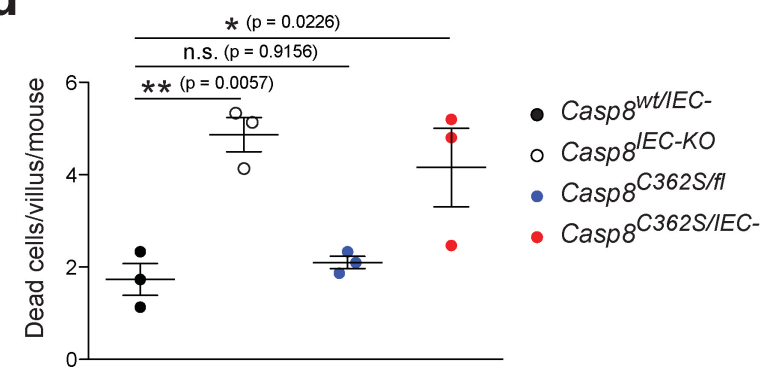

Figure 3.6 Tissue-specific expression of Casp8 ${ }^{\mathrm{c} 362 \mathrm{~S}}$ results in inflammatory destruction of the small intestine. a Expected and observed numbers of mice per genotype obtained from the indicated crossings. $\mathbf{b}$ lleal sections from $\operatorname{Casp}^{\text {wt/IEC- }}(\mathrm{n}=4), \operatorname{Casp}^{\text {IEC-KO }}(\mathrm{n}=4), \operatorname{Casp}^{\mathrm{C362S/fI}}(\mathrm{n}=3), \operatorname{Casp}^{\text {C3625/IEC- }}(\mathrm{n}=4)$ and mice at 10 weeks of age stained with H\&E (upper panel), for lysozyme (Paneth cells, middle panel) and Periodic Acid-Schiff (PAS) (lower panel). Scale bars, $100 \mu \mathrm{m}$. c-d Count of Paneth cells (c) and dead IECs (d) (per crypt per mouse, n=3). Dots, individual mice. Lines, mean \pm s.e.m. P-values by One-way ANOVA followed by Dunnett's post-analysis.

\subsection{Casp8 ${ }^{\mathrm{C362S}}$ induces TNF $\alpha$-mediated necroptosis}

To mechanistically characterise the capability of catalytically inactive Casp8 to mediate cell death, ECs from Casp $8^{\text {wt/fl }}$ and Casp $8^{C 362 S / f l}$ mice were isolated and Casp8 gene deletion was induced in vitro using recombinant cell-permeable active Cre protein (HTNCre, His-tagged, TAT-fusion Cre with nuclear localisation signal (Peitz et al. 2002)) (Figure 3.7 a). ECs were then treated with TNF $\alpha$ and cycloheximide (CHX) to induce cell death and cleavage of Casp3, as a marker for apoptosis, was examined. Western blot analysis revealed cleavage and therefore activation of Casp8 as wells as Casp3 in wildtype (wt) ECs upon stimulation with TNF $\alpha$ and CHX (Figure 3.7 b). As expected, ECs expressing Casp8 ${ }^{\mathrm{C} 362 \mathrm{~S}}$ showed no cleavage of Casp8 and were unable to activate Casp3 in response to TNF $\alpha$ and $\mathrm{CHX}$ indicating an inhibition of apoptosis in ECs expressing catalytically inactive Casp8. However, Casp8 ${ }^{\mathrm{C362S}} \mathrm{ECS}$ were sensitised to TNF $\alpha$-induced cell death as the viability of these cells was significantly reduced upon TNF $\alpha$ stimulation (Figure 3.7 c, upper diagram). The cytotoxic effect of TNF $\alpha$ was associated with MLKL phosphorylation and was abolished by co-treatment with the RIPK1 kinase inhibitor Necrostatin-1 (Nec-1) (Figure $3.7 \mathrm{c}$ ), suggesting that Casp8 ${ }^{\mathrm{C} 362 \mathrm{~S}}$ ECS undergo TNF $\alpha$-mediated necroptosis. 

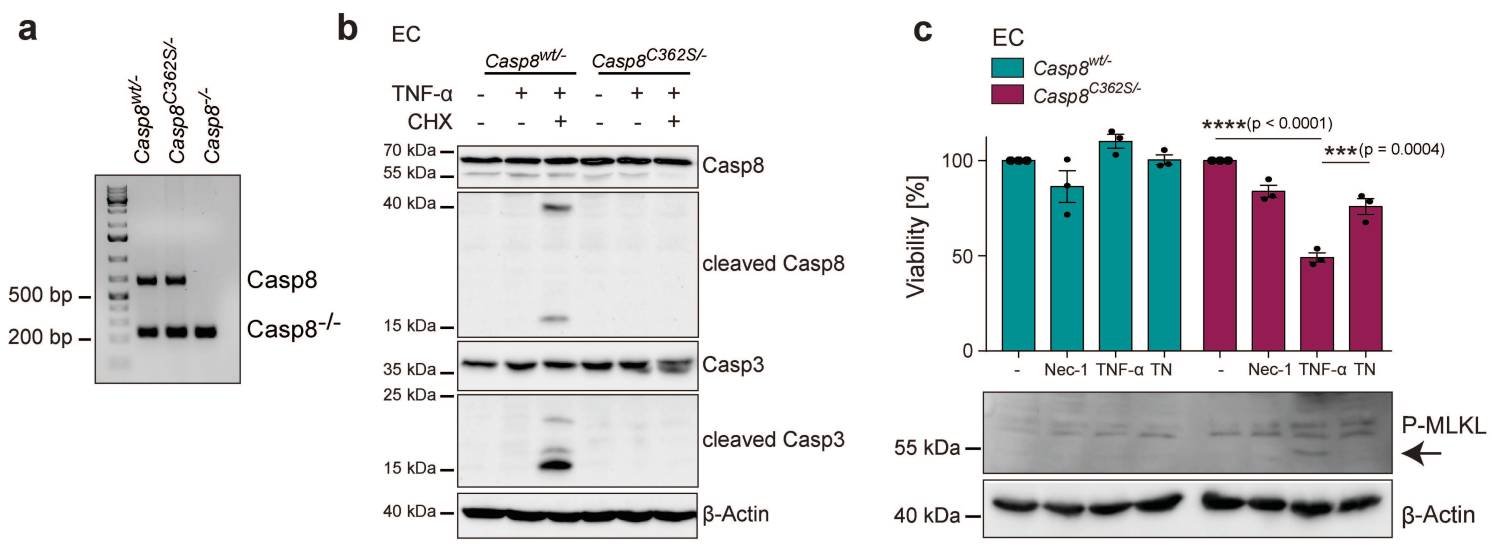

Figure 3.7 Casp8 ${ }^{\mathrm{C} 362 \mathrm{~S}}$ induces TNF $\alpha$-mediated necroptosis. a Genotyping PCR of respective ECs after treatment with cell-permeable recombinant HTNCre protein. Results representative for two individual experiments. b Analysis of Casp8 and Casp3 processing by Western blot after treatment with TNF $\alpha(10 \mathrm{ng} / \mathrm{ml}), \mathrm{CHX}(2.5 \mu \mathrm{g} / \mathrm{ml})$ or both $(\mathrm{TNF} \alpha / \mathrm{CHX})$. Results representative of two individual experiments. c Viability of ECs after treatment with TNF $\alpha(10 \mathrm{ng} / \mathrm{ml})$, Nec-1 (30 $\mu \mathrm{M})$ or both (TNF $\alpha / \mathrm{Nec}-1)$ for $6 \mathrm{~h}$ (upper panel) in biologically independent replicates. Dots, individual mice. Bars, mean \pm s.e.m. P-values by One-way ANOVA followed by Sidak's postanalysis ( $n=3$, representative of two individual experiments). Western blot analysis of cell lysates examining Phospho-MLKL (P-MLKL) and $\beta$-Actin served as loading control. Results representative of two individual experiments.

\subsection{RIPK3 deficiency partially rescues the Casp8 ${ }^{\mathrm{C} 362 \mathrm{~S}}$ phenotype}

ECs expressing Casp8 $8^{\mathrm{C} 362 \mathrm{~S}}$ are protected against apoptosis in vitro, but clearly induce necroptosis upon TNFa stimulation. As loss of RIPK3 or MLKL was previously shown to inhibit necroptosis and to prevent embryonic lethality caused by Casp8 knockout (Alvarez-Diaz et al. 2016; Kaiser et al. 2011; Oberst et al. 2011), the potential role of the key factors mediating necroptosis RIPK3 and MLKL in the pathology caused by enzymatically inactive Casp8 was examined. First, the capacity of RIPK3 to rescue the embryonic lethal phenotype of Casp8 ${ }^{\mathrm{C} 362 \mathrm{~S}}$ mice was determined.

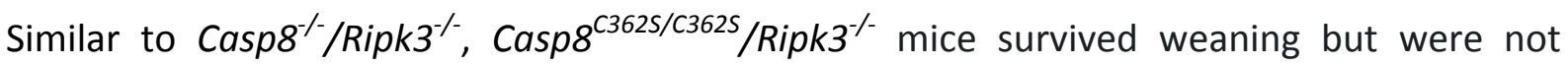
observed at the expected mendelian ratio (Figure 3.8 a). Around $39 \%$ of

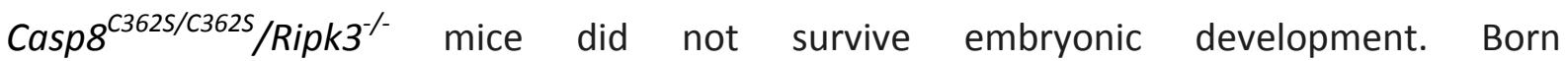

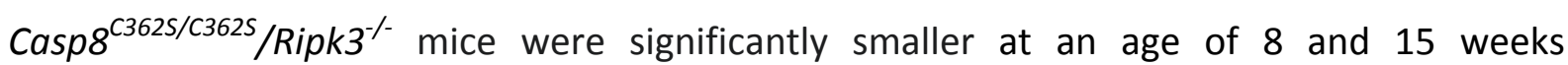
compared to their control littermates, whereas Casp $8^{-/} /$Ripk $^{-/-}$mice showed no differences in body weight as already described (Figure 3.8 b \& d, left panel). Additionally, for

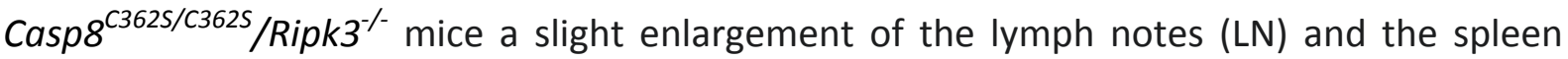
was observed (Figure 3.8 c \& d, middle panel). In relation to the reduced body weight, 


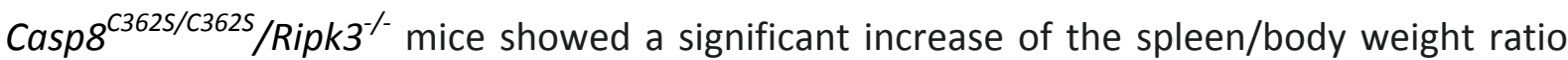
comparable to $\mathrm{Casp}^{-/} / \mathrm{Ripk}^{-/}$mice (Figure $3.8 \mathrm{~d}$, right panel) indicating that these mice develop a sever splenomegalie caused by expression of catalytically inactive Casp8.

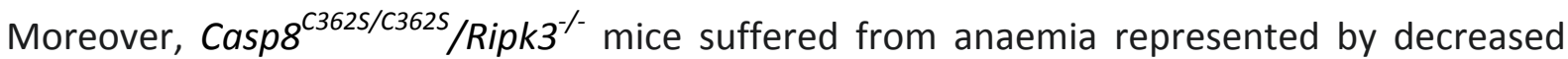
haematocrit, haemoglobin and a slight reduction of erythrocytes (Figure 3.8 e). Numbers of circulating immune cells like lymphocytes, monocytes and neutrophils were unaffected. Taken together, RIPK3 deficiency rescues the embryonic lethal phenotype of Casp8 ${ }^{\text {C362S/C362S }}$ mice, but only partially. Only a small proportion of animals survived embryonic development suffering from anaemia with distinct haematologic abnormalities leading to splenomegaly and lymphadenopathy.

a

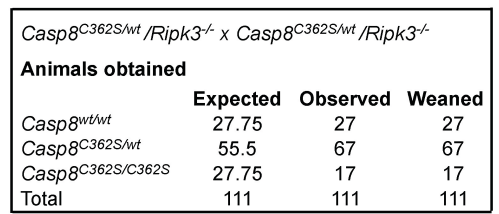

d

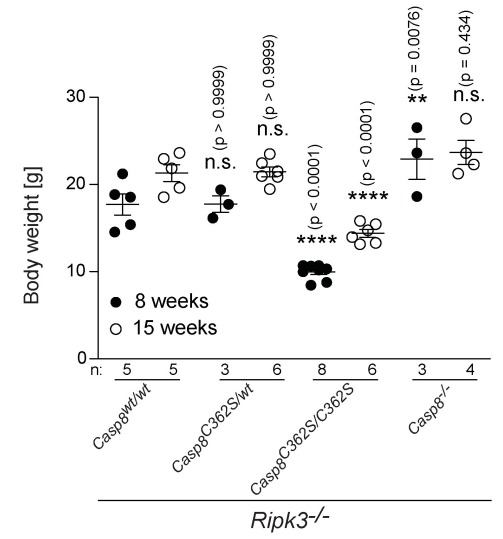

e

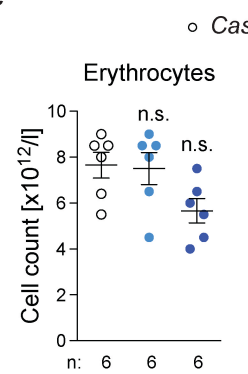

Haematocrit b

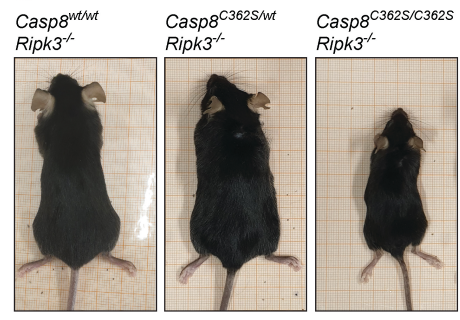

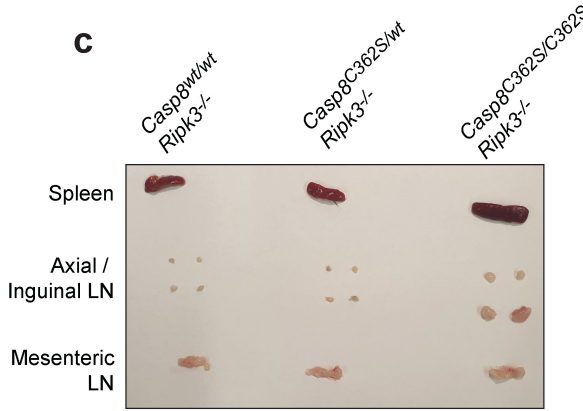
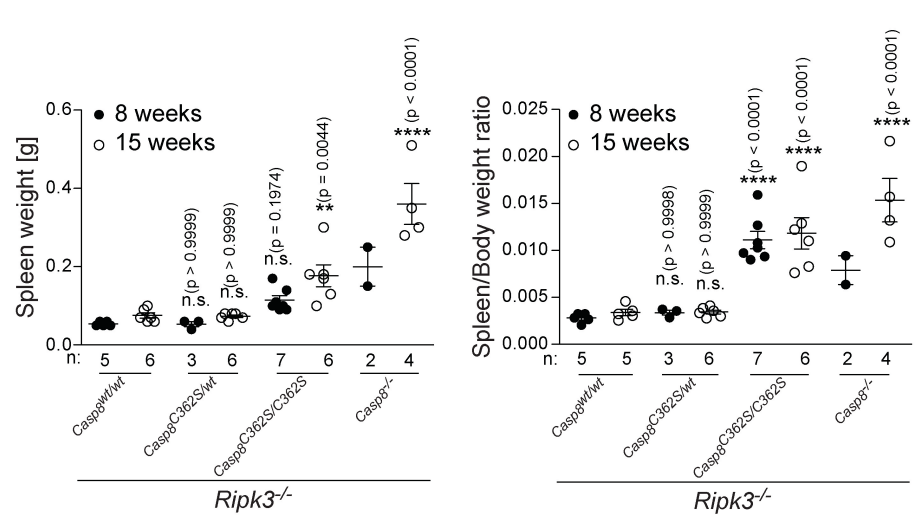

- Casp8 $8^{\mathrm{C} 362 \mathrm{~S} / \mathrm{wt}^{\prime}} / \mathrm{Ripk}^{-1}$

- Casp8 $8^{\mathrm{C} 362 \mathrm{~S} / \mathrm{C} 362 \mathrm{~S}} / \mathrm{Ripk}^{-1-}$
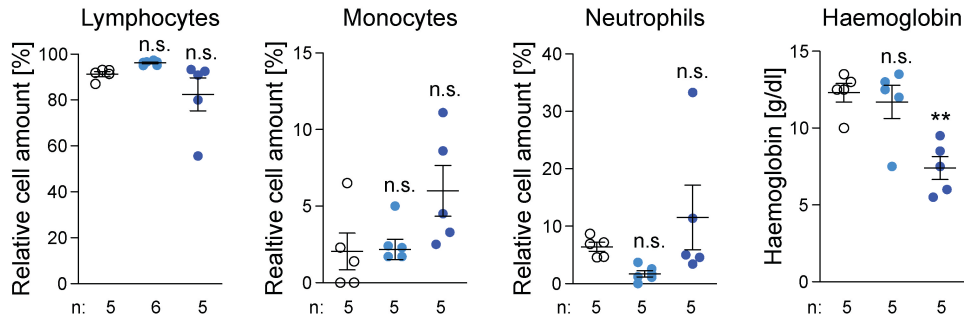
Figure 3.8 RIPK3 deficiency partially rescues the Casp8 ${ }^{\mathrm{C} 362 \mathrm{~S}}$ phenotype. a Expected and observed numbers of mice per genotype obtained from the indicated crossings. b Mice at 8 weeks of age. c Representative images of spleen, axial and inguinal lymph nodes (LN) and mesenteric LN from Casp $8^{\text {wt } / w t} / \operatorname{Ripk}^{\%} \quad(\mathrm{n}=3)$,

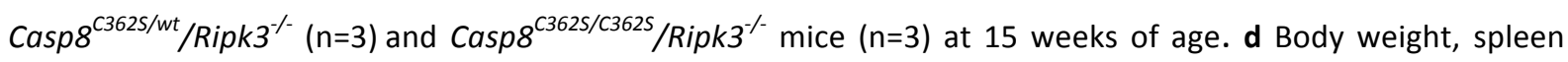
weight and spleen/body weight ratio of the indicated genotypes from 8 and 15 weeks old mice. Dots and circles, individual mice. Lines, mean \pm s.e.m. P-values by One-way ANOVA followed by Sidak's post-analysis to the corresponding $C a s p 8^{w t / w t}$ values. e Cardiac blood was analysed for cell amount, haematocrit and haemoglobin from mice with an age of 8-15 weeks. Dots and circles, individual mice. Lines, mean \pm s.e.m. Pvalues by One-way ANOVA followed by Dunnett's post-analysis to the corresponding Casp $8^{\text {wt } / w t} /$ Ripk $^{\%-}$ values. Exact p-values (from left to right) Erythrocytes: 0.9774, 0.0607, Haematocrit: 0.9961, 0.0462, Lymphocytes: 0.5812, 0.2426, Monocytes: 0.9944, 0.0693, Neutrophils: 0.4614, 0.4349, Haemoglobin: 0.8326, 0.0025

\subsection{MLKL deficiency results in perinatal death of Casp8 ${ }^{\mathrm{C} 362 \mathrm{~S}}$ mice}

To further investigate the role of necroptosis in mice with a specific Casp8 ${ }^{\mathrm{C} 362 \mathrm{~S}}$ mutation, MLKL was additionally deleted. It has been already described that similar to Casp $8^{-/} /$Ripk $^{-/-}$ mice additional deletion of MLKL in Casp $8^{-/-}$mice prevents embryonic lethality, but these mice develop a severe lympadenopathy and splenomegaly at an age of 8 to 15 weeks (Alvarez-Diaz et al. 2016). Surprisingly, MLKL deficiency did not rescue lethality caused by the Casp8 ${ }^{\mathrm{C} 362 \mathrm{~S}}$ mutant as no animals were observed at weaning (Figure 3.9 a). Analysis of the

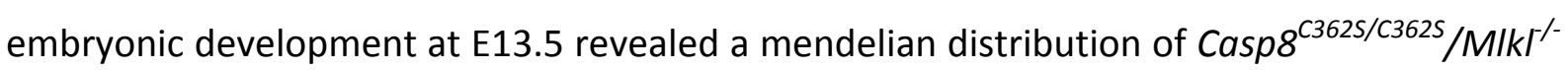
embryos as expected (Figure $3.9 \mathrm{~b}$ ). These embryos displayed no phenotypic alterations and a normal vascular structure of the yolk sac as shown by CD31 staining (Figure $3.9 \mathrm{c}$ ). Despite

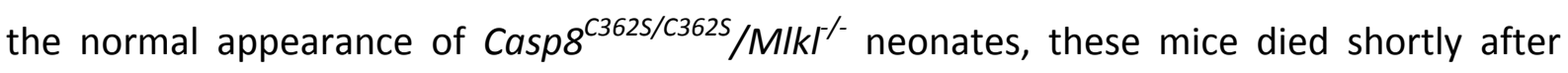
birth (Figure 3.9 d). Together, MLKL deficiency did not rescue the lethal phenotype of

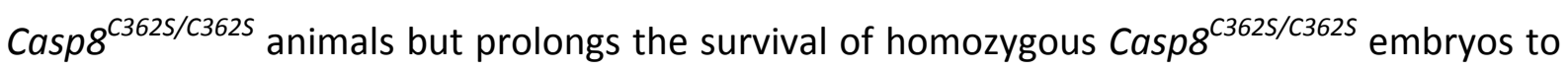
birth, suggesting that the loss of Casp8 enzymatic activity compromises perinatal development by additional, necroptosis-independent functions. 
a

\begin{tabular}{|c|c|c|c|}
\hline \multicolumn{4}{|c|}{ Casp8 $8^{\mathrm{C} 362 \mathrm{~S} / \mathrm{wt}} / \mathrm{Mlk}^{-\alpha} \times \mathrm{Casp}^{\mathrm{C} 362 \mathrm{~S} / \mathrm{wt}} / \mathrm{Mlk}^{-\alpha}$} \\
\hline Animals weaned & Expected & Observed & Weaned \\
\hline Casp $8^{w t / W t} / M_{1 / k} \Gamma^{-}$ & 26.25 & 45 & 43 \\
\hline Casp8 $8^{\text {C362S/Wt }} /$ MIK $^{--}$ & 52.5 & 57 & 53 \\
\hline Casp8 ${ }^{\mathrm{C} 362 S / C 362 S} / M_{1 k} \Gamma^{-}$ & 26.25 & 3 & 0 \\
\hline Total & 105 & 105 & 96 \\
\hline
\end{tabular}

b

\begin{tabular}{|c|c|c|}
\hline Embryo E13.5 & Expected & Observed \\
\hline Casp $8^{w t / w t} / M_{1 k} I^{--}$ & 3.75 & 8 \\
\hline Casp8 ${ }^{\mathrm{C} 362 \mathrm{~S} / \mathrm{wt}} / \mathrm{MIkI}^{--}$ & 7.5 & 4 \\
\hline Casp8 ${ }^{\mathrm{C} 362 \mathrm{~S} / \mathrm{C} 362 \mathrm{~S}} / \mathrm{MIKI}^{/-}$ & 3.75 & 3 \\
\hline Total & 15 & 15 \\
\hline
\end{tabular}

C

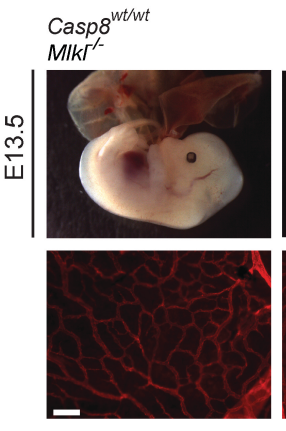
Casp $^{\text {C362S/Wt }}$ $M \mid k T^{-}$

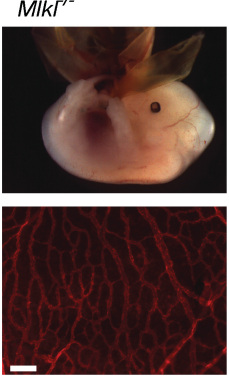

CD31

d

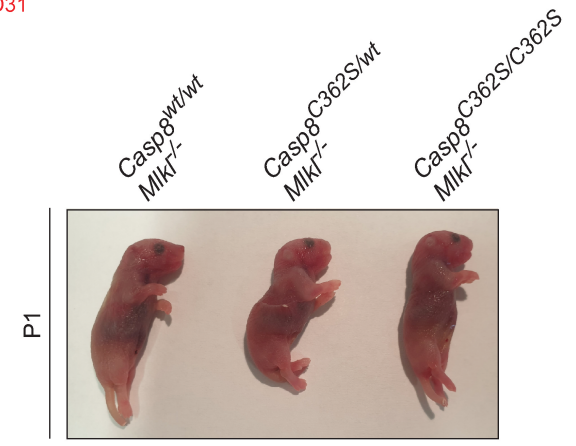

Figure 3.9 RIPK3 deficiency partially rescues Casp8 ${ }^{\text {C362S }}$ phenotype. a Expected and observed numbers of mice per genotype obtained from the indicated crossings at weaning. b Expected and observed numbers of embryos per genotype obtained from the indicated crossings at E13.5. c Representative images of Casp $8^{w t / w t} / \mathrm{MlkI}^{--}(\mathrm{n}=8)$,

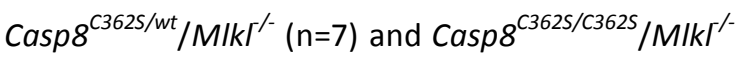
$(n=3)$ mouse embryos at E13.5 (upper panel). Whole mount yolk sacs stained with CD31 antibody as endothelial marker (lower panel). Scale bars, 100 $\mu \mathrm{m}$. d Representative images of $\mathrm{Mlkl}^{-/}(\mathrm{n}=2)$,

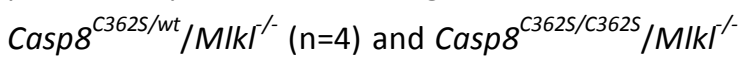
$(n=3)$ mouse neonates (P1).

\subsection{Inhibition of necroptosis prevents the inflammatory phenotype of Casp8 $8^{\mathrm{C} 362 \mathrm{~S}}$ mice in}

\section{the endothelium and the skin}

Necroptosis clearly impacts on the embryonic development of Casp8 $8^{\text {C362S/C362S }}$ animals since RIPK3 as well as MLKL, both important factors involved in the execution of necroptosis, prevent embryonic lethality. In order to dissect the function of necroptosis mediating the inflammatory phenotypes in mice with a tissues-specific expression of catalytic inactive Casp8, we assessed how MLKL deficiency affects the phenotypes developing upon specific expression of Casp8 ${ }^{\mathrm{C} 362 \mathrm{~S}}$ in the endothelium (and haematopoietic cells) and the skin. In contrast to $\operatorname{Casp} 8^{\text {C362S/EC- }}$ mice, $\operatorname{Casp} 8^{\text {C362S/EC- }}$ mice with an additional deletion of MLKL survived embryonic development without gross phenotypic alterations (Figure 3.10 a, upper panel). 
Furthermore, analysis of the yolk sac vascularisation using CD31 staining revealed a normal vascular architecture of the yolk sac at E11.5 (Figure $3.10 \mathrm{a}$, lower panel). These observations indicate that Casp8 enzymatic activity is required to inhibit necroptosis at early stages of embryonic development (E9-12) involving the formation of the cardiovascular system and the placenta.

Inflammatory skin lesions induced by Casp8 ${ }^{\mathrm{C} 362 \mathrm{~S}}$ expression were not detected in Casp $8^{\mathrm{C} 362 \mathrm{~S} / \mathrm{E}-} / \mathrm{Mlkl}^{--}$mice (Figure 3.10 b). In addition, Casp $8^{\mathrm{C} 362 \mathrm{~S} / \mathrm{E}-} / \mathrm{Mlkl}^{-/}$mice showed no hyperplasia of the skin or epidermal immune cell infiltration and were completely protected against the inflammatory phenotype caused by expression of catalytic inactive Casp8 (Figure $3.10 \mathrm{~b}$, lower panel), indicating that prevention of necroptosis by intact Casp8 enzymatic activity is crucial for skin homeostasis.

a

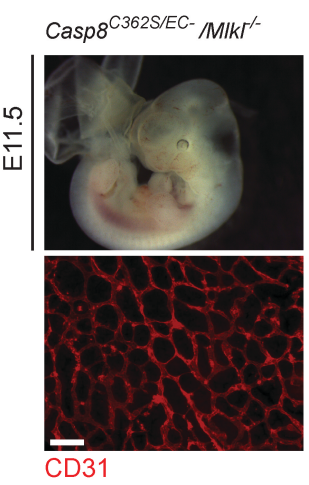

b

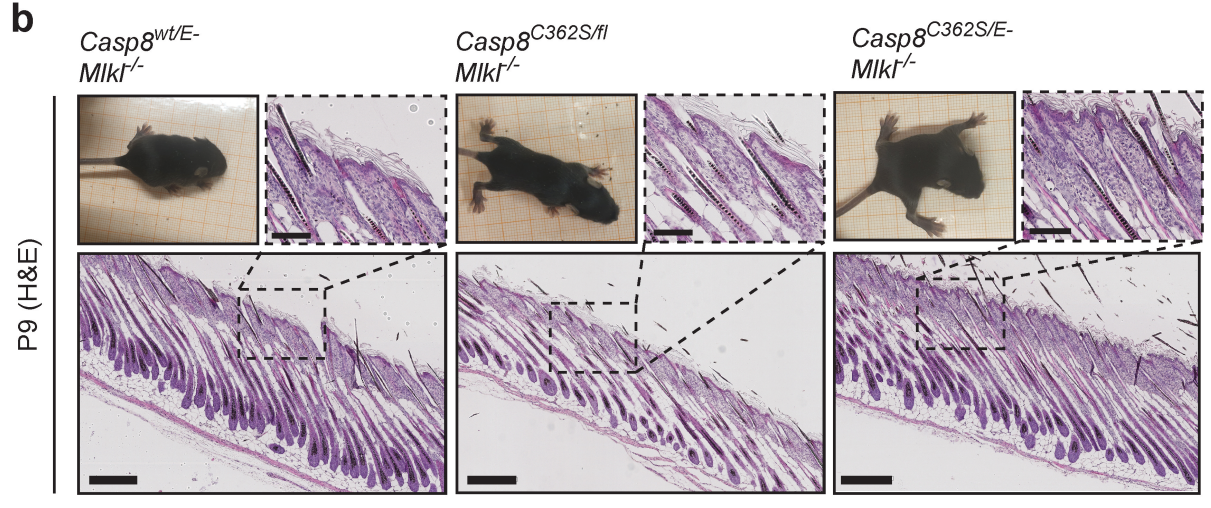

Figure 3.10 Inhibition of necroptosis prevents inflammatory phenotype Casp8 ${ }^{\mathrm{C362S}}$ mice in endothelium and

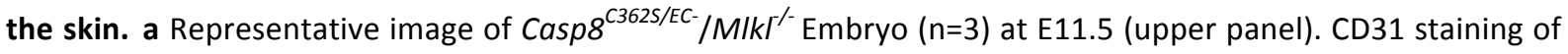
whole mount yolk sac (lower panel). Scale bar, $100 \mu \mathrm{m}$. b Representative images of mice at 9 days of age (left

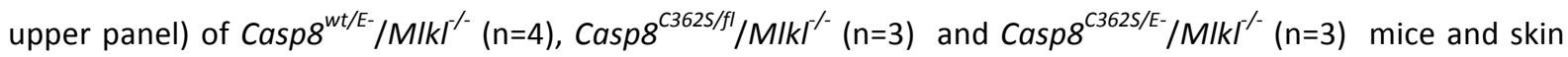
sections stained with H\&E (upper panel right and lower panel). Scale bars, $100 \mu \mathrm{m}$ (upper panel) and $300 \mu \mathrm{m}$ (lower panel).

\subsection{Casp8 ${ }^{\mathrm{C} 362 \mathrm{~S}}$ induces necroptosis-independent tissue destruction in the gut}

Similar to the already described specific knockout of Casp8 in intestinal epithelial cells (Günther et al. 2011), Casp8 $8^{\text {C362S/IEC- }}$ mice suffer from an inflammatory destruction of the small intestine. As MLKL deficiency prevents the inflammatory phenotype in the endothelium and the skin caused by Casp8 ${ }^{\mathrm{C} 362 \mathrm{~S}}$ expression, the capability of MLKL deletion to rescue Casp $8^{\text {C362S/IEC- }}$ mice was examined. 
Casp $8^{\text {C362S/IEC- }}$ mice survived weaning and were observed at the expected mendelian ratio independent of the breeding strategy (Figure 3.11 a). However, in contrast to mice with an endothelial- and skin-specific Casp8 ${ }^{\mathrm{C} 362 \mathrm{~S}}$ expression in an MLKL deficient background,

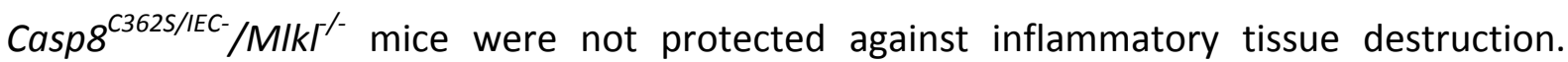
Additional MLKL deletion even worsened the pathology caused by expression of catalytic inactive Casp8 as these mice showed a significant reduction of the body weight and died within 4-8 weeks of age (Figure 3.11 b \& c).
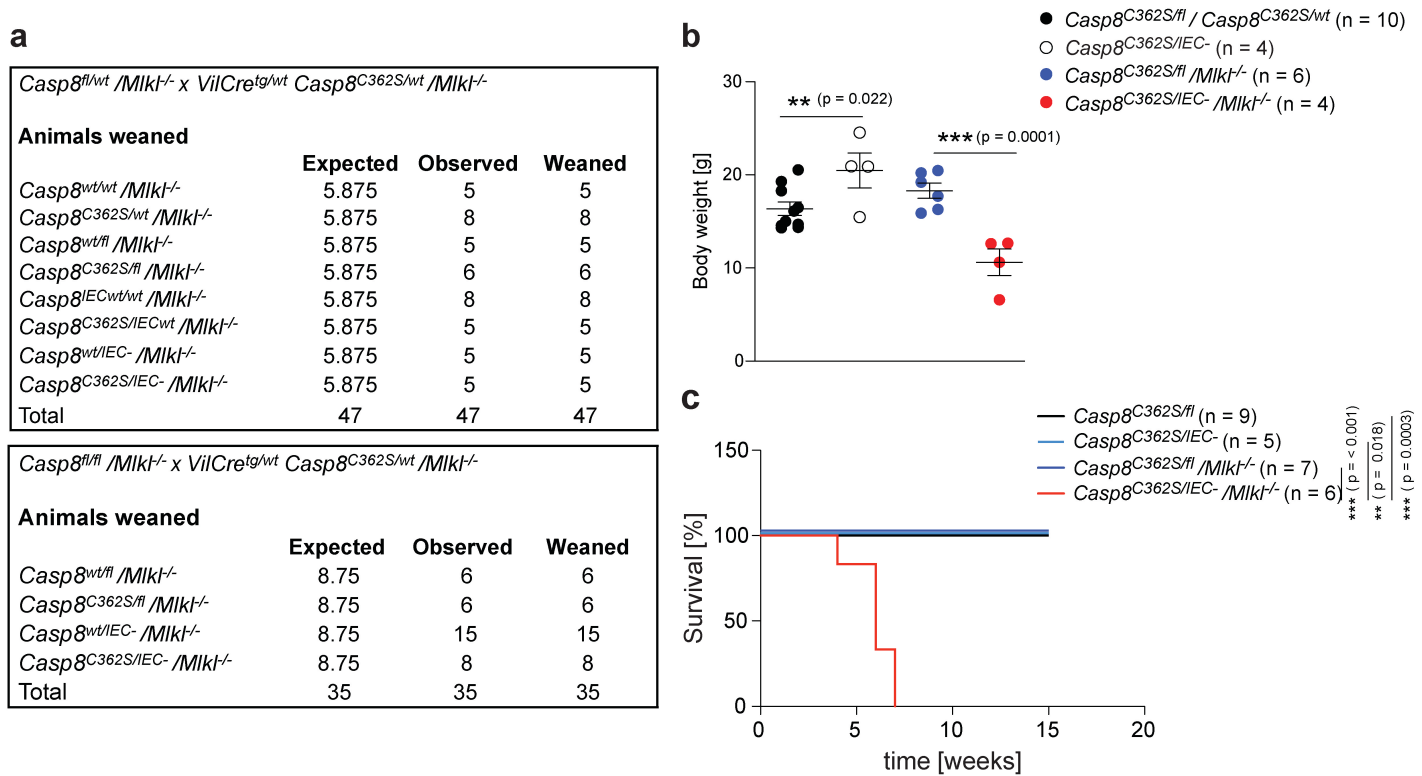

Figure 3.11 Casp8 ${ }^{\mathrm{C} 362 \mathrm{~S}}$ induces necroptosis-independent tissue destruction in the gut. a Expected, observed and weaned numbers of mice per genotype obtained from indicated crossings. b Body weight of mice at 5 weeks of age (upper panel). Dots, individual mice. Lines, mean \pm s.e.m. P-values by One-way ANOVA followed by Sidak's post-analysis. c Kaplan-Meier survival curves of mice as indicated (lower panel). P-values by twosided log-rank test.

Histological analyses of ileal sections of $\mathrm{Casp}^{\mathrm{C} 362 \mathrm{~S} / \mathrm{IEC}-} / \mathrm{MIKI}^{--}$mice revealed severe intestinal inflammation at 5-7 weeks of age similar to Casp $8^{\text {C362S/IEC- }}$ mice characterised by pronounced villus atrophy, crypt elongation and hyperplasia in the ileum (Figure 3.12). Moreover,

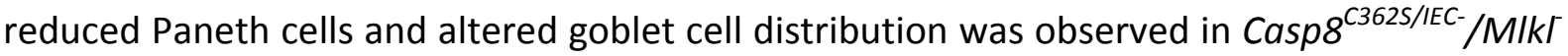
/- mice comparable to Casp $8^{\text {C362S/IEC- }}$ mice. These findings reveal that catalytically inactive Casp8 triggers intestinal pathology in a necroptosis-independent way. 


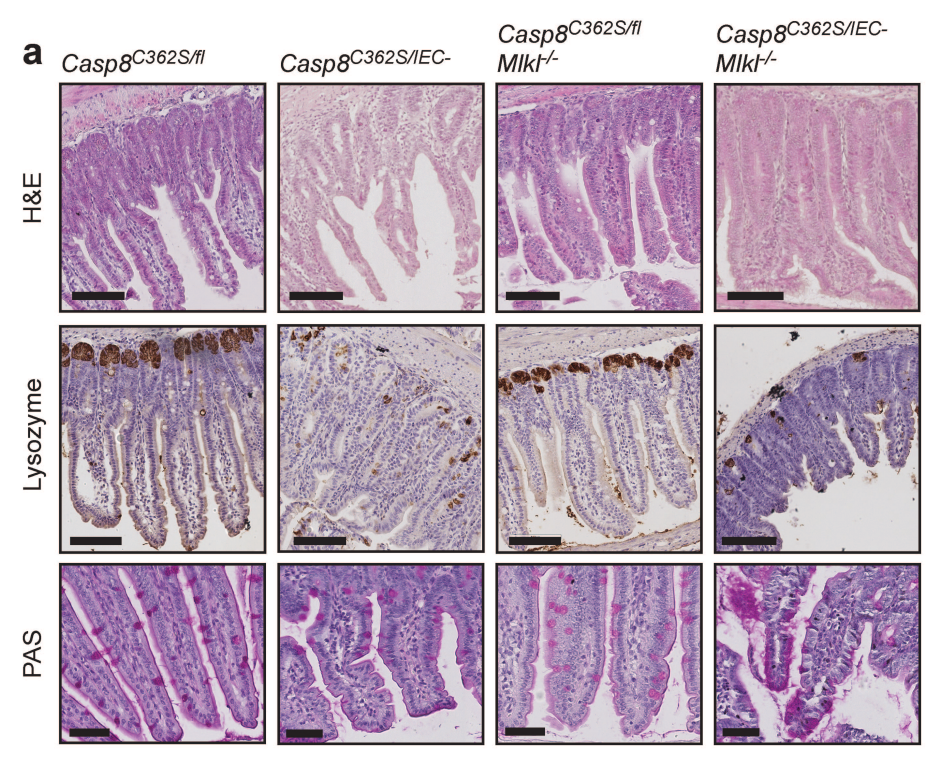

Figure 3.12 Casp $^{\mathrm{C} 362 \mathrm{~S}}$ induces necroptosisindependent tissue destruction in the gut. a lleal sections of Casp $8^{\mathrm{C362S/fl}} \quad(\mathrm{n}=4)$, $\operatorname{Casp}^{\text {C362S/IEC- }}(\mathrm{n}=5), \operatorname{Casp}^{\mathrm{C362S/fI}} / \mathrm{MIKI}^{-1-}(\mathrm{n}=4)$ and $\mathrm{Casp}^{\mathrm{C} 362 \mathrm{~S} / \mathrm{IEC}-} / \mathrm{MlkT}^{--}(\mathrm{n}=5)$ mice at 5 weeks of age with H\&E, lysozyme, PAS staining. Scale bars, $100 \mu \mathrm{m}$ for $\mathrm{H} \& E$ and lysozyme, $50 \mu \mathrm{m}$ for PAS.

\subsection{Casp8 ${ }^{\mathrm{C} 362 \mathrm{~S}}$ activates the inflammasome}

To further characterise the mechanisms underlying the necroptotic-independent intestinal pathology in Casp8 $8^{\mathrm{C} 362 \mathrm{~S} / \mathrm{IEC}-} / \mathrm{MIKl}^{-/}$mice, we examined the expression of a panel of secreted and soluble cytokines in ileal protein lysates (Figure 3.13 a). This analysis revealed

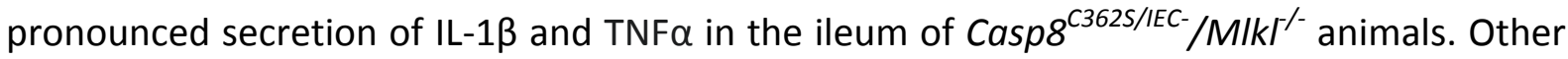
cytokines such as IL-2, IL-4, IL-5, IL-6, IL-10, IL-12p70, IL-17, IFN- $\gamma$ and GM-CSF were not significantly elevated. Of note, there were no increased cytokine levels in ileal lysates from 6 weeks old $\operatorname{Casp} 8^{\text {C362S/IEC- }}$ mice detectable.

In particular, increased levels of IL-1 $\beta$ were associated with proteolytic processing/activation of the inflammatory Casp1 (Lamkanfi and Dixit 2014), implying an involvement of pyroptosis in the pathology of Casp8 $8^{\mathrm{C} 362 \mathrm{~S} / \mathrm{IEC}-} / \mathrm{MIKI}^{--}$mice. Western blot analysis from Triton $\mathrm{X}-100$ soluble and insoluble fractions of ileal lystates was performed and processed and therefore activated Casp1 was detected in the soluble fraction of ileal lysates (Figure 3.13 b). Casp1 is activated by canonical inflammasomes involving members of the Nod-like receptor protein family such as NLRP3. Upon activation of the inflammasome the adaptor-protein ASC aggregates to form macromolecular ASC specks and serves as activation platform for Casp1 which in turn cleaves pro-IL-1 $\beta$ into its mature form (Broz and Dixit 2016). Expression of Casp8 ${ }^{\mathrm{C} 362 \mathrm{~S}}$ resulted in aggregation of ASC in the insoluble fraction of ileal lysates from Casp $8^{\text {C362S/IEC- }}$ which was markedly increased upon inhibition of necroptosis in Casp $8^{\text {C362S/IEC- }}$ $/ \mathrm{Mlkl}^{-/}$mice (Figure $3.13 \mathrm{~b}$ ) pointing to the formation of large protein-complexes containing

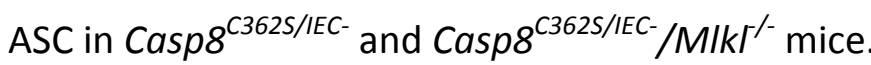


Immunostaining of histosections from different mouse lines revealed ASC speck formation in the small intestine of $\mathrm{Casp} 8^{\mathrm{C} 362 \mathrm{~S} / \mathrm{IEC}-}$ mice, in particular, when necroptosis was blocked in

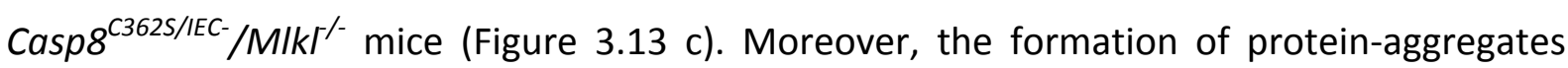
composed by Casp8, similar to ASC specks was detected in the ileum of Casp8 $8^{\text {C362S/IEC- }}$ and Casp8 $8^{\mathrm{C} 3625 / \mathrm{IEC}-} / \mathrm{MIKI}^{--}$mice. These results suggest that the expression of catalytically inactive Casp8 causes activation of the inflammasome in the small intestine, especially in Casp $8^{\text {C362S/IEC- }}$ mice when necroptosis is blocked upon additional deletion of MLKL.

a

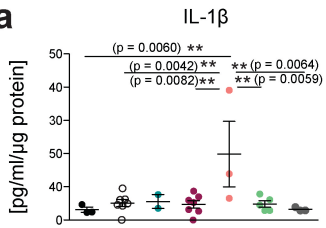

IL-5

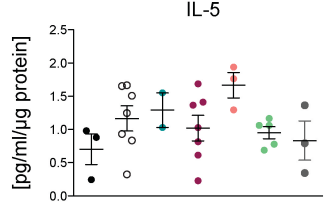

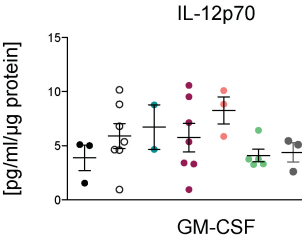

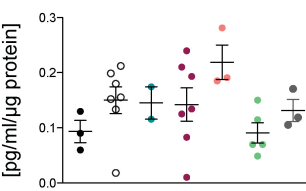

C
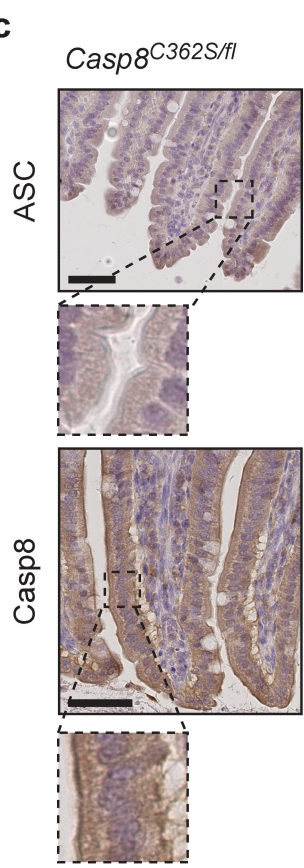
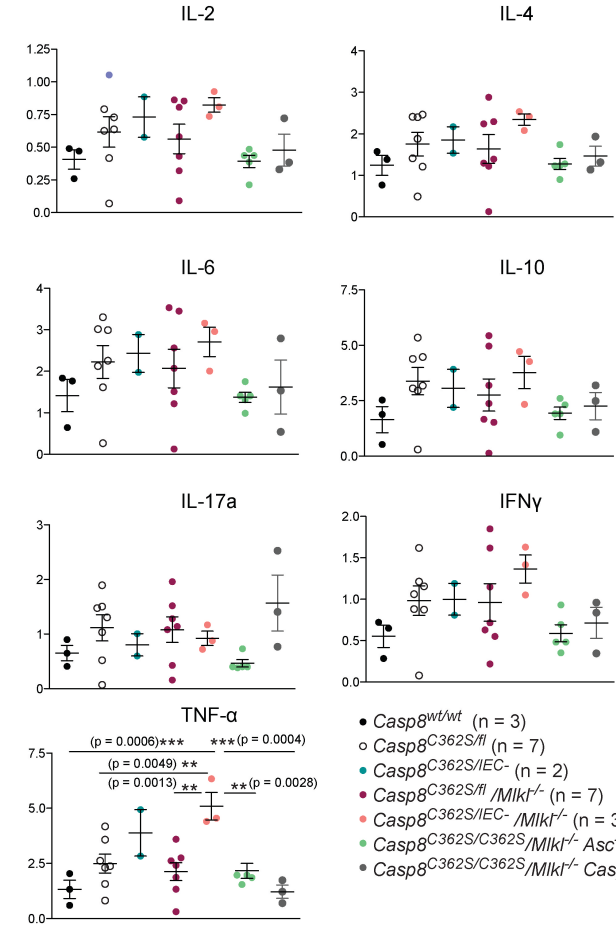

IL-10
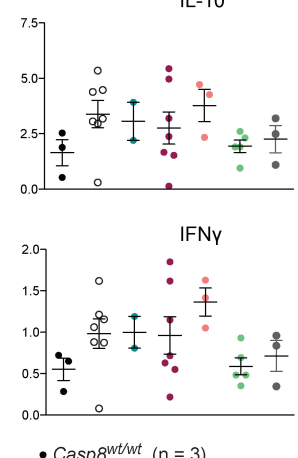

- $\operatorname{Casp8} 8^{\text {wtwt }}(\mathrm{n}=3)$

- Casp8 $83625 / I E C-(n=2)$

- Casp8 $8^{\mathrm{C} 362 S \mathrm{SAl} / \mathrm{M} / \mathrm{k} \mathrm{H}^{--}(\mathrm{n}=7)}$ - Casp8 $8^{C 362 S / I E C-} /$ MIKF $^{-1}(\mathrm{n}=3)$

- Casp8 $8^{\mathrm{C} 362 \mathrm{~S} / \mathrm{C} 362 \mathrm{~S} / \text { MIKI }^{-1-} \text { Asc }}$ - $(\mathrm{n}=5)$

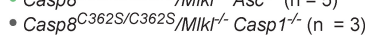

b

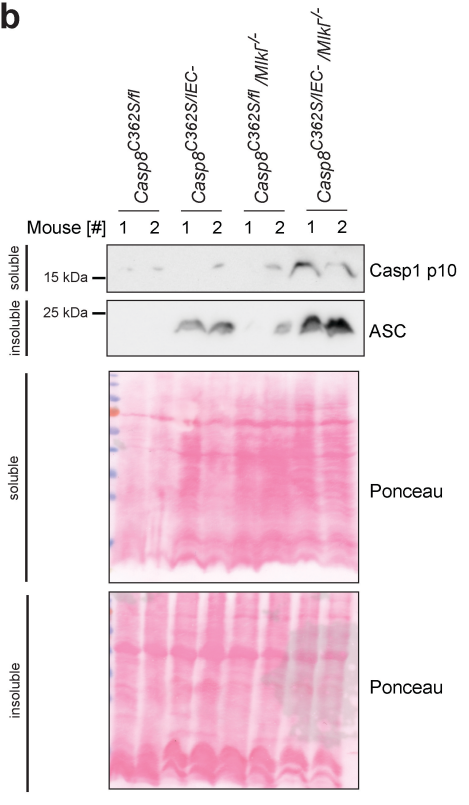


Figure 3.13 Casp8 ${ }^{\text {C362S }}$ activates the inflammasome in IECs. a Cytokine array (AYOXXA Lunaris) to detect the indicated cytokines in ileal lysates derived from mice at 6 weeks of age. Dots and circles, individual mice. Lines, mean \pm s.e.m. P-values by One-way ANOVA followed by Turkey's post-analysis. $\mathbf{b}$ Western blot analysis of ileal lysates from two representative mice with the indicated genotypes detecting cleaved Casp1 and ASC. Lanes, individual mice. Ponceau serves as loading control. c lleal sections of Casp $8^{\text {C362S/fI }}(n=4)$, Casp $8^{\text {C362S/IEC- }}(n=5)$,

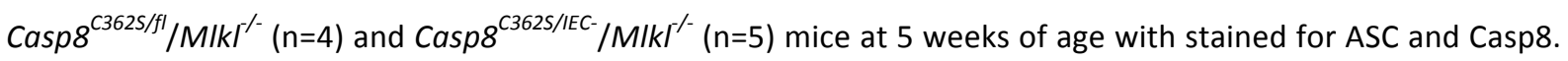
Scale bars, $50 \mu \mathrm{m}$ for ASC and Casp8. Arrows, ASC or Casp8 aggregates.

To investigate the role of inflammasome activation in the lethality of Casp8 $8^{\mathrm{C} 3625 / \mathrm{C362S}} / \mathrm{MlkI}^{-1-}$ neonates (Figure $3.9 \mathrm{~d}$ ), the secretion pattern of several cytokines in the gut of MLKL deficient neonates (P1) was analysed. Similar to mice with a specific expression of catalytic inactive Casp8 in IECs, elevated levels of IL-1 $\beta$ were detected in the intestine of Casp $8^{\mathrm{C} 362 \mathrm{~S} / \mathrm{C362S}} / \mathrm{Mlkl}^{-/}$neonates (Figure $3.14 \mathrm{a}$ ), whereas other analysed cytokines levels, such as IL-2, IFN- $\gamma$ or GM-CSF did not show any differences. In contrast to Casp8 $8^{\text {C362S/IEC- }}$ $/ \mathrm{MlkI}^{--}$mice, no elevated levels of TNFa were detected in intestinal lysates of

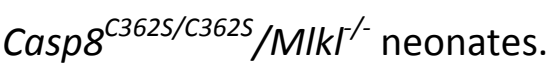

Moreover, cleaved and therefore activated Casp1 was present in the Triton X-100 soluble fraction and the aggregation of ASC in the insoluble fraction of ileal lystaes from

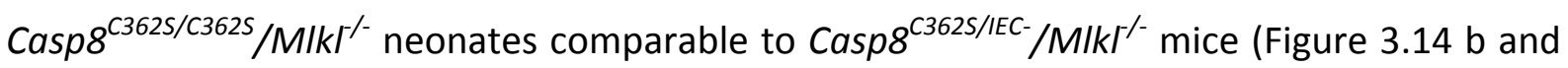
Figure 3.13 b). Together, these results indicate an activation of the inflammasome in mice expressing catalytically inactive Casp8 when necroptosis is blocked.

a

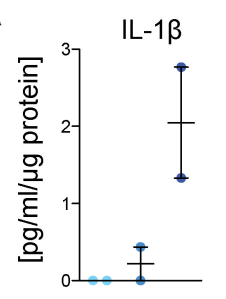

IL-6
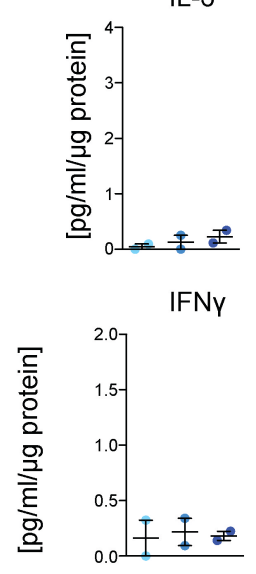

IL-2

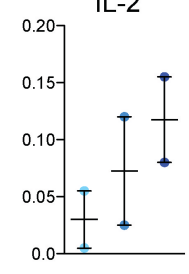

IL-10

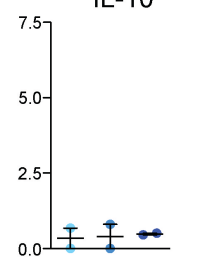

GM-CSF

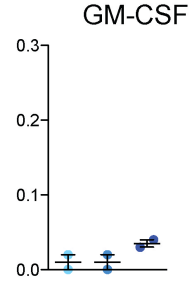

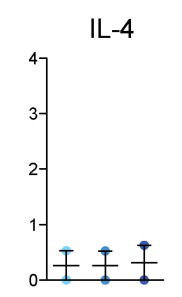

IL-12p70

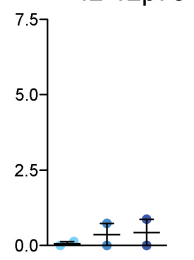

TNF- $\alpha$

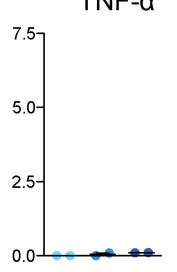

IL-5

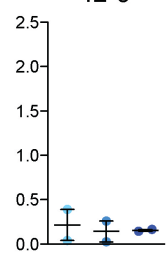

IL-17a

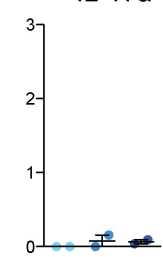

Neonates

$\mathrm{P} 1(\mathrm{n}=2)$

- Casp $8^{\mathrm{wt} / \mathrm{wt}} / \mathrm{MIKT}^{\mathrm{H}}$

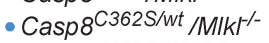

- Casp8 ${ }^{\mathrm{C} 362 \mathrm{~S} / \mathrm{C} 362 \mathrm{~S}} / \mathrm{MIKT}^{-1}$ b

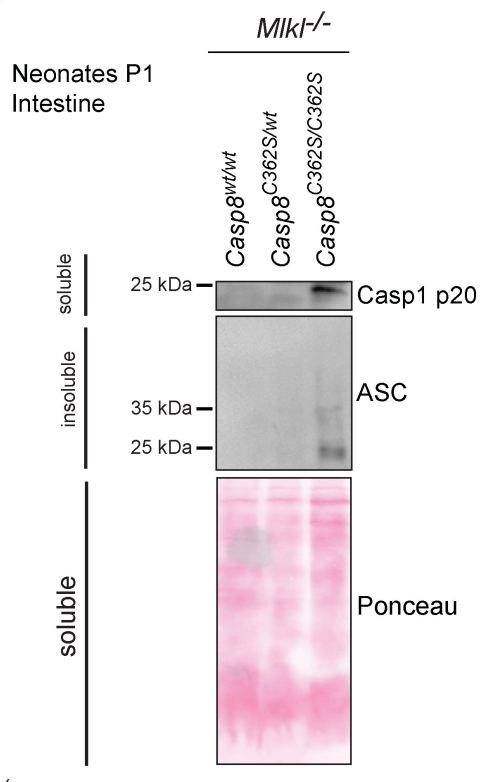


Figure 3.14 Casp8 ${ }^{\mathrm{C362S}}$ activates the inflammasome in the small intestine of $\mathrm{Casp}^{\mathrm{C} 362 \mathrm{~S} / \mathrm{C362S}} / \mathrm{MIkI}^{/-}$neonates. a Cytokine array (AYOXXA Lunaris) to detect the indicated cytokines in ileal lysates derived from P1 neonate. Dots and circles, individual mice. Lines, mean \pm s.e.m. P-values by One-way ANOVA followed by Turkey's postanalysis. b Western blot analysis of ileal lysates derived from one representative with the indicated genotype detecting cleaved Casp1 and ASC. Lanes, individual mice. Ponceau serves as loading control.

\subsection{Catalytically inactive Casp8 induces the formation of the inflammasome}

Casp8 enzymatic activity seems to play a key factor in the activation of the inflammasome when necroptosis is absent. However, the mechanisms of ASC speck formation induced by enzymatic inactive Casp8 remains unknown. In order to mechanistically characterise the capability of catalytically inactive Casp8 to induce ASC speck formation in vitro, we established two independent human cell lines, lacking Casp8 gene expression. In the human colon cancer cell line HCT-116 and the human embryonic kidney cell line HEK293T endogenous Casp8 was deleted using the CRISPR/Cas9 system. Western blot analysis of cells transiently transfected with either human wt Casp8 or catalytic inactive Casp8 ${ }^{\mathrm{C} 360 \mathrm{~S}}$ together with DsRed-ASC after treatment with the pan-caspase inhibitor IDN-6556 (Emricasan) (Brumatti et al. 2016), Nec1 or the combination of both was performed. Only upon ectopic expression of enzymatically inactive human Casp8 ${ }^{\mathrm{C} 360 \mathrm{~S}}$, but not wild-type Casp8, ASC aggregates were increasingly detected in the Triton X-100 insoluble cellular fractions in both cell lines indicating the formation of large protein-complexes containing ASC (Figure 3.15). Wild-type Casp8 only induced ASC aggregation in the insoluble fraction when transfected cells were additionally treated with the pan-caspase inhibitor IDN-6556. ASC aggregation caused by catalytically inactive Casp8 was not altered upon additional treatment of transfected cells with Nec-1. Notably, Casp8 $8^{\mathrm{C360S}}$ was detected in the soluble and insoluble cellular fractions independent of IDN-6556 treatment, whereas full-length wild-type Casp8 was expressed at low levels in untreated cells, which markedly increased in the presence of the pan-caspase inhibitor IDN-6556. 

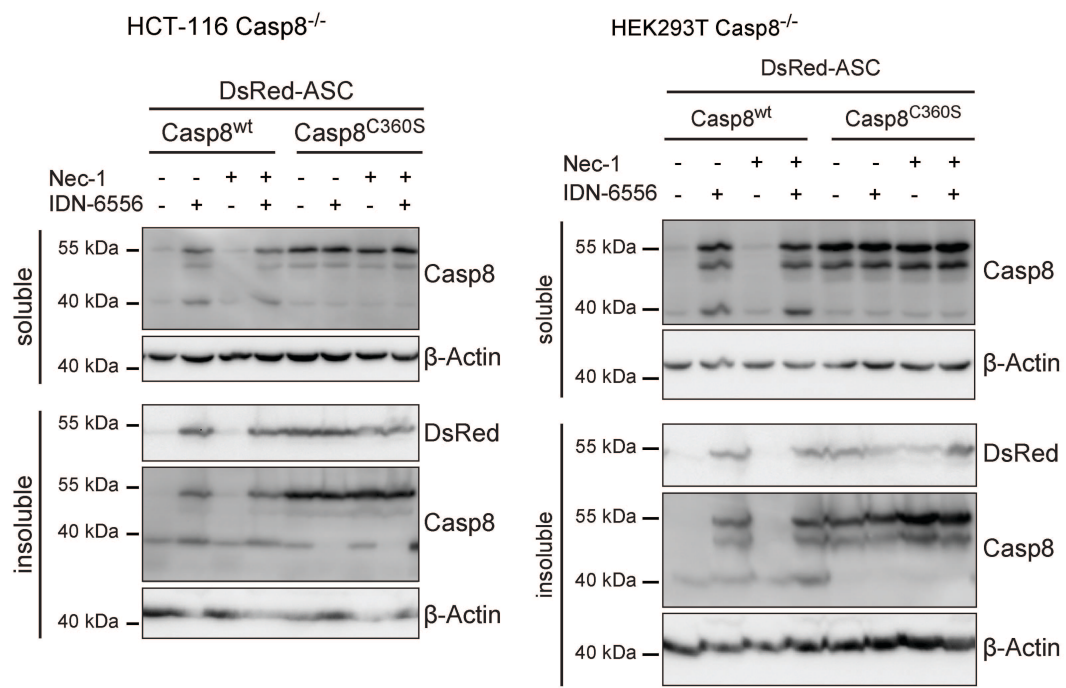

Figure 3.15 Catalytic inactive Casp8 is sufficinet to induce ASC aggregation in vitro. Western blot analysis from Casp $8^{-/-}$HCT-116 clone 2 or Casp $8^{-/-}$HEK293T cells clone 1 soluble and insoluble fraction with overexpression of either human Casp8 $^{\text {wt }}$ or Casp8 ${ }^{\text {C360S }}$ after treatment with IDN-6556 (20 $\left.\mu \mathrm{M}\right)$, Nec-1 (10 $\left.\mu \mathrm{M}\right)$ or both (IDN$6556 / \mathrm{Nec}-1$ ) for $14 \mathrm{~h}$. $\beta$-Actin serves as loading control. Results representative of two individual experiments. (In collaboration with Fabian Schorn).

In addition, immunofluorescence staining of Casp8 in transfected HCT-116 cells revealed that the majority of Casp8 ${ }^{\mathrm{C} 360 \mathrm{~S}}$ co-localised with cytoplasmic ASC aggregates (Figure $3.16 \mathrm{a}$, upper panel). Wild-type Casp8 only co-localised with ASC upon additional treatment of these cells with IDN-6556 (Figure 3.16 a, middel \& lower panel).

To further investigate the ability of catalytic inactive Casp8 to directly interact with ASC, an immunoprecipitation (IP) of Casp8 in total cell lysates from transfected HEK293T cells was performed (Figure 3.16 b). Casp8 ${ }^{\mathrm{C} 360 \mathrm{~S}}$ lacking enzymatic activity clearly interacted with ASC, whereas wt Casp8 solely interacted with ASC when Casp8 activity was blocked by IDN-6556. Notably, overexpression of wild-type Casp8 in cells resulted in its auto-cleavage and reduced protein level. Only upon IDN-6556 treatment, comparable amounts of Casp8 could be detected which in turn induced ASC aggregation and co-immunoprecipitation. Thus, these overexpression studies suggest that the ectopic expression of inactive Casp8 alone is sufficient to induce the formation of the inflammasome where Casp8 is able to interact with ASC. 
a

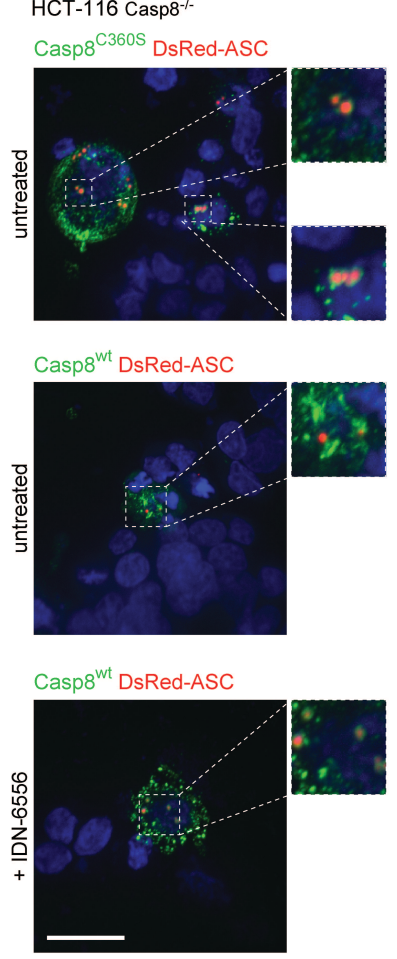

b HEK293T Casp8 ${ }^{-\%}$

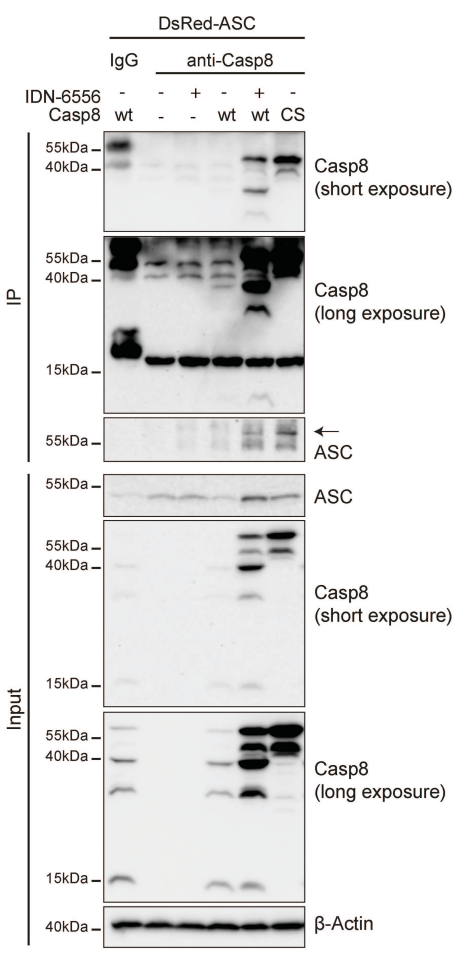

Figure 3.16 Catalytic inactive Casp8 interacts with ASC in vitro. a Immunofluorescence confocal images of Casp8 $8^{-1}$ HCT-116 clone 2 overexpressing either human Casp8 ${ }^{\text {wt }}$ or Casp8 ${ }^{\text {C360S }}$ together with DsRed-ASC untreated or treated with IDN-6556 $(20 \mu \mathrm{M})$ and stained for Casp8 after $24 \mathrm{~h}$. Scale bar, $20 \mu \mathrm{m}$. Results representative of two individual experiments. b Immunoprecipitation of Casp $8^{-1-}$ HEK293T clone 1 lysates overexpressing either human Casp8 ${ }^{\mathrm{wt}}, \mathrm{Casp}^{\mathrm{C} 360 \mathrm{~S}}$ or empty vector (-) together with DsRed-ASC untreated or treated with IDN-6556 $(20 \mu \mathrm{M})$ as indicated. $\beta$-Actin serves as loading control. Results representative of two individual experiments. (In collaboration with Saskia Günther, Marie Albert and Fabian Schorn).

To determine, if endogenous Casp8 is also able to induce ASC speck formation in the absence of its catalytic activity, bone marrow-derived macrophages (BMDMs) and endothelial cells (ECs) from different Casp8 floxed mice were isolated and the deletion of the Casp8 floxed alleles was introduced by HTNCre (His-tagged, TAT-fusion Cre with nuclear localisation signal) treatment in vitro. Immunofluorescence staining revealed the formation of ASC specks in BMDMs expressing catalytically inactive Casp8, but not in Casp8 ${ }^{\mathrm{C} 362 \mathrm{~S} / \mathrm{fl}} \mathrm{ECS}$ upon HTNCre treatment (Figure 3.17 a \& b). Moreover, IL-1 $\beta$ was significantly increased only in Casp8 ${ }^{\text {C362S/fl }}$ BMDMs treated with HTNCre compared to BMDMs with a deletion of Casp8, whereas Casp $8^{\text {C362S/fl }}$ ECs showed no elevated levels of IL-1 $\beta$ (Figure 3.17 a \& b) indicating that endogenous catalytically inactive Casp8 is sufficient to induce the formation of the inflammasome preferentially in a certain cell type including BMDMs. In addition, deletion of the floxed Casp8 allele in Casp8 $8^{\mathrm{C362S/fl}}$ and Casp $8^{\mathrm{C} 362 \mathrm{~S} / \mathrm{fl}} / \mathrm{Mlk}^{/-}$macrophages (Casp $8^{\mathrm{C} 362 \mathrm{~S} /-}$ and 
Casp $\left.8^{\mathrm{C} 362 \mathrm{~S} /-} / \mathrm{Mlkl}^{--}\right)$resulted in ASC speck formation and IL-1 $\beta$ secretion in both cell lines

(Figure $3.17 \mathrm{c}$ ), suggesting an activation of the inflammasome independent of MLKL and therefore necroptosis.

a
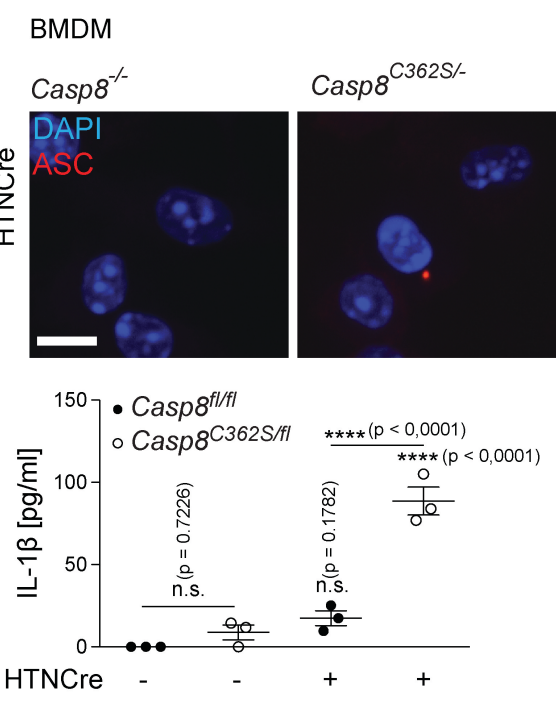

C

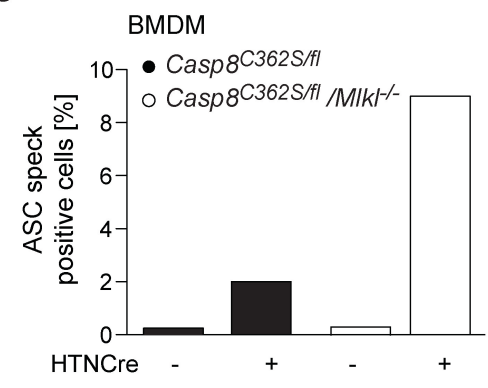

b
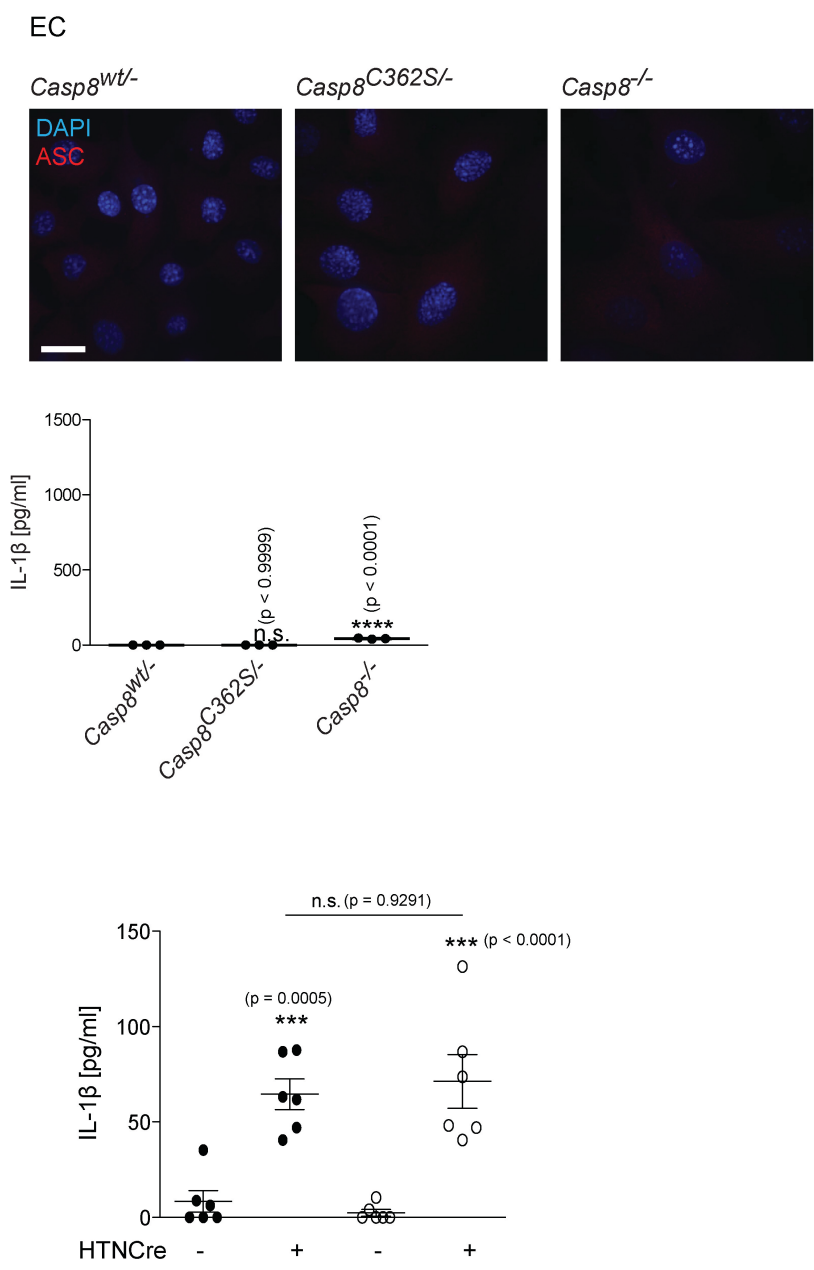

Figure 3.17 Catalytically inactive Casp8 is sufficient to induce ASC aggregation only in certain cell types. a Immunofluorescence confocal images of BMDMs derived from $\operatorname{Casp} 8^{f / f f l}$ or $\operatorname{Casp} 8^{\mathrm{C} 3625 / f l}$ mice treated with HTNCre for $24 \mathrm{~h}$ and stained for ASC (upper panel) or IL-1 $\beta$ measurement in the supernatant of BMDMs (lower panel, $n=3$ biologically independent replicates). Scale bar, $20 \mu \mathrm{m}$. Dots and circles, individual mice. Lines, mean \pm s.e.m. P-values by One-way ANOVA followed by Sidak's post-analysis to the corresponding untreated value. Results representative of two individual experiments. $\mathbf{b}$ Immunofluorescence confocal images of ECs treated with HTNCre and stained for ASC after $24 \mathrm{~h}$ (upper panel; scale bar, $20 \mu \mathrm{m}$ ). IL-1 $\beta$ measurement in supernatants of ECs after $24 \mathrm{~h}$ HTNCre treatment (lower panel; $n=3$ biologically independent replicates). Dots and circles, individual mice. Lines, mean \pm s.e.m. P-values by One-way ANOVA followed by Sidak's post-analysis. Results representative of two individual experiments. c ASC speck positive BMDMs ( $n=100$, one representative experiment) (upper panel) and IL-1 $\beta$ measurement in supernatants of BMDMs (lower panel) after $24 \mathrm{~h}$ HTNCre treatment in biologically independent replicates ( $n=6$, representative of two individual experiments). Dots, individual mice. Lines, mean \pm s.e.m. P-values by One-way ANOVA followed by Sidak's post-analysis to the corresponding values without HTNCre. (In collaboration with Saskia Günther). 
Importantly, inhibition of caspase activity in BMDMs by using IDN-6556 did not recapitulate the data obtained by endogenous expression of Casp $8^{\mathrm{C} 362 \mathrm{~S}}$. In line with previous findings (Conos et al. 2017), IDN-6556 was only able to induce IL-1 $\beta$ release, LDH release (as an indicator for cell death) and ASC speck formation when BMDMs were co-treated with LPS to activate the formation of the inflammasome (Figure 3.18). In contrast to endogenous Casp8 ${ }^{\mathrm{C} 362 \mathrm{~S}}$ expression, IDN-6556 and LPS co-treatment IL-1 $\beta$ release, LDH release as well as was ASC speck formation was completely abolished in cells lacking MLKL. However, LDH release and ASC speck formation was not affected in Casp1 knock-out BMDMs, whereas release of IL-1 $\beta$ was not detectable confirming the already described possible Casp1independent formation of ASC specks, the involvement of Casp1 in the secretion of IL-1 $\beta$ and the induction of cell death.

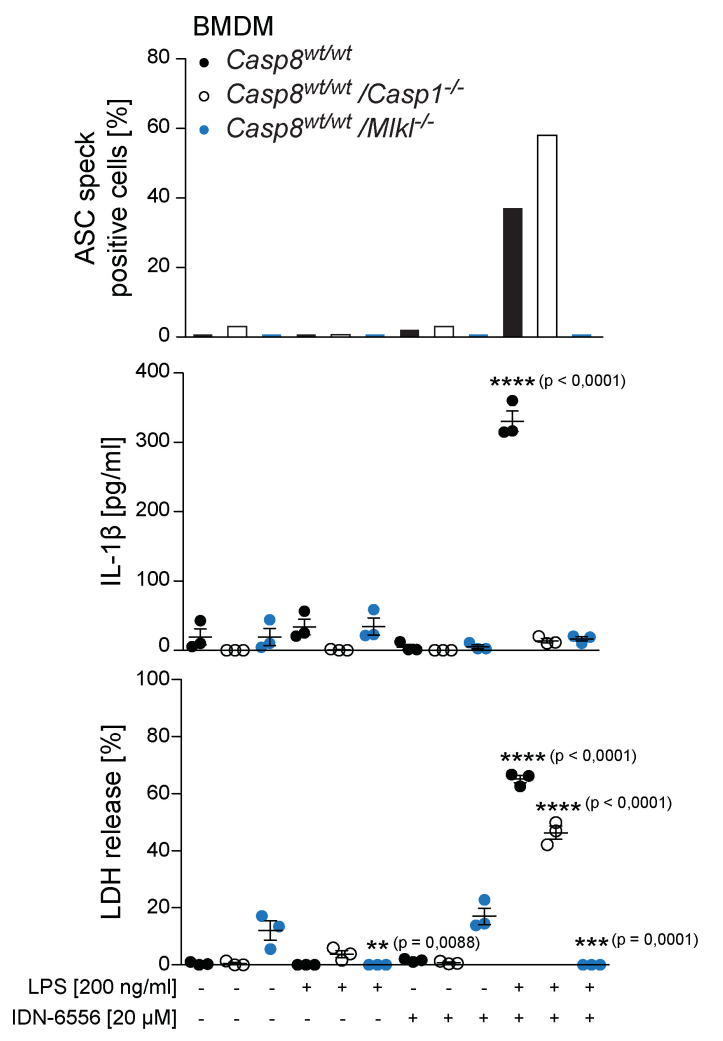

Figure 3.18 Inhibition of endogenous Casp8 did only affect formation of the inflammasome upon additional LPS treatment. ASC speck positive BMDMs (upper panel; $n=100$ of one representative experiment), IL-1 $\beta$ measurement (middle panel; $n=3$ biologically independent replicates) and LDH release (lower panel; $\mathrm{n}=3$ biologically independent replicates) in the supernatants of BMDMs after treatment with LPS (200 $\mathrm{ng} / \mathrm{ml})$, IDN-6556 (20 $\mu \mathrm{M})$ or both (LPS/IDN-6556) for $24 \mathrm{~h}$. Dots and circles, individual mice. Lines, mean \pm s.e.m. P-values by One-way ANOVA followed by Sidak's post-analysis to the corresponding untreated value and shown for $p>0,1$. Results representative of two individual experiments. (In collaboration with Saskia Günther). 


\subsection{ASC or Casp1 deficiency rescues embryonal lethality and restores inflammatory tissue} destruction of adult mice expressing Casp ${ }^{\text {C362S }}$

Catalytically inactive Casp8 seems to play an important role in the activation of the inflammasome in vivo and in vitro. To assess whether Casp1 or ASC contributes to the pathology causing the lethality and tissue destruction of $\mathrm{Casp} 8^{\mathrm{C} 362 \mathrm{~S} / \mathrm{C362S}} / \mathrm{MlkI}^{--}$animals, ASC

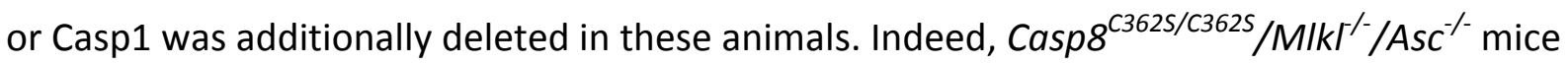
were observed at the expected mendelian ratio independent of the breeding strategy and survived beyond parturition (Figure 3.19 a, left panel). In contrast, around $30 \%$ of

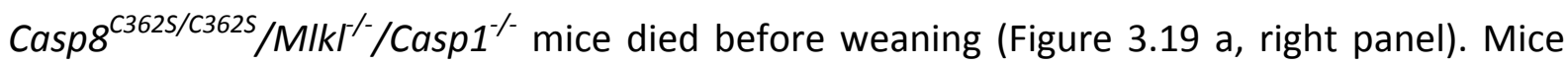
from both lines which survived weaning, were fertile and developed normally without any major macroscopic alterations and showed no differences in body weight compared to their control littermates (Figure 3.19 b \& c, upper panels). However, both genotypes led to abnormal haematopoiesis characterised by a strong increase in spleen size and weight (Figure 3.19 b \& c, lower panels) as observed in the already desribed $\mathrm{Casp}^{-/} / \mathrm{MlkI}^{--}$mice (Alvarez-Diaz et al. 2016), indicating that additional Casp1 or ASC deficiency rescues the lethality of $\mathrm{Casp}^{\mathrm{C} 362 \mathrm{~S} / \mathrm{C3}^{2} \mathrm{~S}} / \mathrm{MIKI}^{-/}$mice.

a

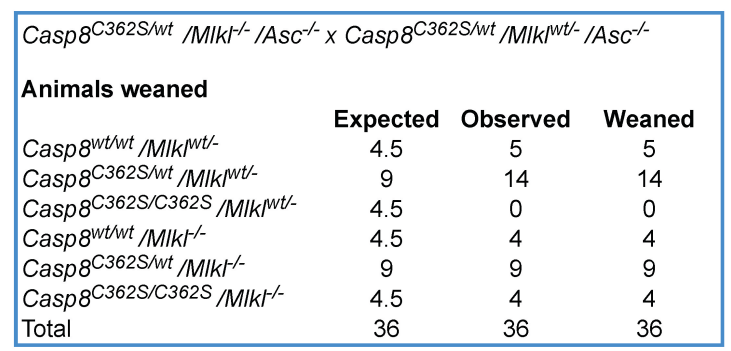

\begin{tabular}{|c|c|c|c|}
\hline \multicolumn{4}{|c|}{ 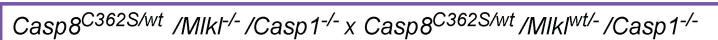 } \\
\hline \multicolumn{4}{|l|}{ Animals weaned } \\
\hline & Expected & Observed & Weaned \\
\hline Casp8 $8^{\text {wtwt }} /$ MIk/wt- & 5.25 & 6 & 6 \\
\hline Casp8 ${ }^{C 362 S / w t} /$ Mlkwt/- & 10.5 & 12 & 11 \\
\hline 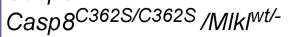 & 5.25 & 0 & 0 \\
\hline Casp8 wtwt $_{\text {MIlkr- }}^{-}$ & 5.25 & 11 & 11 \\
\hline Casp8 $8^{\mathrm{C} 362 \mathrm{~S} / \mathrm{wt}} / \mathrm{MIKK}^{-}$ & 10.5 & 9 & 9 \\
\hline Casp8 $8^{\mathrm{C} 362 \mathrm{~S} / \mathrm{C} 362 \mathrm{~S}} / \mathrm{MIKH}^{-}$ & 5.25 & 4 & 3 \\
\hline Total & 42 & 42 & 40 \\
\hline \multicolumn{4}{|c|}{ 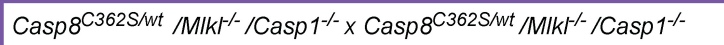 } \\
\hline \multicolumn{4}{|l|}{ Animals weaned } \\
\hline & Expected & Observed & Weaned \\
\hline Casp $8^{\text {wtiwt }}$ & 3.25 & 2 & 2 \\
\hline Casp8 C362S/wt $^{2}$ & 6.5 & 8 & 8 \\
\hline Casp8 $8^{C 362 S / C 362 S}$ & 3.25 & 3 & 1 \\
\hline Total & 13 & 13 & 11 \\
\hline
\end{tabular}



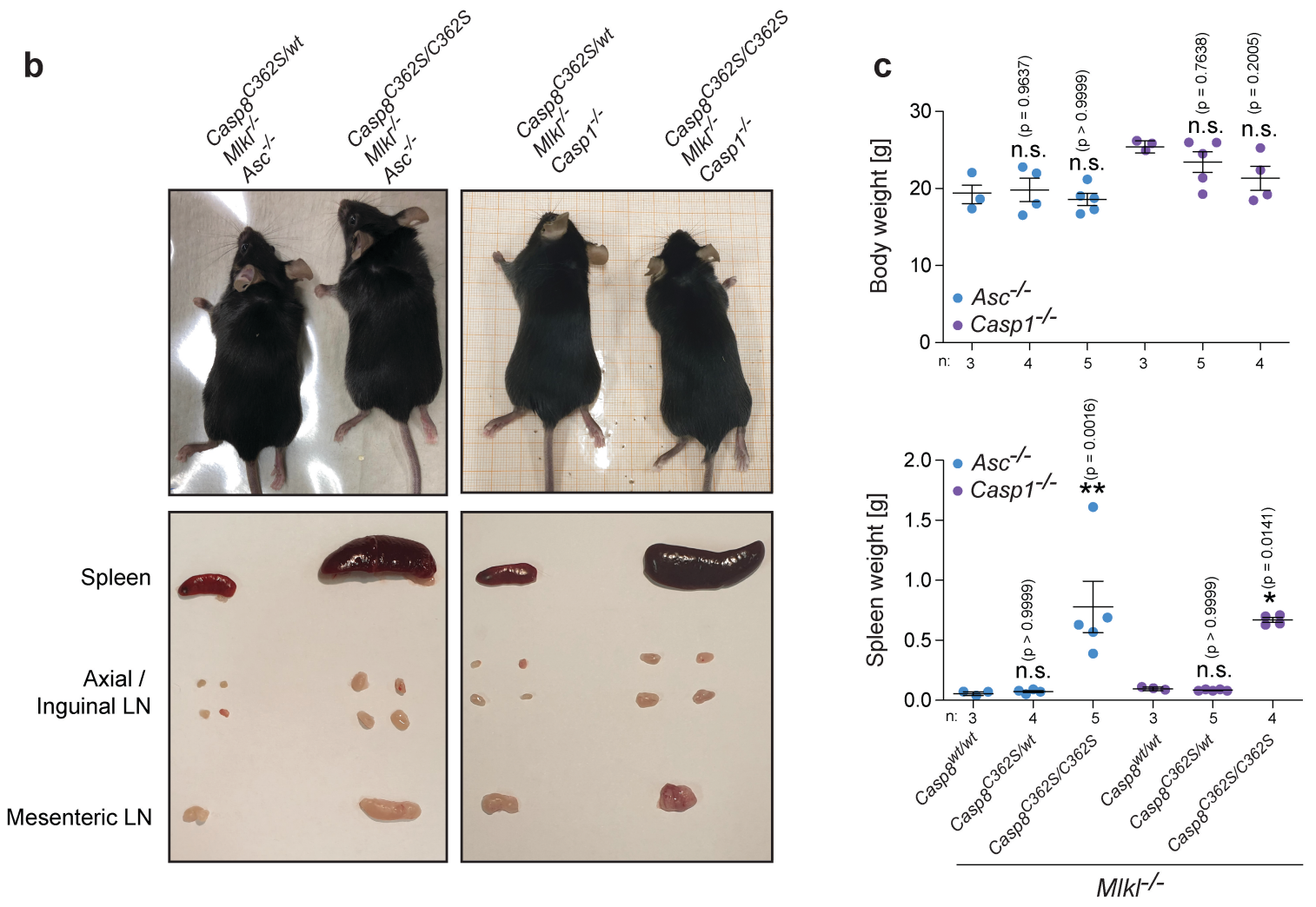

Figure 3.19 ASC or Casp1 deficiency rescues lethality of mice expressing Casp8 ${ }^{\text {C362s }}$. a Expected, observed and weaned numbers of mice per genotype obtained from indicated crossings. b Representative images of mice at 8 weeks of age (upper panel) and spleen, axial and inguinal LN and mesenteric LN (middle panel) from

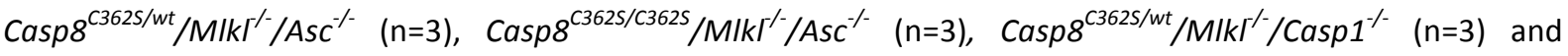

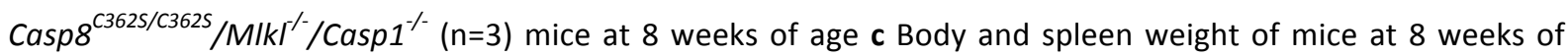
age. Dots, individual mice. Lines, mean \pm s.e.m. P-values by One-way ANOVA followed by Sidak's post-analysis to the corresponding Casp $8^{\text {wt } / w t}$ values.

Histological analyses of sections from the ileum were performed to examine the ability of additonal ASC or Casp1 deficiency to prevent inflammatory tissue destruction of the small intestine in $\mathrm{Casp}^{\mathrm{C} 362 \mathrm{~S} / \mathrm{C} 362 \mathrm{~S}} / \mathrm{Mlk}^{-/}$mice. H\&E and lysozyme staining did not display overwhelming tissue damage or loss of Paneth cells in intestines of Casp $8^{\mathrm{C} 3625 / \mathrm{C362S}} / \mathrm{MlkI}^{-1}$

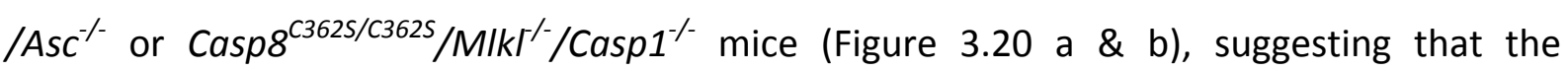
lethality of mice expressing catalytically inactive Casp8 is mainly caused by Casp1 and ASC. Furthermore, IL-1 $\beta$ secretion was significantly reduced upon additional deletion of ASC or Casp1 (Figure $3.20 \mathrm{c}$ ) and in line with this, cleavage of Casp1 was not detectable in ileal

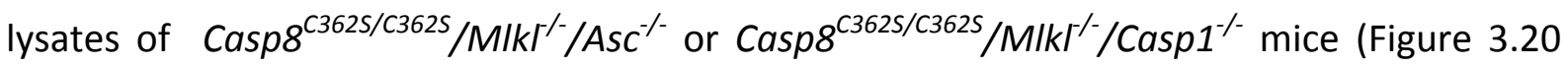
d). 
However, lack of Casp1 in Casp8 $8^{\mathrm{C362S/C362S}} / \mathrm{Mlkl}^{-/-}$mice did not affect the aggregation of ASC and Casp8 in the Triton X-100 insoluble fraction of ileal lysates as protein level were

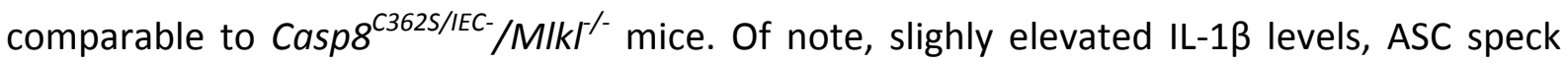
formation and Casp8 aggregation were still detectable in the intestinal tissues of

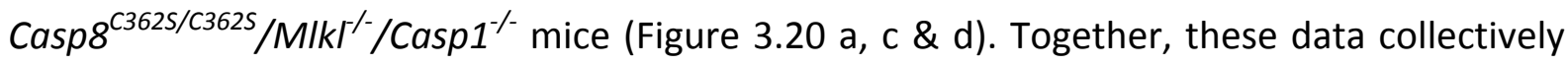
demonstrate that catalytically inactive Casp8 serves as a nucleation signal for the formation of ASC specks and activation of Casp1 ultimately leading to premature death of mice when necroptosis is blocked.

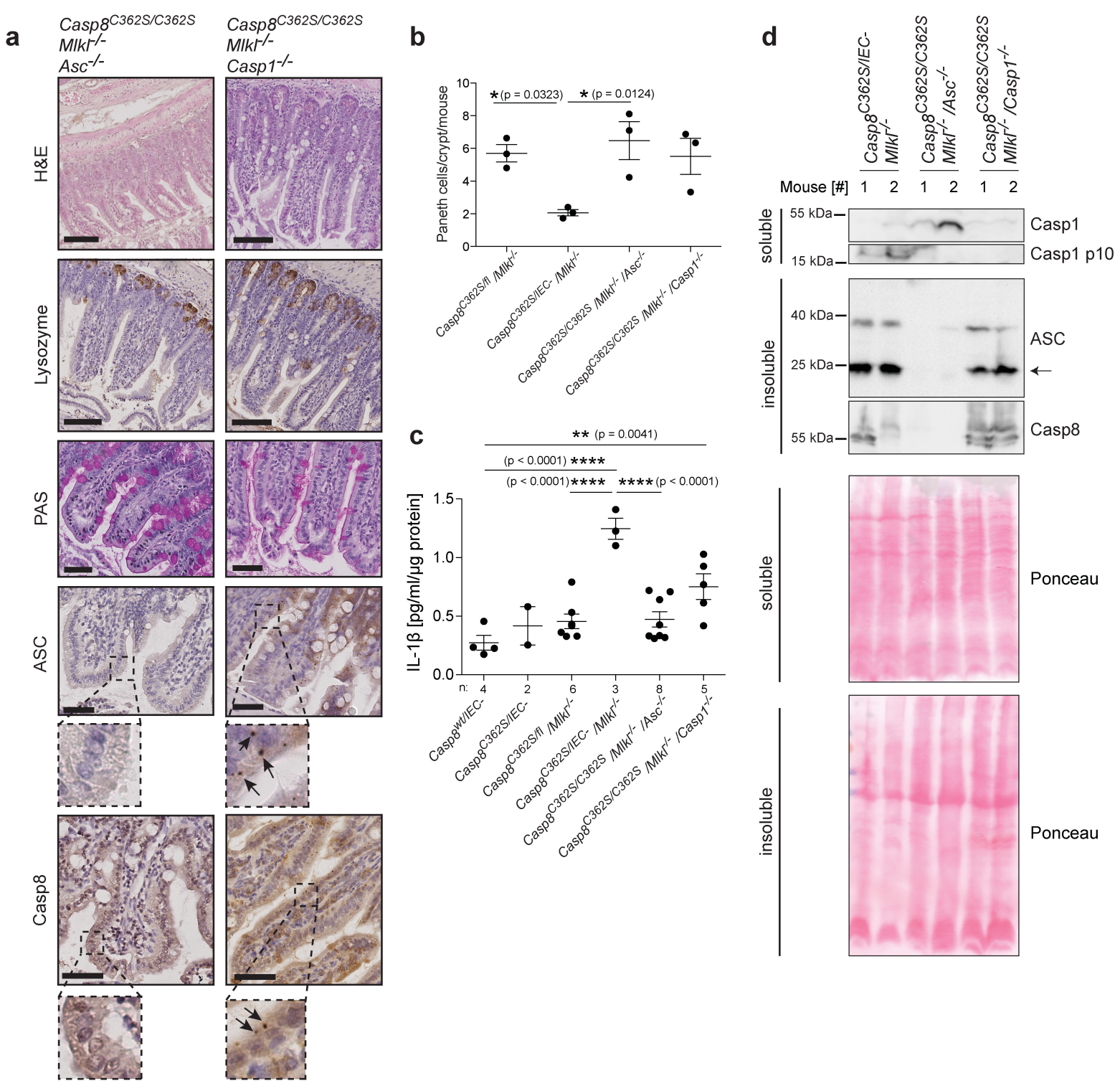


Figure 3.20 ASC or Casp1 deficiency prevents inflammatory destruction of the small intestine in

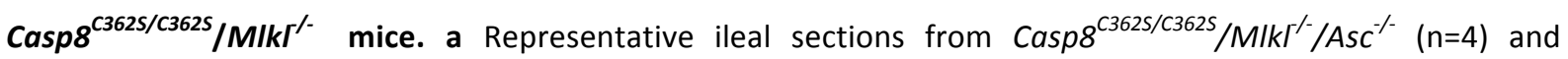
Casp $8^{\mathrm{C} 362 S / C 362 S} / \mathrm{MlkN}^{/-}$Casp1 $^{-/}(\mathrm{n}=3)$ mice at 5 weeks of age with H\&E, lysozyme, PAS, ASC and Casp8 staining. Scale bars, $100 \mu \mathrm{m}$ for H\&E and lysozyme and $50 \mu \mathrm{m}$ for PAS, ASC and Casp8. Arrows, ASC or Casp8 aggregates b Count of Paneth cells (per crypt per mouse, $n=3$ ). Dots, individual mice. Lines, mean \pm s.e.m. P-values by Oneway ANOVA followed by Sidak's post-analysis. c IL-1 $\beta$ ELISA in ileal lysates of the indicated mouse lines. Dots, individual mice. Lines, mean \pm s.e.m. P-values by One-way ANOVA followed by Tukey's post-analysis. $\mathbf{d}$ Western Blot analysis of ileal lysates from two representative mice with the indicated genotypes detecting cleaved Casp1, ASC and Casp8. Lanes, individual mice. Ponceau serves as loading control.

\subsection{Casp8 inhibition prolongs the survival of mice infected with Shigella flexneri}

The fact that the inhibition of Casp8 enzymatic activity causes necroptosis and, when necroptsis is blocked, it leads to pyroptosis raise the question, why bacterial infection induces Casp8 activity. As Shigella efficiently inhibits apoptosis the induction of Casp8 activity can not induce apoptosis (Andree et al. 2014, Günther et al. 2020). The requirement of Casp8 in LPS-mediated endotoxin shock and E. coli sepsis has been described recently (Mandal et al. 2018). Similar to the infection with the Gram-negative bacterium E. coli, mice are highly susceptible to intravenous infection with the invasive strain Shigella flexneri M90T (Martino et al. 2004). In order to investigate the role of Casp8 enzymatic activity in Shigella flexneri infection, mice were infected intravenously (i.v.) with the invasive strain Shigella flexneri M90T (Figure 3.21). As Casp8 ${ }^{\mathrm{C} 362 \mathrm{~S}}$ mice are embryonically lethal, additional treatment of mice with IDN-6556 was used to inhibit enzymatic activity of Casp8 to examine the role of catalytically inactive Casp8 upon Shigella flexneri infection in vivo (Figure 3.21 a). Inhibition of Casp8 enzymatic activity prolongs the survival of mice infected with Shigella flexneri M90T for several hours (Figure $3.21 \mathrm{~b}$ ). In addition, bacterial burden in livers and spleens from mice infected with Shigella flexneri M90T was reduced upon treatment with IDN-6556 (Figure 3.21 c). Together these data suggested that Casp8 activity supports bacterial growth. This issue however requires an indepth analysis of how Casp8 activity interferes with immunity against bacterial infection. 
a

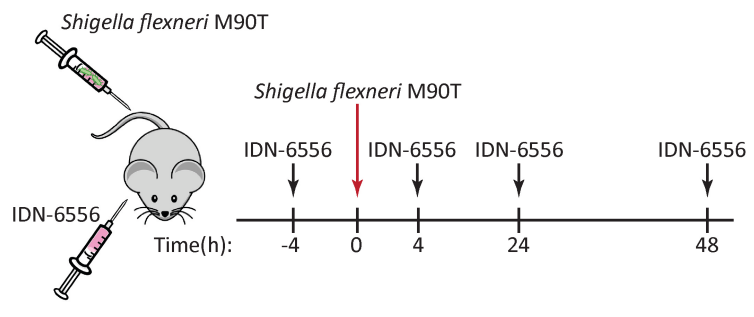

C

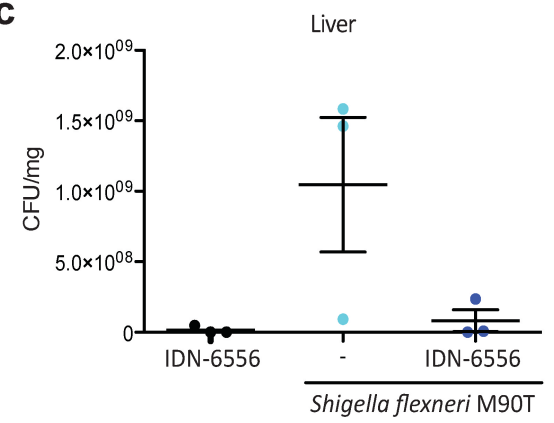

b
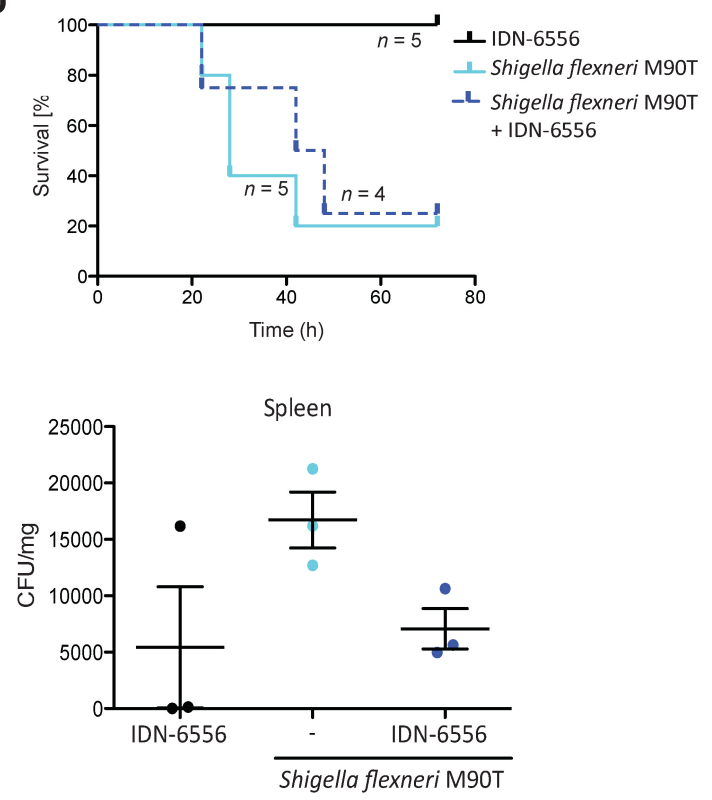

Figure 3.21 Casp8 inhibition prolongs the survival of mice infected with Shigella flexneri. a wt mice were treated with IDN-6556 (or captisol as negative control), to inhibit Casp8 enzymatic activity, intraperitoneally $4 \mathrm{~h}$ before i.v. Shigella flexneri infection as well as 4,24 and $48 \mathrm{~h}$ after infection. b Kaplan-Meier survival curve of wt mice infected with Shigella flexneri i.v. (CFU $1 \times 10^{8}$ ) with or without treatment with IDN-6556. C Bacterial burden of livers and spleens from mice infected with Shigella flexneri M90T after 24 p.i. by measuring CFU. 


\section{Discussion}

In the present work we identified a novel and essential role of Casp8 enzymatic activity in embryonic development, tissue homeostasis, as well as in immunity against intracellular bacteria. Mutation of the catalytic cysteine of Casp8 $\left(\right.$ Casp $\left.8{ }^{\mathrm{C} 3625}\right)$ results in embryonic lethality due to accelerated necroptosis, especially in the cardiovascular system. Moreover, Casp8 enzymatic activity preserves the balance of tissue homeostasis in the skin by inhibiting necroptosis. When necroptosis is blocked, catalytically inactive Casp8 serves as a nucleation signal for ASC speck formation and activation of Casp1, ultimately leading to premature death of mice. Our data clearly demonstrate that catalytically inactive Casp8 co-localises with ASC mediating the maturation of pro-inflammatory cytokines in a Casp1-dependent manner. These results reveal a yet unknown and unexpected role for Casp8 enzymatic activity and scaffold function involving the inflammasome and pyroptosis under circumstances where apoptosis and necroptosis are compromised.

\subsection{Casp8 enzymatic activity in embryonic development and tissue homeostasis}

Programmed cell death plays a crucial role in processes during embryonic development (Suzanne and Steller 2013). Apoptosis for example is responsible for organ shaping (e.g. by digit individualisation) and the elimination of damaged or unwanted cells. Mice with a deletion of key factors of the apoptotic machinery, such as Casp3, Casp9 and Apaf1 display severe developmental defects and embryonic/prenatal lethality (Cecconi et al. 1998; Kuida et al. 1996, 1998). In contrast, mice with a lack of various components involved in the necroptotic machinery, like RIPK3 or MLKL develop normally and show no specific phenotype (Newton, Sun, and Dixit 2004; Wu et al. 2013), suggesting that necroptosis is not involved in embryonic development under normal circumstances. Nevertheless, our knowledge of the regulation of cell death signalling pathways during development is still fragmentary.

The role of Casp8 as central regulator in embryonic development has already been described by Casp8 knockout mice (Varfolomeev et al. 1998). Genetic ablation of Casp8 results in defective yolk sac vascularisation and impaired neural tube and heart muscle development. 
Our data demonstrate that, similar to knockout of Casp8, expression of catalytically inactive Casp8 (Casp8 ${ }^{\mathrm{C} 3625}$ ) results in embryonic lethality around E10.5 associated with defective yolk sac vascularisation and pericardial edema (Figure 3.3), suggesting that embryogenesis relies on the proteolytic activity of Casp8. This is consistent with recent data from Newton et al. (Newton et al. 2019a). Accordingly, several studies showed that mice with specific mutations of the Casp8 cleavage sites were viable and therefore auto-processing of Casp8 is not required during embryonic development (Kang et al. 2008; Newton et al. 2019b; Philip et al. 2016). Together, embryonic development is highly dependent on Casp8 enzymatic activity and the resulting regulation of apoptosis and necroptosis.

Apoptosis is an important process during cardiovascular development and the remodelling of cardiovascular tissues that needs to be tightly regulated. The severe cardiac phenotype of

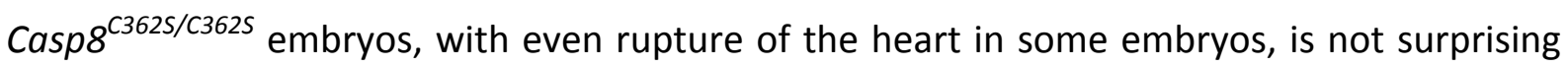
as high levels of Casp8 transcripts are detectable in the heart (especially in the primitive ventricles) in mid-gestation wildtype embryos (E9.5-E12.5) (Varfolomeev et al. 1998). In addition a recent study demonstrated a peak of programmed cell death at the same stages of cardiogenesis (Martínez-Lagunas et al. 2019). This is underlined by the development of the same phenotype, as Casp8 deletion and whole-body $\operatorname{Casp} 8^{\mathrm{C} 3625}$, upon specific expression of catalytically inactive Casp8 in endothelial cells (Casp8 $\left.{ }^{C 3625 / E C_{-}}\right)$, which are a major component of blood vessels and the heart (Figure 3.4 and Kang et al. 2004). These observations indicate that Casp8-dependent signalling pathways especially in endothelial cells are responsible for embryonic lethality and vascular defects. The survival of Casp $8^{\mathrm{C} 362 \mathrm{~S}}$ embryos is prolonged until birth upon additional deletion of MLKL, demonstrating that inhibition of necroptosis clearly rescues the vascular phenotype (Figure 3.9). Moreover, necroptosis of endothelail cells seems to be the main driver of the observed lethal phenotypes (Figure 3.10), as additional deletion of MLKL was able to rescue lethality of mice with a specific expression of catalytically inactive Casp8 in endothelial cells. On the other hand, a recent study showed that Casp8 deficiency triggers the up-regulation of proinflammatory gene expression, which is initiated exclusively by endothelial cells and then transferred to various other embryonic tissues (Kang et al. 2018). Conclusively, these findings demonstrate that dysregulation of signalling pathways dependent on Casp8 proteolytic activity in endothelial cells mainly cause the destructive vascular phenotype and embryonic lethality observed in $\operatorname{Casp} 8^{\mathrm{C} 362 \mathrm{~S}}$ mice. 
The underlying mechanism and the contribution of necroptosis, pro-inflammatory cytokine gene expression or a combination of both needs further investigation. Furthermore, the involvement of RIPK1 needs to be examined as Casp8 deficiency was found to facilitate RIPK1-dependent activation of inflammatory genes (Christofferson et al. 2012; Cuda et al. 2014; Najjar et al. 2016)

Casp8 has also been linked to the maintenance of tissue homeostasis (Günther et al. 2011; Kovalenko et al. 2009). Deficiency of Casp8 in the gut leads to an inflammatory destruction of the epithelial barrier. We could confirm these data and furthermore show that Casp8 enzymatic activity is indispensable to sustain tissue homeostasis (Figure 3.6). In contrast to Casp8 $8^{\text {C362SIEC }} / \mathrm{MLKL}^{-1-}$ mice, intestinal inflammation from mice with an IEC-specific expression of catalytically inactive Casp8 (Casp8 ${ }^{\text {C362S/IEC- })}$ could not be prevented by additional deletion of MLKL implying that other signalling pathways are involved when apoptosis and necroptosis are blocked. We clearly demonstrate a novel function of Casp8 as scaffold protein involved in pyroptotic cell death primarily in the small intestine as ASC and Casp1 deficiency deminished ilietis (Figure 3.20). An explanation for the increased inflammatory phenotype could be the induction of inflammasome formation in response to the gut microbiota.

The first hint that catalytically inactive Casp8 is involved in the development of an inflammatory disorder was observed by the use of bacterial artificial chromosome (BAC)mediated transgenic mice that express an additional copy of Casp8 carrying a mutation of the catalytic cysteine (Kovalenko et al. 2009a). The generation of mice specifically expressing catalytically inactive Casp8 in keratinocytes $\left(\mathrm{Casp}^{\mathrm{C} 362 \mathrm{~S} / \mathrm{E}-}\right.$ ) confirmed these data (Figure 3.5). However, the situation in mice with a keratinocyte-specific expression of Casp $8^{\text {c362S }}$ is contrary to $\operatorname{Casp} 8^{\mathrm{C} 3625 / I E C-}$, as MLKL deficiency has the ability to rescue inflammatory destruction of the skin (Figure 3.10). Moreover, additional deletion of RIPK3 in Casp8 $8^{\text {C362S }}$ mice also prevented the inflammatory destruction of the skin (Figure 3.8). The fact, that keratinocytes seem to not express or only express low levels of important components of the inflammasome, such as Casp1, pro-IL-1 $\beta$ and ASC (Mizutani, Black, and Kupper 1991; Sand et al. 2018 ) could be responsible for the prevention of the inflammtory skin phenotype only by deletion of MLKL or RIPK3. 
Upon inhibiton of necroptosis, inflammasome formation mediating pyroptotic cell death can not proceed due to the lack of these components.

In conclusion, Casp8 enzymatic activity is necessary for embryonic development and the maintenance of tissue homeostasis.

\subsection{Casp8 enzymatic activity is required to inhibit necroptosis}

Besides its well-known function in mediating extrinsic apoptosis (Boldin et al. 1996; Muzio et al. 1996), loss of Casp8 in mice demonstrates an inhibitory role of Casp8 in necroptosis (Varfolomeev et al. 1998). In line with this, deletion of important factors of the necroptotic signalling pathway was shown to rescue embryonic lethality of $\mathrm{Casp}^{-/-}$mice (Alvarez-Diaz et

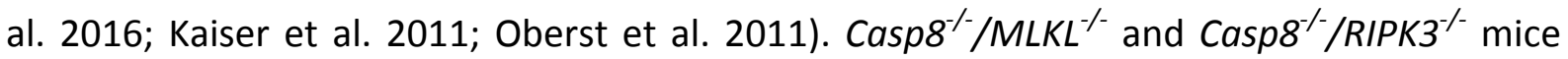
are viable but developed a severe enlargement of the lymphoid organs. Similar to deletion of Casp8, $\operatorname{Casp} 8^{\mathrm{C} 362 \mathrm{~S}}$ mice are embryonically lethal at E10.5 and can be rescued upon additional deletion of MLKL and RIPK3, as already discussed and resemble the data published recently back to back with our work (Newton et al. 2019a; Newton et al. 2019b). These observations indicate that enzymatic activity of Casp8 is necessary to inhibit necroptosis.

Chemical inhibition of Casp8 activity revealed the induction of necroptosis in response to TNF $\alpha$ (Dillon et al. 2014a). In line with this, catalytically inactive Casp8 mediates TNF $\alpha$ induced cell death of ECs associated with MLKL phosphorylation (Figure 3.7). Moreover, viability was restored when necroptosis was blocked by the RIPK1 kinase inhibitor Necrostatin-1 (Nec-1) pointing to the inhibitory effect of active Casp8 and towards RIPK1, RIPK3 and MLKL as possible targets of Casp8. Already in 1998 Lin and colleagues identified RIPK1 as a target of Casp8 that is cleaved during TNF $\alpha$-induced apoptosis suggesting that RIPK1 cleavage is the underlying mechanism in Casp8-mediated inhibition of necroptosis (Lin et al. 1999). This hypothesis could be confirmed by recent publications demonstrating that mutation of the Casp8 cleavage site of RIPK1 (Ripk1 ${ }^{\mathrm{D} 325 \mathrm{~A}}$ ) results in embryonic lethality at E10.5 (Newton et al. 2019b; Zhang, Dowling, and Zhang 2019). Together, Casp8 enzymatic activity is required to inhibit necroptosis by cleavage of RIPK1.

In vitro studies proposed a model, where Casp8 cleavage is essential to achieve full activity (Oberst et al. 2010). This would lead to the hypothesis that mutation of the self-processing sites of Casp8 mice should mimic catalytic inactivation of Casp8 resulting in a comparable phenotype than Casp8 ${ }^{\mathrm{C} 362 \mathrm{~S}}$ mice develop. 
Surprisingly, mice with a mutation of the cleavage site of Casp8 at position D387 (between the large and the small subunit) are viable with no obvious phenotype (Kang et al. 2008; Philip et al. 2016). Moreover, the generation of a complete uncleavable Casp8 mouse by mutating the cleavage sites between the large and the small subunit as well as between the prodomain and the large subunit (Casp8 ${ }^{\mathrm{D} 212 \mathrm{~A} / \mathrm{D} 218 \mathrm{~A} / \mathrm{D} 225 \mathrm{~A} / \mathrm{D} 378 \mathrm{~A}}$ ) did not display a phenotype that is manifested in embryonic lethality similar to Casp8 ${ }^{\mathrm{C} 362 \mathrm{~S}}$ (Newton et al. 2019b). Conclusively, cleavage of Casp8 is not relevant to ensure Casp8 activity and has therefore no impact on the inhibition of necroptosis during embryonic development.

\subsection{Catalytically inactive Casp8 has a scaffold function activating the inflammasome}

Casp8 is mainly known for its function in the regulation of programmed cell death. However, in contrast to $\operatorname{Casp} 8^{-/} / \mathrm{MLKL}^{-/}$mice, our data revealed that the embryonic lethality of mice expressing catalytically inactive Casp8 is rescued upon additional deletion of MLKL. Nonetheless, these mice die shortly after birth (Figure 3.9). This indicates, that catalytically inactive Casp8 not only plays an important role in the regulation of programmed cell death but also is involved in cell death-independent signalling pathways. Recent studies provide evidence that Casp8 also induce the production of pro-inflammatory cytokines due to its scaffold function (Hartwig et al. 2017; Henry et al. 2017; Kang et al. 2015). In line with this hypothesis, elevated levels of IL-1 $\beta$ were present in the small intestine of Casp8 ${ }^{\text {C362S/IEC- } / M I k I ~}$ /- mice as well as in Casp8 $8^{\mathrm{C} 362 \mathrm{~S} / \mathrm{C362S}} / \mathrm{MlkT}^{/-}$neonates (Figure $3.13 \& 3.14$ ). Catalytically inactive Casp8 forms a multimeric complex together with ASC, thereby activating Casp1 in vivo and in vitro (Figure 3.13-18). As previously shown, Casp8 possess the ability to bind ASC via DED-PYD interaction under various circumstances resulting in the formation of the inflammasome (Man et al. 2014; Mascarenhas et al. 2017; Van Opdenbosch et al. 2017; Schneider et al. 2017; Vajjhala et al. 2015). The involvement of components of the inflammasome in lethality and tissue homeostasis is obvious as deletion of ASC or Casp1 rescues the lethal phenotype of Casp8 ${ }^{\mathrm{C} 3625 / \mathrm{C3}_{3} \mathrm{SS}} / \mathrm{MlkI}^{-1-}$ mice (Figure 3.19), which is also

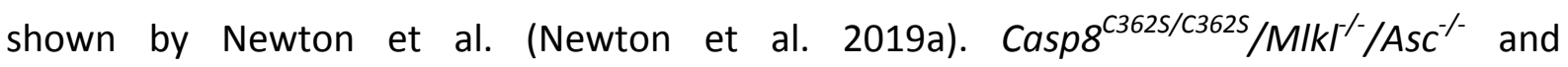
Casp $8^{\mathrm{C} 3625 / \mathrm{C362S}} / \mathrm{Mlkl}^{-1} / \mathrm{Casp}^{-/}$mice were viable and showed no obvious phenotype (Figure 3.19). Moreover, the inflammatory destruction of the small intestine of these mice was alleviated (Figure 3.20). 


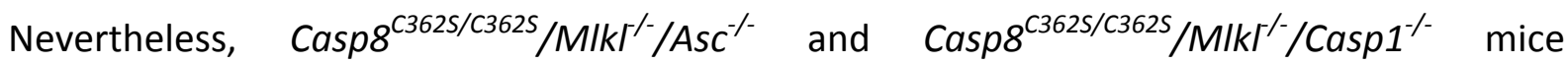
developed a severe splenomegaly, but did not suffer from lymphadenopathy (Figure 3.19). Furthermore, the phenotypes described for Casp8 $8^{\mathrm{C} 3625 / \mathrm{C362S}} / \mathrm{MlkI}^{-/} / \mathrm{Asc}^{-/}$and

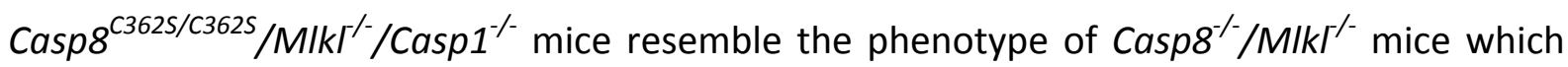
also develop a severe splenomegaly (Alvarez-Diaz et al. 2016). Loss of Casp8 circumvenst inflammasome formation as Casp8 is not present to serve as a scaffold platform interacting with ASC and Casp1. To prevent premature death of $\mathrm{MLKL}^{\%}$ mice expressing catalytically inactive Casp8 and the formation of the inflammasome, the additional deletion of ASC or Casp1 is indispensable. Taken together, our data clearly demonstrate that Casp8 serves as a scaffold platform promoting inflammasome formation ultimately leading to premature death of mice when necroptosis is blocked. Moreover, necroptosis seems to be a more inflammatory mode of cell death, as expression of $\operatorname{Casp}^{\mathrm{C} 362 \mathrm{~S}}$ leads to embryonic lethality whereas inhibition of necroptosis by MLKL deletion and the resulting activation of pyroptotic cell death prolongs the survival of embryos until birth.

Casp $8^{\mathrm{C} 3625 / \mathrm{C362S}} / \mathrm{MlkT}^{-1-}$ mice show a dramatic dicrepancy compared to Casp $8^{\mathrm{C} 362 \mathrm{~S} / \mathrm{C362S}} / \mathrm{RIPK}^{-/-}$ mice (Figure $3.8 \&$ 3.9). As Casp8 $8^{\mathrm{C362S} / \mathrm{C} 3625} / \mathrm{MlkI}^{\%}$ mice die shortly after birth, Casp $8^{\mathrm{C} 362 S / C 362 S} / \mathrm{RIPK}^{-/-}$mice survived weaning but were significantly smaller compared to their control littermates and developed a severe lymphadenopathy and splenomegaly. A possible explanation for this difference could be the fact that in contrast to MLKL, RIPK3 has been shown to be involved in inflammation and the regulation of cytokine production independently of necroptosis. For example, Casp8 inhibition by the pan-caspase inhibitor ZVAD promotes LPS-induced cytokine secretion in BMDMs deficient for RIPK3 or RIPK1 (Najjar et al. 2016). In this context, pro-inflammatory cytokine production relies on the kinase activity of RIPK3 and RIPK1, but MLKL-dependent necroptosis is dispensable for this process. Additionally, RIPK1 and RIPK3 kinase activity was shown to be required for LPS/ZVAD-induced type I Interferon (IFN) production in BMDMs (Saleh et al. 2017). Aside from that Casp8 deficiency in dendritic cells was described to facilitate the assembly of the NLRP3 inflammasome in a RIPK3 dependent manner (Kang et al. 2013). However both, the reason why deletion of RIPK3 prolongs the survival of Casp8 ${ }^{\mathrm{C} 362 \mathrm{~S}}$ mice far beyond weaning and the underlying mechanism remains elusive and needs futher investigations. 
Therefore, it would be of great interest to clarify the role of the kinase activity of RIPK1 and RIPK3 in the scaffold function of Casp8 and whether catalytically inactive RIPK1 or RIPK3 are able to prevent the lethal phenotype caused by expression of Casp8 ${ }^{\mathrm{C} 362 \mathrm{~S}}$.

\subsection{Casp8 enzymatic activity influence anti-microbial immunity}

The capability of Casp8 to interact with different adaptor molecules, namely FADD and ASC is the basis for the regulation of three distinct cell death types and the question arises, what is the benefit for the cell to switch between different cell death modes.

One striking observation was the induction of pyroptosis exclusively in IECs and macrophages (Figure 3.13 \& 3.17). ECs and keratinocytes expressing Casp8 ${ }^{\mathrm{C} 362 \mathrm{~S}}$ did not undergo pyroptosis (Figure 3.10 \& 3.17), indicating that the function of Casp8 to serve as a scaffold platform mediating pyroptosis is restricted to a specific cell type such as myeloid cells and IECs. These cell types need to respond regularly to invading pathogens indicating that Casp8-dependent regulation of several cell death modes plays a key role in immunity. Here, Casp8-mediated apoptosis is the first line of defence. Invading pathogens are recognised rapidly and removed immunologically silent without the release of the intracellular content. However, some pathogens evolved specific caspase-8 inhibitors, like viral CrmA and vICA as virulence strategies to bypass elimination by apoptosis (McCormick et al. 2010; Oberst et al. 2011; Skaletskaya et al. 2001; Zhou et al. 1997). The adaption of necroptosis is a backdoor for the host to cope with pathogens that suppress caspase- 8 enzymatic activity. When the first line of defence, Casp8-mediated apoptosis fails, RIPK1 and RIPK3-dependent necroptosis serves as a second guard for the removal of pathogens. The murine cytomegalovirus bypasses necroptosis by expressing the RHIM inhibitor viral inhibitor of RIP activation (VIRA) preventing the interaction between RHIM-containing proteins like RIPK1 and RIPK3 (Mocarski, Upton, and Kaiser 2012). It is therefore tempting to speculate that the abundance of such viral inhibitors may have driven the counteradaptation of pyroptosis for host defence (Fritsch et al. 2019). Thus, the Casp8-mediated switch between different cell death modes adds a critical layer to the plasticity of specific pathogen-tailored immune responses.

In contrast to viruses, which inhibit Casp8 enzymatic activity, we observed the induction of Casp8 activity upon infection of BMDMs with the Gram-negative cytosolic bacterium Shigella flexneri (Figure 3.1), that does not culminate in apoptosis (Günther et al. 2020). This 
observation strengthens the hypothesis, that Casp8 enzymatic activity has other functions in myeloid cells apart from mediating apoptosis in anti-bacterial immunity. This is tempting to speculate that bacteria induce Casp8 in order to inhibit two strongly inflammatory death pathways, which may decisively counteract bacterial colonisation and growth. This is even more convincing by the fact, that our preliminary data showed that chemical inhibition of Casp8 activity by IDN-65556 in vivo extents the survival of wt mice infected with Shigella flexneri and reduced bacterial burden in different tissues (Figure 3.21). The exact role of Casp8 enzymatic activity in the regulation of different cell death modes, especially in myeloid cells during anti-bacterial immunity and the impact on host survival as well as bacterial propagation need further investigation. The infection of mouse lines with a myeloid cell-specific expression of catalytically inactive Casp8 would be of major interest to answer these questions.

\subsection{Conclusion}

Dysregulation of cell death processes results in developmental disorders and alteration of tissue homeostasis. Furthermore, the control of cell death influences the course of infection as part of the host defence mechanism or as survival strategy of invading pathogens. It is increasingly evident that Casp8 plays a central role in the regulation of different cell death modes.

Our preliminary data demonstrates that in myeloid cells Casp8 is activated upon infection with the Gram-negative enteroinvasive bacterium Shigella flexneri. The inhibition of Casp8 enzymatic activity in infected myeloid cells caused lytic cell death and reduced bacterial propagation in mice suggesting that Casp8 activity support bacterial colonisation. Generation of a mouse line lacking Casp8 enzymatic activity clearly describe a yet unknown and unexpected function of Casp8, apart from activating apoptosis and inhibiting necroptosis, it can serve as a scaffold protein which, potentiates ASC nucleation and inflammasome formation which ultimately leads to highly inflammatory pyroptotic cell death. Enzymatically inactive Casp8 ${ }^{\mathrm{C} 362 \mathrm{~S}}$ fails to induce apoptosis, but primarily induces lytic cell death by involving necroptotic cell death machinery. When necroptosis is blocked the inactive Casp8 induces pyroptosis, which causes severe inflammatory tissue destruction. Therefore, Casp8 enzymatic activity is the key switch between apoptosis, necroptosis and pyroptosis by guiding their crosstalk and determines the fate of the cell. 


\section{References}

Alnemri, Emad S et al. 1996. "Human ICE/CED-3 Protease Nomenclature." Cell 87(2): 171.

Alvarez-Diaz, Silvia et al. 2016. "^The Pseudokinase MLKL and the Kinase RIPK3 Have Distinct Roles in Autoimmune Disease Caused by Loss of Death-Receptor-Induced Apoptosis." Immunity 45(3): 513-26. http://dx.doi.org/10.1016/j.immuni.2016.07.016.

Andree, Maria et al. 2014. "BID-dependent Release of Mitochondrial SMAC Dampens XIAPmediated Immunity against \&lt;em\&gt;Shigella\&lt;/em\&gt;" The EMBO Journal 33(19): 2171 LP-2187.

Berghe, T Vanden et al. 2010. "Necroptosis, Necrosis and Secondary Necrosis Converge on Similar Cellular Disintegration Features." Cell Death \& Differentiation 17(6): 922-30.

Bergsbaken, Tessa, Susan L. Fink, and Brad T. Cookson. 2009. "Pyroptosis: Host Cell Death and Inflammation." Nature Reviews Microbiology 7(2): 99-109.

Boatright, Kelly M et al. 2003. "A Unified Model for Apical Caspase Activation." Molecular Cell 11(2): 529-41.

Boldin, Mark P, Tanya M Goncharov, Yury V Goltseve, and David Wallach. 1996. "Involvement of MACH, a Novel MORT1/FADD-Interacting Protease, in Fas/APO-1- and TNF Receptor-Induced Cell Death." Cell 85(6): 803-15.

Bossaller, Lukas et al. 2012. "Cutting Edge: FAS (CD95) Mediates Noncanonical IL-1 $\beta$ and IL18 Maturation via Caspase-8 in an RIP3-Independent Manner." Journal of immunology (Baltimore, Md. : 1950) 189(12): 5508-12.

Boucher, Dave et al. 2018. "Caspase-1 Self-Cleavage Is an Intrinsic Mechanism to Terminate Inflammasome Activity." The Journal of experimental medicine 215(3): 827-40.

Broz, Petr, and Vishva M. Dixit. 2016. "Inflammasomes: Mechanism of Assembly, Regulation and Signalling." Nature Reviews Immunology 16(7): 407-20.

Brumatti, Gabriela et al. 2016. "The Caspase-8 Inhibitor Emricasan Combines with the SMAC Mimetic Birinapant to Induce Necroptosis and Treat Acute Myeloid Leukemia." Science translational medicine 8(339): 339ra69.

Cecconi, Francesco et al. 1998. "Apaf1 (CED-4 Homolog) Regulates Programmed Cell Death in Mammalian Development." Cell 94(6): 727-37.

Cerretti, Douglas Pat et al. 1992. "Molecular Cloning of the Interleukin-1ß Converting Enzyme." Science 256(5053): 97-100.

Chauhan, Dhruv et al. 2018. "BAX/BAK-Induced Apoptosis Results in Caspase-8-Dependent IL-1ß Maturation in Macrophages." Cell Reports 25(9): 2354-2368.e5.

Chen, Kaiwen W et al. 2019. "Extrinsic and Intrinsic Apoptosis Activate pannexin-1 to Drive NLRP 3 Inflammasome Assembly." The EMBO Journal 38(10).

Chen, Mingkuan et al. 2015. "Internalized Cryptococcus Neoformans Activates the Canonical Caspase-1 and the Noncanonical Caspase-8 Inflammasomes." Journal of immunology (Baltimore, Md. : 1950) 195(10): 4962-72.

Chen, Xin et al. 2016. "Pyroptosis Is Driven by Non-Selective Gasdermin-D Pore and Its Morphology Is Different from MLKL Channel-Mediated Necroptosis." Cell Research

Chinnaiyan, Arul M., Karen O'Rourke, Muneesh Tewari, and Vishva M. Dixit. 1995. "FADD, a Novel Death Domain-Containing Protein, Interacts with the Death Domain of Fas and Initiates Apoptosis." Cell 81(4): 505-12.

Christofferson, D E et al. 2012. "A Novel Role for RIP1 Kinase in Mediating TNFa Production." Cell Death \& Disease 3(6): e320-e320. 
Chun, Hyung J. et al. 2002. "Pleiotropic Defects in Lymphocyte Activation Caused by Caspase8 Mutations Lead to Human Immunodeficiency." Nature 419(6905): 395-99.

Clerc, P L, A Ryter, J Mounier, and P J Sansonetti. 1987. "Plasmid-Mediated Early Killing of Eucaryotic Cells by Shigella Flexneri as Studied by Infection of J774 Macrophages." Infect. Immun. 55(3): 521-27.

Clerc, P, and P J Sansonetti. 1987. "Entry of Shigella Flexneri into HeLa Cells: Evidence for Directed Phagocytosis Involving Actin Polymerization and Myosin Accumulation." Infection and immunity 55(11): 2681-88.

Conos, Stephanie A et al. 2017. "Active MLKL Triggers the NLRP3 Inflammasome in a CellIntrinsic Manner." Proceedings of the National Academy of Sciences of the United States of America 114(6): E961-69.

Constien, Rainer et al. 2001. "Characterization of a Novel EGFP Reporter Mouse to Monitor Cre Recombination as Demonstrated by a Tie2 Cre Mouse Line." genesis 30(1): 36-44.

Creagh, Emma M. 2014. "Caspase Crosstalk: Integration of Apoptotic and Innate Immune Signalling Pathways." Trends in immunology 35(12): 631-40..

Cuda, Carla M et al. 2014. "Caspase-8 Acts as a Molecular Rheostat to Limit RIPK1- and MyD88-Mediated Dendritic Cell Activation." Journal of immunology (Baltimore, Md. : 1950) 192(12): 5548-60.

Degterev, Alexei et al. 2005. "Chemical Inhibitor of Nonapoptotic Cell Death with Therapeutic Potential for Ischemic Brain Injury." Nature Chemical Biology 1(2): 112-19.

Dickens, Laura S. et al. 2012. "A Death Effector Domain Chain DISC Model Reveals a Crucial Role for Caspase-8 Chain Assembly in Mediating Apoptotic Cell Death." Molecular Cell 47(2): 291-305.

Dillon, Christopher P et al. 2014. "RIPK1 Blocks Early Postnatal Lethality Mediated by Caspase-8 and RIPK3." Cell 157: 1189-1202. http://dx.doi.org/10.1016/j.cell.2014.04.018

Ding, Jingjin et al. 2016. "Pore-Forming Activity and Structural Autoinhibition of the Gasdermin Family." Nature 535(7610): 111-16.

Ellis, H M, and H R Horvitz. 1986. "Genetic Control of Programmed Cell Death in the Nematode C. Elegans." Cell 44(6): 817-29.

Faustin, Benjamin et al. 2007. "Reconstituted NALP1 Inflammasome Reveals Two-Step Mechanism of Caspase-1 Activation." Molecular Cell 25(5): 713-24.

Feltham, Rebecca, James E Vince, and Kate E Lawlor. 2016. "Caspase-8: Not so Silently Deadly." Nature Publishing Group 683.

Feng, Shanshan et al. 2007. "Cleavage of RIP3 Inactivates Its Caspase-Independent Apoptosis Pathway by Removal of Kinase Domain." Cellular Signalling 19(10): 2056-67.

Fischer, U, R U Jänicke, and K Schulze-Osthoff. 2003. "Many Cuts to Ruin: A Comprehensive Update of Caspase Substrates." Cell Death \& Differentiation 10(1): 76-100.

Franchi, Luigi, Tatjana Eigenbrod, Raúl Muñoz-Planillo, and Gabriel Nuñez. 2009. "The Inflammasome: A Caspase-1-Activation Platform That Regulates Immune Responses and Disease Pathogenesis." Nature Immunology 10(3): 241-47.

Franchi, Luigi, Raul Muñoz-Planillo, and Gabriel Núñez. 2012. "Sensing and Reacting to Microbes through the Inflammasomes." Nature Immunology 13(4): 325-32. http://www.nature.com/articles/ni.2231 (November 18, 2019).

Fritsch, Melanie et al. 2019. "Caspase-8 Is the Molecular Switch for Apoptosis, Necroptosis and Pyroptosis." Nature 575(7784): 683-87. 
FUENTES-PRIOR, Pablo, and Guy S. SALVESEN. 2004. "The Protein Structures That Shape Caspase Activity, Specificity, Activation and Inhibition." Biochemical Journal 384(2): 201-32.

Gaidt, Moritz M. et al. 2016. "Human Monocytes Engage an Alternative Inflammasome Pathway." Immunity 44(4): 833-46.

Green, Douglas R, and Fabien Llambi. 2015. "Cell Death Signaling." Cold Spring Harbor perspectives in biology 7(12).

Gringhuis, Sonja I et al. 2012. "Dectin-1 Is an Extracellular Pathogen Sensor for the Induction and Processing of IL-1 $\beta$ via a Noncanonical Caspase- 8 Inflammasome." Nature Immunology 13(3): 246-54.

Günther, Claudia et al. 2011. "Caspase-8 Regulates TNF- $\alpha$-Induced Epithelial Necroptosis and Terminal Ileitis." Nature 477(7364): 335-39.

Günther, Claudia et al. 2015. "Caspase-8 Controls the Gut Response to Microbial Challenges by Tnf- $\alpha$-Dependent and Independent Pathways." Gut 64(4): 601-10.

Günther, Saskia., et al. (2020) Cytosolic Gram-negative bacteria prevent apoptosis by inhibition of effector caspases through Lipopolysaccaride. Nature Microbiology (in press). http://doi.org/10.1038/s41564-019-0620-5

Gurung, Prajwal et al. 2014. "FADD and Caspase-8 Mediate Priming and Activation of the Canonical and Noncanonical NIrp3 Inflammasomes." Journal of immunology (Baltimore, Md. : 1950) 192(4): 1835-46.

Gurung, Prajwal et al. 2015. “Chronic TLR Stimulation Controls NLRP3 Inflammasome Activation through IL-10 Mediated Regulation of NLRP3 Expression and Caspase-8 Activation." Scientific Reports 5(1): 14488.

Gutierrez, Kimberley D et al. 2017. "MLKL Activation Triggers NLRP3-Mediated Processing and Release of IL-1 $\beta$ Independently of Gasdermin-D." Journal of immunology (Baltimore, Md. : 1950) 198(5): 2156-64.

Hafner, Martin et al. 2004. "Keratin 14 Cre Transgenic Mice Authenticate Keratin 14 as an Oocyte-Expressed Protein." genesis 38(4): 176-81.

Hartwig, Torsten et al. 2017. "The TRAIL-Induced Cancer Secretome Promotes a TumorSupportive Immune Microenvironment via CCR2." Molecular Cell 65(4): 730-742.e5.

Hay, Bruce A. 2000. "The Drosophila Caspase DRONC Is a Glutamate/aspartate Protease Whose Activity Is Regulated by DIAP1, HID and GRIM." Journal of Biological Chemistry.

Henry, Conor M., and Seamus J. Martin. 2017a. "Caspase-8 Acts in a Non-Enzymatic Role as a Scaffold for Assembly of a Pro-Inflammatory 'FADDosome' Complex upon TRAIL Stimulation." Molecular Cell 65(4): 715-729.e5.

Hilbi, H. 1998. "Shigella-Induced Apoptosis Is Dependent on Caspase-1 Which Binds to IpaB." Journal of Biological Chemistry 273(49): 32895-900.

Hildebrand, Joanne M. et al. 2014. "Activation of the Pseudokinase MLKL Unleashes the Four-Helix Bundle Domain to Induce Membrane Localization and Necroptotic Cell Death." Proceedings of the National Academy of Sciences 111(42): 15072-77.

Holler, Nils et al. 2000. "Fas Triggers an Alternative, Caspase-8-independent Cell Death Pathway Using the Kinase RIP as Effector Molecule." Nature Immunology 1(6): 489-95.

Hughes, Michelle A. et al. 2016. "Co-Operative and Hierarchical Binding of c-FLIP and Caspase-8: A Unified Model Defines How c-FLIP Isoforms Differentially Control Cell Fate." Molecular Cell 61(6): 834-49.

Jorgensen, Ine, Manira Rayamajhi, and Edward A Miao. 2017. "Programmed Cell Death as a Defence against Infection." Nature reviews. Immunology 17(3): 151-64. 
Jost, Philipp J. et al. 2009. "XIAP Discriminates between Type I and Type II FAS-Induced Apoptosis." Nature 460(7258): 1035-39.

Julien, Olivier, and James A Wells. 2017. "Caspases and Their Substrates." Cell Death and Differentiation 24: 1380-89.

Juncadella, Ignacio J. et al. 2013. "Apoptotic Cell Clearance by Bronchial Epithelial Cells Critically Influences Airway Inflammation." Nature 493(7433): 547-51.

Kaiser, William J. et al. 2011. "RIP3 Mediates the Embryonic Lethality of Caspase-8-Deficient Mice." Nature 471(7338): 368-72.

Kang, Seokwon et al. 2015a. "Caspase-8 Scaffolding Function and MLKL Regulate NLRP3 Inflammasome Activation Downstream of TLR3." Nature Communications 6(1): 7515.

Kang, Tae-Bong et al. 2004. "Caspase-8 Serves Both Apoptotic and Nonapoptotic Roles." Journal of immunology (Baltimore, Md. : 1950) 173(5): 2976-84.

Kang, Tae-Bong et al. 2008. "Mutation of a Self-Processing Site in Caspase-8 Compromises Its Apoptotic but Not Its Nonapoptotic Functions in Bacterial Artificial ChromosomeTransgenic Mice." Journal of immunology (Baltimore, Md. : 1950) 181(4): 2522-32.

Kang, Tae-Bong et al. 2013. "Caspase-8 Blocks Kinase RIPK3-Mediated Activation of the NLRP3 Inflammasome." Immunity 38(1): 27-40.

Kang, Tae-Bong et al. 2018. "Caspase-8 Deficiency in Mouse Embryos Triggers Chronic RIPK1-Dependent Activation of Inflammatory Genes, Independently of RIPK3." Cell Death \& Differentiation 25(6): 1107-17.

Kayagaki, Nobuhiko et al. 2011. "Non-Canonical Inflammasome Activation Targets Caspase11." Nature 479(7371): 117-21

Kayagaki, Nobuhiko et al.2015. "Caspase-11 Cleaves Gasdermin D for Non-Canonical Inflammasome Signalling." Nature 526(7575): 666-71.

Kerr, J F, A H Wyllie, and A R Currie. 1972. "Apoptosis: A Basic Biological Phenomenon with Wide-Ranging Implications in Tissue Kinetics." British journal of cancer 26(4): 239-57.

Kovalenko, Andrew et al. 2009a. "Caspase-8 Deficiency in Epidermal Keratinocytes Triggers an Inflammatory Skin Disease." The Journal of Experimental Medicine 206(10): 2161-77.

Kuida, Keisuke et al. 1996. "Decreased Apoptosis in the Brain and Premature Lethality in CPP32-Deficient Mice." Nature 384(6607): 368-72.

Kuida, Keisuke et al. 1998. "Reduced Apoptosis and Cytochrome c-Mediated Caspase Activation in Mice Lacking Caspase 9." Cell 94(3): 325-37.

Lamkanfi, Mohamed, and Vishva M Dixit. 2010. "Manipulation of Host Cell Death Pathways during Microbial Infections." Cell host \& microbe 8(1): 44-54.

Lamkanfi, Mohamed, and Vishva M Dixit. 2014. "Mechanisms and Functions of Inflammasomes." Cell 157(5): 1013-22.

Latz, Eicke, T. Sam Xiao, and Andrea Stutz. 2013. "Activation and Regulation of the Inflammasomes." Nature Reviews Immunology 13(6): 397-411.

Lee, Pedro et al. 2009. "Dynamic Expression of Epidermal Caspase 8 Simulates a Wound Healing Response." Nature 458(7237): 519-23.

$\mathrm{Li}$, Honglin, Hong Zhu, Chi-jie Xu, and Junying Yuan. 1998. "Cleavage of BID by Caspase 8 Mediates the Mitochondrial Damage in the Fas Pathway of Apoptosis." Cell 94(4): 491$501 .$.

Lin, Yong, Anne Devin, Yolanda Rodriguez, and Zheng-gang Liu. 1999. "Cleavage of the Death Domain Kinase RIP by Caspase-8 Prompts TNF-Induced Apoptosis." Genes \& Development 13(19): 2514-26.

Liu, Xing et al. 2016. "Inflammasome-Activated Gasdermin D Causes Pyroptosis by Forming Membrane Pores." Nature 535(7610): 153-58. 
Luo, Xu et al. 1998. "Bid, a Bcl2 Interacting Protein, Mediates Cytochrome c Release from Mitochondria in Response to Activation of Cell Surface Death Receptors." Cell 94(4): 481-90.

Madison, Blair B et al. 2002. "Cis Elements of the Villin Gene Control Expression in Restricted Domains of the Vertical (Crypt) and Horizontal (Duodenum, Cecum) Axes of the Intestine." The Journal of biological chemistry 277(36): 33275-83.

Man, Si Ming et al. 2013. "Salmonella Infection Induces Recruitment of Caspase-8 to the Inflammasome to Modulate IL-1 $\beta$ Production." Journal of immunology (Baltimore, Md. : 1950) 191(10): 5239-46.

Man, Si Ming et al. 2014. "Inflammasome Activation Causes Dual Recruitment of NLRC4 and NLRP3 to the Same Macromolecular Complex." Proceedings of the National Academy of Sciences of the United States of America 111(20): 7403-8.

Man, Si Ming, and Thirumala-Devi Kanneganti. 2015. "Gasdermin D: The Long-Awaited Executioner of Pyroptosis." Cell Research 25(11): 1183-84.

Mandal, Pratyusha et al. 2018. "Caspase-8 Collaborates with Caspase-11 to Drive Tissue Damage and Execution of Endotoxic Shock." Immunity 49(1): 42-55.e6.

Martínez-Lagunas, Kristel et al. 2019. "In Vivo Detection of Programmed Cell Death during Mouse Heart Development." Cell Death \& Differentiation: 1-17.

Martino, Maria Celeste et al. 2004. "Intravenous Infection of Virulent Shigellae Causes Fulminant Hepatitis in Mice." Cellular Microbiology 7(1): 115-27. http://doi.wiley.com/10.1111/j.1462-5822.2004.00441.

Martinon, Fabio, Kimberly Burns, and Jürg Tschopp. 2002. "The Inflammasome: A Molecular Platform Triggering Activation of Inflammatory Caspases and Processing of prolL- $\beta . "$ Molecular Cell 10(2): 417-26.

Mascarenhas, Danielle P. A. et al. 2017. "Inhibition of Caspase-1 or Gasdermin-D Enable Caspase-8 Activation in the Naip5/NLRC4/ASC Inflammasome" ed. H. Steven Seifert. PLOS Pathogens 13(8): e1006502. https://dx.plos.org/10.1371/journal.ppat.1006502 (November 23, 2019).

Matsumura, H et al. 2000. "Necrotic Death Pathway in Fas Receptor Signaling." The Journal of cell biology 151(6): 1247-56.

McCormick, A Louise, Linda Roback, Devon Livingston-Rosanoff, and Courtney St Clair. 2010. "The Human Cytomegalovirus UL36 Gene Controls Caspase-Dependent and Independent Cell Death Programs Activated by Infection of Monocytes Differentiating to Macrophages." Journal of virology 84(10): 5108-23.

Meng, Lingjun, Wei Jin, and Xiaodong Wang. 2015. "RIP3-Mediated Necrotic Cell Death Accelerates Systematic Inflammation and Mortality." Proceedings of the National Academy of Sciences of the United States of America 112(35): 11007-12.

Miura, Masayuki et al. 1993. "Induction of Apoptosis in Fibroblasts by IL-1ß-Converting Enzyme, a Mammalian Homolog of the C. Elegans Cell Death Gene Ced-3." Cell 75(4): 653-60.

Mizutani, H, R Black, and T S Kupper. 1991. "Human Keratinocytes Produce but Do Not Process pro-Interleukin-1 (IL-1) Beta. Different Strategies of IL-1 Production and Processing in Monocytes and Keratinocytes." Journal of Clinical Investigation 87(3):

Mocarski, Edward S., Hongyan Guo, and William J. Kaiser. 2015. "Necroptosis: The Trojan Horse in Cell Autonomous Antiviral Host Defense." Virology 479-480: 160-66.

Mocarski, Edward S., Jason W. Upton, and William J. Kaiser. 2012. "Viral Infection and the Evolution of Caspase 8-Regulated Apoptotic and Necrotic Death Pathways." Nature Reviews Immunology 12(2): 79-88. 
Monks, Jenifer et al. 2008. "Epithelial Cells Remove Apoptotic Epithelial Cells During PostLactation Involution of the Mouse Mammary Gland1." Biology of Reproduction 78(4): 586-94.

Moriwaki, Kenta, John Bertin, Peter J Gough, and Francis Ka-Ming Chan. 2015a. "A RIPK3Caspase 8 Complex Mediates Atypical pro-IL-1 $\beta$ Processing." Journal of immunology (Baltimore, Md. : 1950) 194(4): 1938-44.

Murphy, James M. et al. 2013. "The Pseudokinase MLKL Mediates Necroptosis via a Molecular Switch Mechanism." Immunity 39(3): 443-53.

Muzio, Marta et al. 1996. "FLICE, A Novel FADD-Homologous ICE/CED-3-like Protease, Is Recruited to the CD95 (Fas/APO-1) Death-Inducing Signaling Complex." Cell 85(6): 81727.

Najjar, Malek et al. 2016. "RIPK1 and RIPK3 Kinases Promote Cell-Death-Independent Inflammation by Toll-like Receptor 4." Immunity 45(1): 46-59.

Newton, Kim, Katherine E. Wickliffe, Allie Maltzman, et al. 2019a. "Activity of Caspase-8 Determines Plasticity between Cell Death Pathways." Nature 575(7784): 679-82.

Newton, Kim, Katherine E. Wickliffe, Debra L. Dugger, et al. 2019b. "Cleavage of RIPK1 by Caspase-8 Is Crucial for Limiting Apoptosis and Necroptosis." Nature 574(7778): 42831.

Newton, Kim, Xiaoqing Sun, and Vishva M. Dixit. 2004. "Kinase RIP3 Is Dispensable for Normal NF-kBs, Signaling by the B-Cell and T-Cell Receptors, Tumor Necrosis Factor Receptor 1, and Toll-Like Receptors 2 and 4." Molecular and Cellular Biology 24(4): 1464-69.

Oberst, Andrew et al. 2010. "Inducible Dimerization and Inducible Cleavage Reveal a Requirement for Both Processes in Caspase-8 Activation." The Journal of biological chemistry 285(22): 16632-42.

Oberst, Andrew et al. 2011. "Catalytic Activity of the Caspase-8-FLIPL Complex Inhibits RIPK3-Dependent Necrosis." Nature 471(7338): 363-67.

Ofengeim, Dimitry et al. 2015. "Activation of Necroptosis in Multiple Sclerosis." Cell Reports 10(11): 1836-49.

Van Opdenbosch, Nina et al. 2017. "Caspase-1 Engagement and TLR-Induced c-FLIP Expression Suppress ASC/Caspase-8-Dependent Apoptosis by Inflammasome Sensors NLRP1b and NLRC4." Cell reports 21(12): 3427-44.

Orning, Pontus et al. 2018. "Pathogen Blockade of TAK1 Triggers Caspase-8-Dependent Cleavage of Gasdermin D and Cell Death." Science (New York, N.Y.) 362(6418): 1064-69.

Parnaik, Rahul, Martin C. Raff, and John Scholes. 2000. "Differences between the Clearance of Apoptotic Cells by Professional and Non-Professional Phagocytes." Current Biology 10(14): 857-60.

Pasparakis, Manolis, and Peter Vandenabeele. 2015. "Necroptosis and Its Role in Inflammation." Nature 517(7534): 311-20.

Peitz, Michael, Kurt Pfannkuche, Klaus Rajewsky, and Frank Edenhofer. 2002. "Ability of the Hydrophobic FGF and Basic TAT Peptides to Promote Cellular Uptake of Recombinant Cre Recombinase: A Tool for Efficient Genetic Engineering of Mammalian Genomes." Proceedings of the National Academy of Sciences of the United States of America 99(7): 4489-94.

Peter, M E, and P H Krammer. 2003. "The CD95(APO-1/Fas) DISC and beyond." Cell Death \& Differentiation 10(1): 26-35. 
Pfeffer, Klaus et al. 1993. "Mice Deficient for the $55 \mathrm{Kd}$ Tumor Necrosis Factor Receptor Are Resistant to Endotoxic Shock, yet Succumb to L. Monocytogenes Infection." Cell 73(3): 457-67.

Philip, Naomi H et al. 2014. "Caspase-8 Mediates Caspase-1 Processing and Innate Immune Defense in Response to Bacterial Blockade of NF-KB and MAPK Signaling." Proceedings of the National Academy of Sciences of the United States of America 111(20): 7385-90.

Philip, Naomi H. et al. 2016. "Activity of Uncleaved Caspase-8 Controls Anti-Bacterial Immune Defense and TLR-Induced Cytokine Production Independent of Cell Death." PLoS Pathogens 12(10): e1005910.

Philpott, D J, S Yamaoka, A Israël, and P J Sansonetti. 2000. "Invasive Shigella Flexneri Activates NF-Kappa B through a Lipopolysaccharide-Dependent Innate Intracellular Response and Leads to IL-8 Expression in Epithelial Cells." Journal of immunology (Baltimore, Md. : 1950) 165(2): 903-14.

Pierini, R et al. 2012. "AIM2/ASC Triggers Caspase-8-Dependent Apoptosis in FrancisellaInfected Caspase-1-Deficient Macrophages." Cell death and differentiation 19(10): 1709-21. http://dx.doi.org/10.1038/cdd.2012.51

Pop, Cristina et al. 2011. "FLIP(L) Induces Caspase 8 Activity in the Absence of Interdomain Caspase 8 Cleavage and Alters Substrate Specificity." The Biochemical journal 433(3): 447-57.

Repetto, Guillermo, Ana del Peso, and Jorge L Zurita. 2008. "Neutral Red Uptake Assay for the Estimation of Cell Viability/cytotoxicity." Nature Protocols 3(7): 1125-31.

Saelens, Xavier et al. 2004. "Toxic Proteins Released from Mitochondria in Cell Death." Oncogene 23(16): 2861-74.

Sagulenko, V et al. 2013. "AIM2 and NLRP3 Inflammasomes Activate Both Apoptotic and Pyroptotic Death Pathways via ASC." Cell Death \& Differentiation 20(9): 1149-60.

Saleh, Danish et al. 2017. "Kinase Activities of RIPK1 and RIPK3 Can Direct IFN- $\beta$ Synthesis Induced by Lipopolysaccharide." Journal of immunology (Baltimore, Md. : 1950) 198(11): 4435-47.

Salvesen, G S, and V M Dixit. 1999. "Caspase Activation: The Induced-Proximity Model." Proceedings of the National Academy of Sciences of the United States of America 96(20): 10964-67.

Salvesen, Guy S., and Avi Ashkenazi. 2011. "SnapShot: Caspases." Cell 147(5): 1197.

Sand, Jennifer et al. 2018. "Expression of Inflammasome Proteins and Inflammasome Activation Occurs in Human, but Not in Murine Keratinocytes." Cell Death \& Disease 9(2): 24.

Sarhan, Joseph et al. 2018. "Caspase-8 Induces Cleavage of Gasdermin D to Elicit Pyroptosis during Yersinia Infection." Proceedings of the National Academy of Sciences of the United States of America 115(46): E10888-97.

Scheller, Carsten et al. 2002. "Caspase Inhibitors Induce a Switch from Apoptotic to Proinflammatory Signaling in CD95-Stimulated T Lymphocytes." European Journal of Immunology 32(9): 2471-80.

Schneider, Katharina S et al. 2017a. "The Inflammasome Drives GSDMD-Independent Secondary Pyroptosis and IL-1 Release in the Absence of Caspase-1 Protease Activity." Cell reports 21(13): 3846-59.

Shalini, S, L Dorstyn, S Dawar, and S Kumar. 2015. "Old, New and Emerging Functions of Caspases." Cell Death \& Differentiation 22(4): 526-39. 
Shenderov, Kevin et al. 2014. "Cutting Edge: Endoplasmic Reticulum Stress Licenses Macrophages to Produce Mature IL-1 $\beta$ in Response to TLR4 Stimulation through a Caspase-8- and TRIF-Dependent Pathway." Journal of immunology (Baltimore, Md. : 1950) 192(5): 2029-33.

Shi, Jianjin et al. 2014. "Inflammatory Caspases Are Innate Immune Receptors for Intracellular LPS." Nature 514(7521): 187-92.

Shi, Jianjin et al. 2015. "Cleavage of GSDMD by Inflammatory Caspases Determines Pyroptotic Cell Death." Nature 526(7575): 660-65.

Shi, Yigong. 2002. "Mechanisms of Caspase Activation and Inhibition during Apoptosis." Molecular Cell 9(3): 459-70.

Skaletskaya, A et al. 2001. "A Cytomegalovirus-Encoded Inhibitor of Apoptosis That Suppresses Caspase-8 Activation." Proceedings of the National Academy of Sciences of the United States of America 98(14): 7829-34.

Srinivasula, Srinivasa M. et al. 2001. "A Conserved XIAP-Interaction Motif in Caspase-9 and Smac/DIABLO Regulates Caspase Activity and Apoptosis." Nature 410(6824): 112-16.

Stennicke, H R, M Renatus, M Meldal, and G S Salvesen. 2000. "Internally Quenched Fluorescent Peptide Substrates Disclose the Subsite Preferences of Human Caspases 1, 3, 6, 7 and 8." The Biochemical journal 350 Pt 2(Pt 2): 563-68.

Strasser, Andreas, Liam O'Connor, and Vishva M. Dixit. 2000. "Apoptosis Signaling." Annual Review of Biochemistry 69(1): 217-45.

Sun, Liming et al. 2012. "Mixed Lineage Kinase Domain-like Protein Mediates Necrosis Signaling Downstream of RIP3 Kinase." Cell 148(1-2): 213-27.

Suzanne, M, and H Steller. 2013. "Shaping Organisms with Apoptosis." Cell Death \& Differentiation 20(5): 669-75.

Thornberry, N A et al. 1997. "A Combinatorial Approach Defines Specificities of Members of the Caspase Family and Granzyme B. Functional Relationships Established for Key Mediators of Apoptosis." The Journal of biological chemistry 272(29): 17907-11.

Thornberry, Nancy A. et al. 1992. "A Novel Heterodimeric Cysteine Protease Is Required for Interleukin-1ßprocessing in Monocytes." Nature 356(6372): 768-74.

Vajjhala, Parimala R et al. 2015. "The Inflammasome Adaptor ASC Induces Procaspase-8 Death Effector Domain Filaments." The Journal of biological chemistry 290(49): 2921730.

Varfolomeev, Eugene E. et al. 1998. "Targeted Disruption of the Mouse Caspase 8 Gene Ablates Cell Death Induction by the TNF Receptors, Fas/Apo1, and DR3 and Is Lethal Prenatally." Immunity 9(2): 267-76.

Vercammen, D et al. 1998. "Inhibition of Caspases Increases the Sensitivity of L929 Cells to Necrosis Mediated by Tumor Necrosis Factor." The Journal of experimental medicine 187(9): 1477-85.

Vince, James E. et al. 2018. "The Mitochondrial Apoptotic Effectors BAX/BAK Activate Caspase-3 and -7 to Trigger NLRP3 Inflammasome and Caspase- 8 Driven IL-1 $\beta$ Activation." Cell Reports 25(9): 2339-2353.e4.

Wallach, David, Tae-Bong Kang, and Andrew Kovalenko. 2014. "Concepts of Tissue Injury and Cell Death in Inflammation: A Historical Perspective." Nature Reviews Immunology 14(1): 51-59.

Weinlich, Ricardo et al. 2013. "Protective Roles for Caspase-8 and cFLIP in Adult Homeostasis." Cell Reports 5(2): 340-48. 
Weng, Dan et al. 2014. "Caspase-8 and RIP Kinases Regulate Bacteria-Induced Innate Immune Responses and Cell Death." Proceedings of the National Academy of Sciences of the United States of America 111(20): 7391-96.

Wood, W. et al. 2000. "Mesenchymal Cells Engulf and Clear Apoptotic Footplate Cells in Macrophageless PU.1 Null Mouse Embryos." Development 127(24): 5245-52.

Wu, Jianfeng et al. 2013. "Mlkl Knockout Mice Demonstrate the Indispensable Role of Mlkl in Necroptosis." Cell Research 23(8): 994.

Wyllie, A H, J F Kerr, and A R Currie. 1980. "Cell Death: The Significance of Apoptosis." International review of cytology 68: 251-306.

Xia, Bingqing et al. 2016. "MLKL Forms Cation Channels." Cell Research 26(5): 517-28.

Youle, Richard J., and Andreas Strasser. 2008. "The BCL-2 Protein Family: Opposing Activities That Mediate Cell Death." Nature Reviews Molecular Cell Biology 9(1): 47-59.

$\mathrm{Yu}$, Xinchao et al. 2005. "A Structure of the Human Apoptosome at $12.8 \AA$ A Resolution Provides Insights into This Cell Death Platform." Structure 13(11): 1725-35.

Yuan, Junying et al. 1993. "The C. Elegans Cell Death Gene Ced-3 Encodes a Protein Similar to Mammalian Interleukin-1ß-Converting Enzyme." Cell 75(4): 641-52.

Yuan, Shujun et al. 2010. "Structure of an Apoptosome-Procaspase-9 CARD Complex." Structure 18(5): 571-83.

Zhang, J, and A Winoto. 1996. "A Mouse Fas-Associated Protein with Homology to the Human Mort1/FADD Protein Is Essential for Fas-Induced Apoptosis." Molecular and Cellular Biology 16(6): 2756-63.

Zhang, Xuhua, John P. Dowling, and Jianke Zhang. 2019. "RIPK1 Can Mediate Apoptosis in Addition to Necroptosis during Embryonic Development." Cell Death \& Disease 10(3): 245.

Zhou, Q et al. 1997. "Target Protease Specificity of the Viral Serpin CrmA. Analysis of Five Caspases." The Journal of biological chemistry 272(12): 7797-7800. 


\section{Appendix}

\subsection{Abbreviations}

\begin{tabular}{|c|c|c|c|}
\hline$\%$ & Percent sign & DMSO & Dimethylsulfoxid \\
\hline$\alpha$ & Anti & DNA & Deoxyribonucleic acid \\
\hline A & Adenine & dsDNA & Double-stranded DNA \\
\hline AIM2 & Absent in melanoma 2 & $\mathbf{E}$ & Epidermal cell \\
\hline ANOVA & One-way analysis of variance & EC & Endothelial cell \\
\hline \multirow[t]{2}{*}{ ASC } & Apoptosis-associated speck-like & E.coli & Escherichia coli \\
\hline & protein containing a CARD & EDTA & Ethylenendiamine tetraacetic acid \\
\hline Apaf-1 & $\begin{array}{l}\text { Apoptotic protease-activating } \\
\text { factor-1 }\end{array}$ & EGTA & $\begin{array}{l}\text { ethylene glycol-bis(aminoethyl } \\
\text { ether)- } N, N, N^{\prime}, N^{\prime} \text {-tetraacetic acid }\end{array}$ \\
\hline BMDMs & $\begin{array}{l}\text { Bone marrow-derived } \\
\text { macrophages }\end{array}$ & ELISA & $\begin{array}{l}\text { Enzyme-linked immunosorbent } \\
\text { assay }\end{array}$ \\
\hline bp & Basepairs & et al. & et alteri /-a /-um \\
\hline BSA & Bovine serum albumin & & (and others) \\
\hline C, Cys & Cysteine & FADD & Fas-associated death domain \\
\hline${ }^{\circ} \mathrm{C}$ & Degree Celsius & FCS & Fetal calf serum \\
\hline \multirow[t]{2}{*}{ Casp } & Caspase(s): Cysteine-dependent & fl & Flox \\
\hline & aspartate-specific proteases & $H \& E$ & Haematoxylin \& Eosin \\
\hline \multirow[t]{2}{*}{ CARD } & Caspase activation and & HRP & Horseradish peroxidase \\
\hline & recruitment domain & HTNCre & His-tagged, TAT-fusion Cre \\
\hline CD31 & Cluster of differentiation 31 & & with nuclear localisation signal \\
\hline C. elegans & Caenorhabditis elegans & IEC & Intestinal epithelial cell \\
\hline cFLIP & Cellular FLICE inhibitory protein & IL & Interleukine \\
\hline CFU & Colonie forming unit & IFN-Y & Interferon- $\gamma$ \\
\hline CHX & Cycloheximid & IP & Immunoprecipitation \\
\hline CrmA & Cytokine response modifier $A$ & i.p. & Intraperitoneal \\
\hline \multirow[t]{2}{*}{ CRISPR } & Clustered regulatory interspaced & i.v. & Intravenous \\
\hline & short palindromic repeats & kDa & Kilodalton \\
\hline DAB & 3,3`-Diaminobenzidine & LDH & Lactate dehydrogenase \\
\hline \multirow[t]{2}{*}{ DAMPs } & Damage-associated molecular & LN & Lymph node \\
\hline & pattern & LPS & Lipopolysaccharide \\
\hline Dapi & 4',6'-Diamidin-2-phenylindol & $\mathbf{M}$ & Molar, mol/l \\
\hline DD & Death domain & MAPK & Mitogen-activated protein kinases \\
\hline DED & Death effector domain & $\min$ & Minute(s) \\
\hline DISC & Death-inducing signalling complex & $\mathrm{ml}$ & Mililiters \\
\hline DMEM & $\begin{array}{l}\text { Dulbecco's modified Eagle's } \\
\text { medium }\end{array}$ & MLKL & $\begin{array}{l}\text { Mixed lineage kinase domain- } \\
\text { like protein }\end{array}$ \\
\hline
\end{tabular}




\begin{tabular}{|c|c|c|c|}
\hline $\mathrm{mM}$ & Milimolar & TLR & Toll-like receptor \\
\hline MOI & Multiplicity of infection & TNF $\alpha$ & Tumor necrosis factor $\alpha$ \\
\hline \multirow[t]{2}{*}{ MOMP } & Mitochondrial outer membrane & Trail & TNF-related apoptosis-inducing \\
\hline & permeabilisation & & ligand \\
\hline Nec-1 & Necrostatin-1 & vICA & Viral inhibitor of Casp8-induced \\
\hline NF- KB & Nuclear Factor kappa B & & apoptosis \\
\hline \multirow[t]{3}{*}{ NLR } & Nucleuotide-binding & VIRA & Viral inhibitor of RIP activation \\
\hline & oligomerisation domain (NOD) & WB & Western Blot \\
\hline & like receptor & wt & Wildtype \\
\hline \multirow[t]{2}{*}{ NLRC4 } & NLR family CARD domain- & XIAP & X-linked inhibitor of apoptosis \\
\hline & containing protein 4 & YopJ & Yersinia outer protein J \\
\hline \multirow[t]{2}{*}{ NLRP3 } & NACHT, LRR and PYD domains- & $\mu g$ & Microgramm \\
\hline & containing protein 3 & $\mu l$ & Microliter \\
\hline OD & Optical density & $\mu \mathrm{m}$ & Micrometer \\
\hline PAGE & Polyacrylamid gel electrophoresis & & \\
\hline \multirow[t]{2}{*}{ PAMPs } & Pathogen-associated molecular & & \\
\hline & pattern & & \\
\hline PAS & Periodic acid-Schiff stain & & \\
\hline PBS & Phosphate buffered saline & & \\
\hline PCR & Polymerase chain reaction & & \\
\hline PFA & Paraformaldehyde & & \\
\hline pg & Picrogramm & & \\
\hline p.i. & Post infection & & \\
\hline PYD & Pyrin domain & & \\
\hline RHIM & RIPK homotypic interaction motif & & \\
\hline \multirow[t]{2}{*}{ RIPK } & Receptor-interacting & & \\
\hline & serine/threonine-protein kinase & & \\
\hline rpm & Revolutions per minute & & \\
\hline RPMI & Roswell park memorial institute & & \\
\hline RT & Room temperature & & \\
\hline S, Ser & Serine & & \\
\hline SDS & Sodium Dodecyl Sulfate & & \\
\hline s.e.m. & Standard error of the mean & & \\
\hline $\mathbf{T}$ & Thymine & & \\
\hline
\end{tabular}




\subsection{Danksagung}

Ich möchte mich ganz herzlich bei meinen Betreuer Prof. Dr. Hamid Kashkar bedanken, der es mir ermöglicht hat, meine Doktorarbeit in seiner Arbeitsgruppe zu erstellen. Seine Tür stand mir stets offen und die konstruktive Kritik hat mich in meinem wissenschaftlichen Schaffen und Denken sehr weitergebracht.

Ich bedanke mich bei Prof. Dr. Kay Hofmann und Prof. DR. Jan Riemer für die Begutachtung meiner Doktorarbeit.

Prof. Dr. Martin Krönke danke ich dafür, dass ich meine Doktorarbeit in seinem Institut anfertigen durfte.

I would like to thank Prof. Dr. Manolis Pasparakis and Prof. Mo Lamkanfi for providing essential mouse lines.

Des Weiteren möchte ich mich sehr bei all meinen Kollegen in der AG Kashkar, der AG Krönke sowie der AG Schramm bedanken. Danke, dass ihr immer eine lockere und lustige Arbeitsatmosphäre schafft. Einen ganz besonderen Dank gilt Tina, Saskia, Marie und vor allem Maureen. Ohne euch wäre mein Arbeitsalltag nur halb so lustig $(;)$

Abschließend möchte ich mich bei meinen Eltern für grenzenlose Unterstützung und unermüdliche Geduld bedanken. Ihr habt mir die gesamte Ausbildung erst ermöglicht!

Zum Schluss möchte ich mich noch bei meinen längsten Weggefährtinnen Ruth und Helin für ihre jahrelange Freundschaft in guten wie auch in schlechten Zeiten bedanken. Und natürlich nicht zu vergessen die Hühnerparade (Franzi, Sarah, Henny und Alex) und die vielen Abende (und auch Nächte) voller Spaß und Schabernack!

Vielen Dank für alles!! 


\subsection{Erklärung}

Ich versichere, dass ich die von mir vorgelegte Dissertation selbständig angefertigt, die benutzten Quellen und Hilfsmittel vollständig angegeben und die Stellen der Arbeit einschließlich Tabellen, Karten und Abbildungen -, die anderen Werken im Wortlaut oder dem Sinn nach entnommen sind, in jedem Einzelfall als Entlehnung kenntlich gemacht habe; dass diese Dissertation noch keiner anderen Fakultät oder Universität zur Prüfung vorgelegen hat; dass sie - abgesehen von unten angegebenen Teilpuplikationen - noch nicht veröffentlich worden ist, sowie dass ich eine solche Veröffentlichung vor Abschluss des Promotionsverfahrens nicht entnehmen werde. Die Bestimmungen der Promotionsordnung sind mir bekannt. Die von mir vorgelegte Dissertation ist von Prof. Dr. Hamid Kashkar betreut worden.

09.12.2019

Melanie Fritsch

\section{Teilpublikation}

Teile dieser Doktorarbeit wurden in folgender Publikation veröffentlicht:

Fritsch, M., Günther, S. D., Schwarzer, R., Albert, M.-C., Schorn, F., Werthenbach, J. P., ... Kashkar, H. (2019). Caspase-8 is the molecular switch for apoptosis, necroptosis and pyroptosis. Nature, 575(7784), 683-687. http://doi.org/10.1038/s41586-019-1770-6 


\title{
Article Caspase-8 is the molecular switch for
apoptosis, necroptosis and pyroptosis
}

\author{
https://doi.org/10.1038/s41586-019-1770-6 \\ Received: 18 February 2019 \\ Melanie Fritsch', Saskia D. Günther', Robin Schwarzer², Marie-Christine Albert', \\ Fabian Schorn', J. Paul Werthenbach', Lars M. Schiffmann ${ }^{13}$, Neil Stair ${ }^{1.2}$, Hannah Stocks', \\ Accepted: 15 October 2019 \\ Jens M. Seeger', Mohamed Lamkanfi ${ }^{4.5}$, Martin Krönke', Manolis Pasparakis ${ }^{2.6}$ \& \\ Hamid Kashkar ${ }^{1,6 *}$
}

Published online: 20 November 2019

\begin{abstract}
Caspase- 8 is the initiator caspase of extrinsic apoptosis ${ }^{1.2}$ and inhibits necroptosis mediated by RIPK 3 and MLKL. Accordingly, caspase- 8 deficiency in mice causes embryonic lethality ${ }^{3}$, which can be rescued by deletion of either Ripk3 or $M l k l^{t-6}$. Here we show that the expression of enzymatically inactive CASP8(C362S) causes embryonic lethality in mice by inducing necroptosis and pyroptosis. Similar to

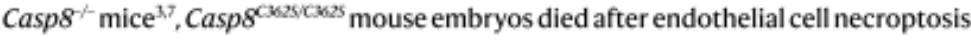
leading to cardiovascular defects. MLKL deficiency rescued the cardiovascular

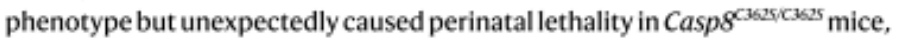
indicating that CASP8(C362S) causes necroptosis-independent death at later stages of embryonic development. Specific loss of the catalytic activity of caspase- 8 in intestinal epithelial cells induced intestinal inflammation similar to intestinal epithelial cell-specific Casp 8 knockout mice ${ }^{8}$. Inhibition of necroptosis by additional deletion of $M l k l$ severely aggravated intestinal inflammation and caused premature lethality in $M l k l$ knockout mice with specific loss of caspase- 8 catalytic activity in intestinal epithelial cells. Expression of CASP8(C362S) triggered the formation of ASC specks, activation of caspase-1 and secretion of IL-1 $1 \beta$. Both embryonic lethality and

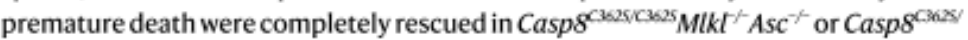
${ }^{\mathrm{C} 625} \mathrm{Mlkl}^{-} \mathrm{Caspl}^{-}$mice, indicating that the activation of the inflammasome promotes CASP8(C362S)-mediated tissue pathology when necroptosis is blocked. Therefore, caspase -8 represents the molecular switch that controls apoptosis, necroptosis and pyroptosis, and prevents tissue damage during embryonic development and adulthood.
\end{abstract}

In addition to its role in apoptosis and necroptosis, recent in vitro stud ies have indicated that caspase-8 induces the production of cytokines by acting as a scaffolding protein and that this role is independent of its enzymatic activity ${ }^{910}$. The scaffold function of caspase- 8 was also shown to be involved in the double-stranded RNA (dsRNA)-induced activa-

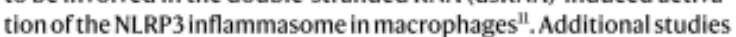
indicate that the enzymatic activity of caspase- 8 is required for the activation of NF-kB and secretion of cytokines in response to activated antigen receptors, Fc receptors or Toll-like receptors (TLRs), independently of cell death ${ }^{12.13}$. To investigate the physiological role of the enzy. matic activity of caspase-8, we generated knock-in mice that expressed catalytically inactive caspase- 8 by mutating Cys 362 in the substrate binding pocket to serine (C362S) (Extended Data Fig. 1a). Although heterozygous Casp $8^{\cos 25 \%}$ mice were viable (Extended Data Fig. 1b), Casp $8^{062503625}$ embryos died around embryonic day 11.5 (E11.5). Hyperaemia in the abdominal areas was detected in Casp8 $8^{\text {cassicoss }}$ embryos (Fig.1a), presumably owing to defects in vascular development, which resembles the phenotype of $\mathrm{Casp}^{\gamma} \mathrm{embryos}^{\text {. In order to address }}$ the role of caspase- 8 in vascular development, we used Tie $2^{\text {re }}$ (also known as $\mathrm{Te}^{\left({ }^{(r)}\right)}$ mice, in which efficient Cre-mediated recombination is induced in all endothelial cells and most haematopoietic cells $\mathbf{s}^{14}$. Loss of the catalytic activity of caspase-8 in Casp ${ }^{c 3.3250} \mathrm{Tie}^{20 \mathrm{re}}$ mice or specific knockout of caspase- 8 in the endothelial cells of Casp $8^{\text {en }}$ $T i e 2^{\text {Tee }}$ mice caused embryonic lethality at the same developmental

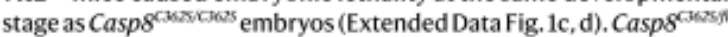

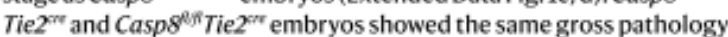
associated with a decrease in yolk-sac vascularization (Fig. $1 \mathrm{~b}$ and Extended Data Fig. 1d).

Specific loss of the catalytic activity of caspase- 8 in epidermal keratinocytes or intestinal epithelial cells was achieved by crossing

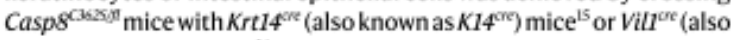
known as Villin ${ }^{\text {(1) }}$ ) mice ${ }^{16}$, respectively. Loss of the catalytic activity of caspase- 8 in these two cell types caused similar pathologies to

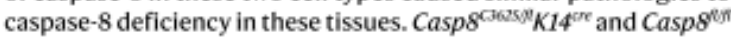

Institute for Medical Microbiology, Immunology and Hygiene (MMMIHO. CECAD Research Center, University of Cologne, Cologne, Germany. Institute for Genetics, CECAD Research Center, Universiny of Cologne, Cologne, Germany. 'Depsrtment of General, Viscersl and Cancer Surgery, University of Cologne, Cologne, Germary. "Department of internsl Medicine and Paediatrics,

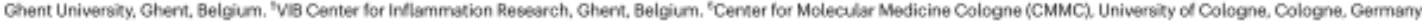
"Q-mail: h.keahkarguni-koein.de 